in

\title{
THE
}

\section{ART OF HORSE.SHOEING}

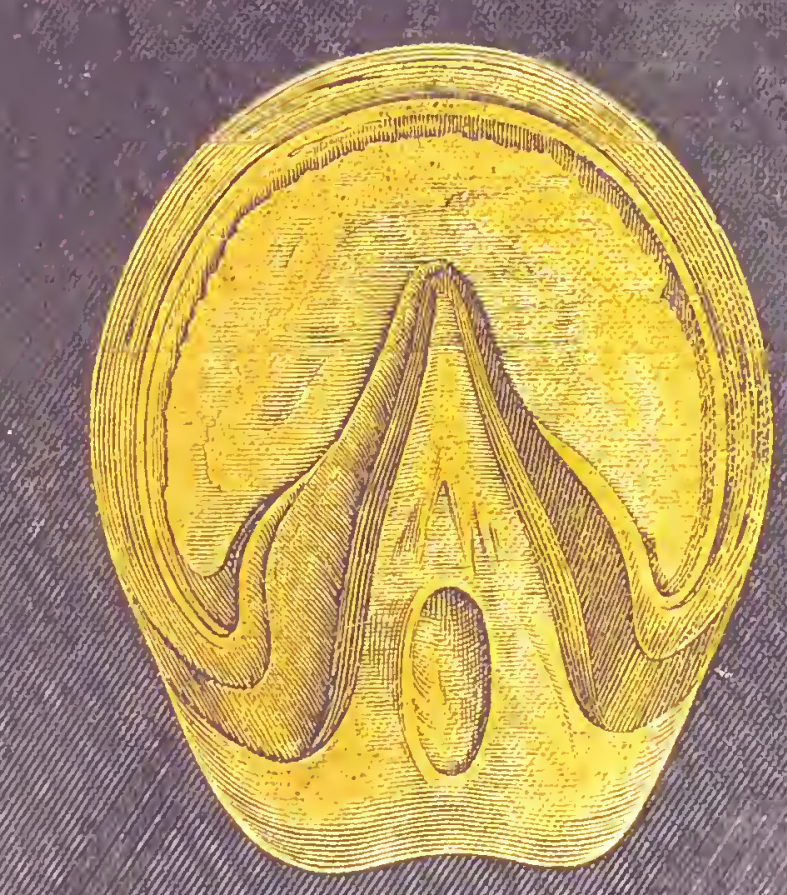

-

-

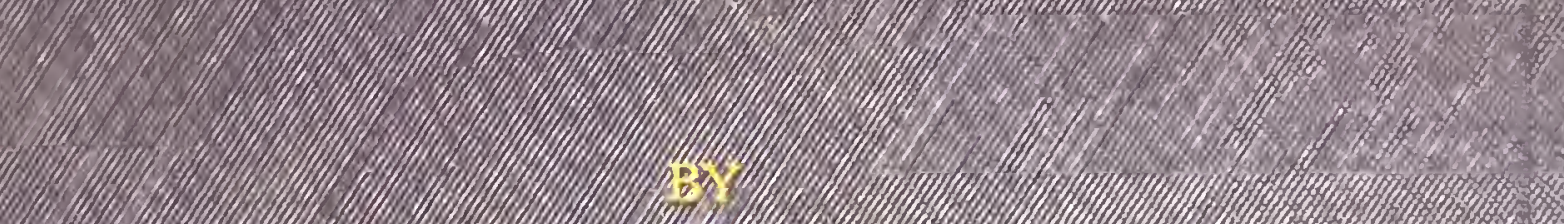




$$
\text { nt. }
$$

R.50102 




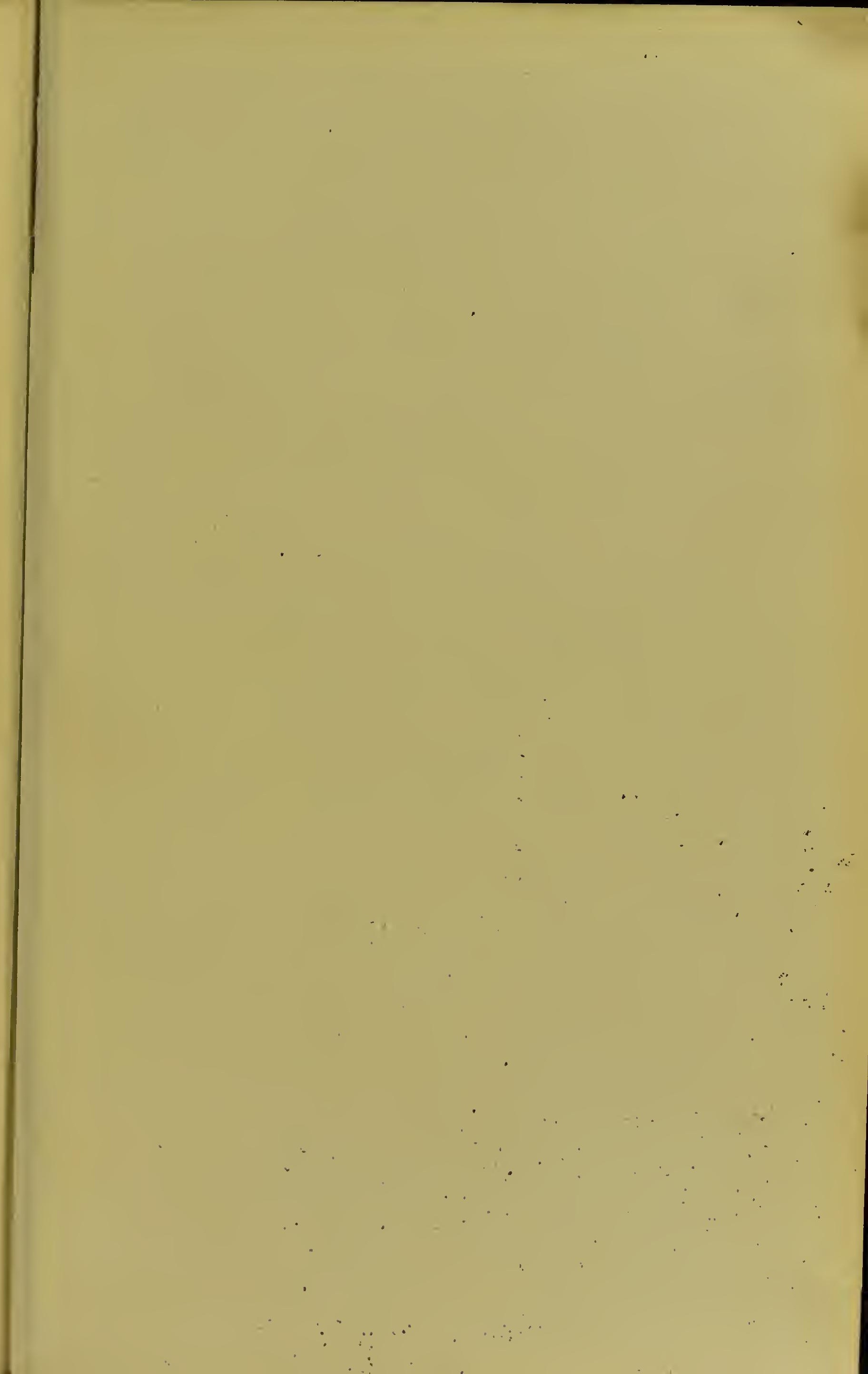





\section{THE \\ ART OF HORSE-SHOEING.}

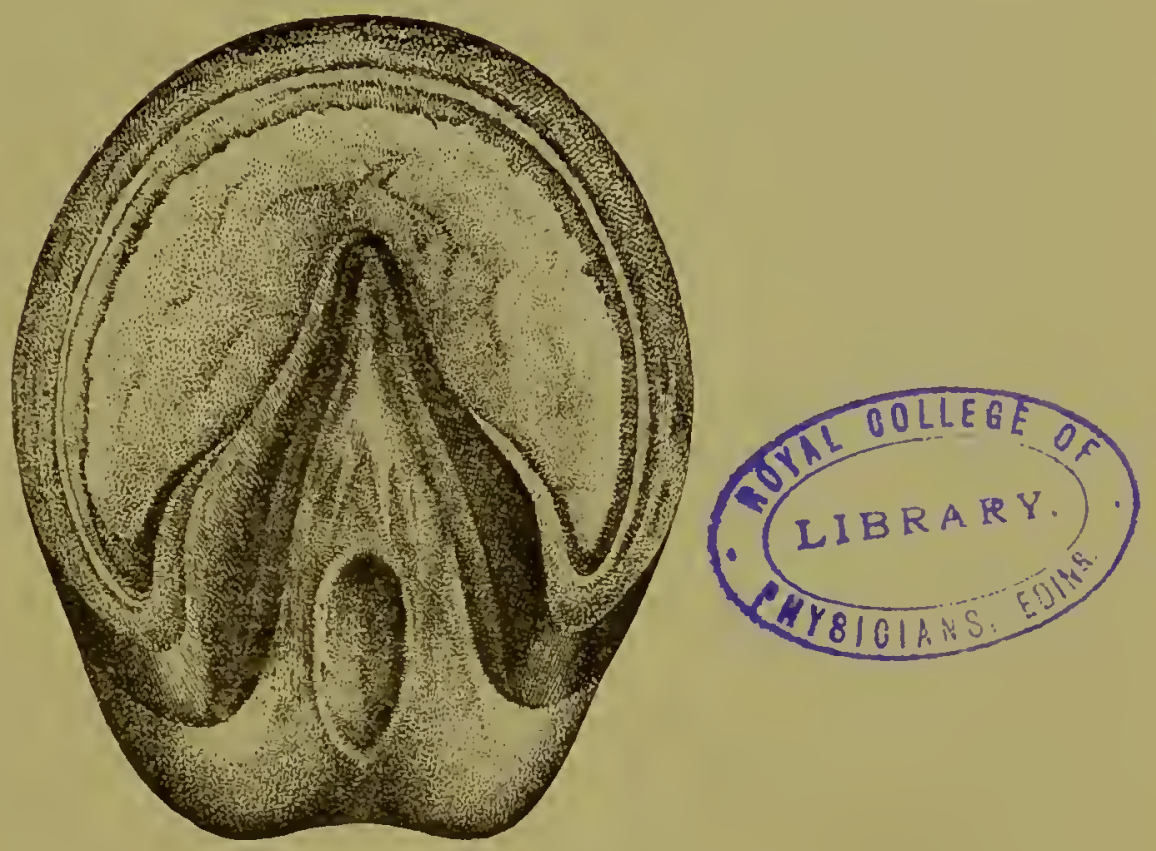

$\mathrm{BT}$

WILLIAM HUNTING, F.R.C.V.S.

Editor of The Vetcrinary Record.

Ex-President of the Royal College of Veterinary Surgcons.

Member of the Committec for National Registration of Farricrs.

WITH OVER ONE IIUNDRED ILLUSTRATIONS.

\section{THIRD EDITION.}

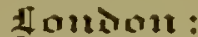

II. \& W. Brows, 20 Fuliam Roid, S.IV. 1899. 



\section{CONTENTS.}

Снар.

Pras.

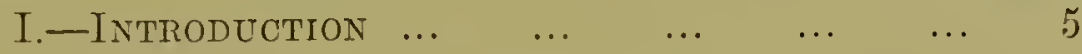

II.-The Form and Action of the Foot $\ldots .8$

The hoof. Divisions of the hoof. The sensitive foot. Growth of hoof. The bones. The elastic structures. The foot as a whole.

III.-PREPARATION OF FOOT. General principles. Instruments. The overgrown
foot. Proportions of the foot. A good bearing foot. Proportions of the sole and frog. Faults to be avoided.

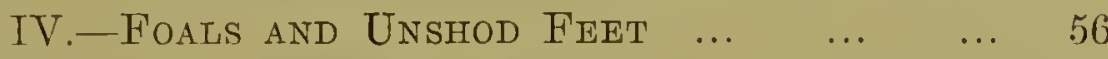

V.-The Form and Manufacture of Shoes...

Material, weight, thickness, width. The foot surface.

The ground surface. Calkins. Nrils, and nail-holes.

Machine-made shoes. Prepared bar-iron.

V1.-Selection of Shoes $\ldots$.. $\quad \ldots \quad \ldots \quad \ldots \quad \ldots$

Racing and steeplechase plates. Hunting and hack shoes. Carriage and draught horse shoes.

VII.-Fitting and Application of Shoes ...

Level or adjusted form. Uutline fitting. surface fit.

ting. Wear of shoes. Clips. Hot and cold fitting.

Tips. The Charlier system. Nailing on shoes.

\section{VIII,-RoUgHING}

Necessity for ; Evils of. Frost-nails. Ordinary " roughing." Removable steel sharps.

IX.-INJURIES FROM SHOEING .. ..
From nails, from clips, from the shoe. "Corns,"
"Burnt sole." "Treads." "Cutting or brushing."

"Over-reaching." "Speedy-cut." Forging or clacking."

X.-Shoeing Bad Feet

... ... ..

Flat feet. Convex soles. Sand crack. Contracted feet. Twisted feet.

XI.-Leather and Rubber Pads

Ring-leathers, Frog-pads. The Pneumatic pad.

The wedge pad. Bar pads. Iron and rubber shoes.

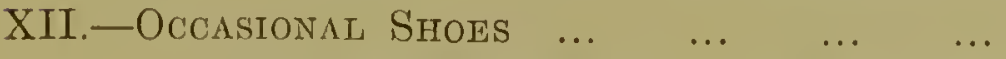

Bar: Patten; The FitzWygram ; Hinged ; expansion

Nrilless: Weighted shoes.

XIII.-Shoeing Competitions. 



\section{PIREFACE.}

'I'his little book is written for three classes of readers: for horse-owners who may interest themselves in the subject, for farrier's who are open to conviction, and for veterinary students who have to be examined.

The method pursued has been, to first describe the form and action of the foot, next the preparation of the foot for shoeing. 'Then the form of a shoe is treated of and the details to be observed in making it. The selection of shoes for varieties of feet or for special kinds of work follows, and afterwards the fitting and nailing-on are considered. Other chapters are devoted to "roughing," shoeing defective feet, accidents, the use of leathers and pads.

Throughout an endeavour has been made to be as simple and clear as possible in expression, to lay down correct general principles and to point out the technical details which are essential to good shoeing. On all these points authorities are not agreed, and I trust those who differ from we will pardon any too dogmatic expressions of opinion in these pages.

The illustrations will be of assistance in making clear the text. Some of these are copied from books, some are drawn from models or preparations, and some are diagrammatic. The books I am indebted to are: "Anatomy of the Domestic Animals," by Gamgee and Law; "On the Horse's Foot," by Bracy Clark; Bouley's "Atlas of the Foot," and Goyau's "Maréchalerie."

Above all, I am indebted to the late Professor Joseph Gaingee, who first gave nie an interest in horse-shoeing and to whose teachings and writings I trace whatever ideas I now possess.

WiLliam HUNTING.

\section{PREFACE-THIRD EDITION.}

When the second edition was published in Anerica, solle corrections and additions were made. This edition is still further enlarged and many new illustrations have been added.

London, 1899.

W. H. 



\section{ART OF HORSE-SHOEING.}

\section{Chapter I.}

Farriery is the art of shoeing horses, and can only be properly learned by a long practical experience in the shoeing-forge. If the foot of the horse were not a living object perlaps the training obtained in the forge would be all that was necessary for efticient workmanship. As, lowever, the hoof is constantly growing, it is constantly changing its form. The duty of a farrier therefore is not merely to fix a shoe upon the hoof but to reduce the horn to proper proportions before doing so. Now, as the hoof is ouly the outer covering of a complex and sensitive foot, damage to the horny surface may injure the structures within. Injury does frequently result, and not always from carelessness. Perhaps as much injury follows careful work, based upon wrong principles, as slovenly work carried out in perfect ignorance of any principle. The injury to feet resulting from shoeing may not be apparent at once. It may be, and often is, of a slow and gradual nature, and not credited to its true cause until the horse is rendered an incurable cripple.

It seems evident then that to do justice to a liorse a farrier should not only possess manipulative skill, but shonld have a correct idea of the structures and functions of the foot, as well as a thorough knowledge of the form and rariations of the hoof.

Ferv persons appleciate the importance of horsesloeing, and a small nmmber tell us it is unnecessary. Here and there an enthusiast has the comrage of his convictions and is able, for a time, to exhibit animals doing work without shoes. In some countrics horses are regu- 
larly ridden with no addition to their natural hoof, but in such places the surface over which the animals travel is grass land. In all civilized countries where good roads exist shoeing is practised. No man of business would pay for shoeing if he could do without it. The "shoeless" experiment has been tried over and over again, but always with the same result-a return to shoeing. In dry weather the hoof becomes hard, and it is wonderful how much wear it will then stand on the hardest of roads. In wet weather the hoof becomes soft, and then the friction on hard roads soon prohibits work without shoes. If work be persisted in, under such circunstances, the hoof rapidly wears away and lameness results. Persons trying to prove a pre-conceived theory meet this difficulty by resting the horse until the horn grows, but business men who keep horses for work in all weathers can afford no such luxury.

Shoeing has been called "a necessary evil." The phrase is a misuse of words, for there is no necessary evil about it. Of course it is no more free from accident than other operations, but its evils are fairly described as accidents, whilst its benefits are apparent to all but the blind. Without shoes horses at work would be inore often lame than with them ; without shoes horses could not do half the work they do with them, and so we need not further discuss the necessity of shoeing.

The value of horse-shoeing depends upon the manner in which it is done. Very seldom does the owner of horses appreciate the quality of the work. As a rule the price charged, or the distance from the forge to the stable, regulates the choice of a farrier. Such matters should not be allowed to decide between one farrier and another. A bad workman may do an injury at one shoeing which will cost the owner of the horse more than would pay ten times over the difference between his charges and the higher prices of a better man.

The old saw- " that for want of a nail the shoe was lost, for want of a shoe the horse was lost, and for want 
of a horse the man was lost," has been illustrated times without number. Few persons, however, arc aware of the terrible consequences which have more than once attended neglect in the shocing of horses. Napoleon's retreat from Moscow depended for most of its hardships and horror's ripon the simple fact that his hor'ses were not shod properly for travelling on snow and ice. The horses could not keep their feet, and were unable to drag the guns and wagons, which had to be abandoned. During the Franco-Prussian war, Bourbaki's retreat became a confused rout from a similar cause. In civil life no winter passes without injury and death to hundreds of horses from the same neglect. These are instances that anyone can see; but heavy losses due to bad shoeing are constant from other and less evident evils-from the adoption of wrong methods and the practice of elroneous theories.

The farrier has not been fairly treated by the public. His practical knowledge has been ignored, he has been instructed by amateurs in all sorts of theories, and coerced into carrying out practices for the untoward results of which he has been blamed. The natural consequence of all this has been that the art of farriery degenerated, and the farrier was forced into a position destructive to the self-respect of any craftsman. In no other trade do persons entirely ignorant of the business presume to direct and dictate as to how the work should be done. No one presumes to instruct the watchmaker or bell-hanger as to the details of his craft, but the farrier. has been compelled to take his instructions from all sorts and conditions of men. Only in recent years has the man who shoes horses been allowed to know something of his calling-since when, horse-shoeing has improved.

My object in writing is not to suggest anything new, but to point out the general principles upon - which the art is based, and to indicate those details which arc essential to success, and those which are to be avoided if soundness and duration of scrvice are recognized as true cconomy in a stud of horses. 


\section{Chap'TER II.}

\section{The Form and Action of the Foot.}

The foot of a loorse consists of a variety of living structures, differing in form and texture, and enclosed in a horny covering called the hoof. Althongh the farrier's work is ouly applied to the hoof, it is necessiry that he should know something of the whole foot, because it is but too easy to injure the structures within by alterations of the horny covering without.

The simplest way to understand the foot is to study separately the different parts, and to apply that knowledge in obtaining a general idea of the relations of all the parts to each other. Then there is not much difficulty in appreciating the functions of each part, and the uses and action of the whole orgiun.

\section{The Hoof.}

Everyone is familiar with the general appearance of the hoof. It is not a regular geometrical figure. Each of the four feet of the horse shows some peculiarity in forn, by which a farrier can at once identify a fore from a hind or a left from a right.

The front feet are rounder and less pointed at the toe than the hind; they are also more sloping in front. The two fore feet and the two hind should be in pairs. The right and left feet are distinguished from each other by the inner side being more upright, or, if examined on the under surface, by the outer border being more prominent.

The fore feet should be similar in size and shape. Disease may be suspected when any marlied difference exists. But a healthy hoof which has been brokien, or much rasped, does not retain its proper form, and may thus confuse a norice. 

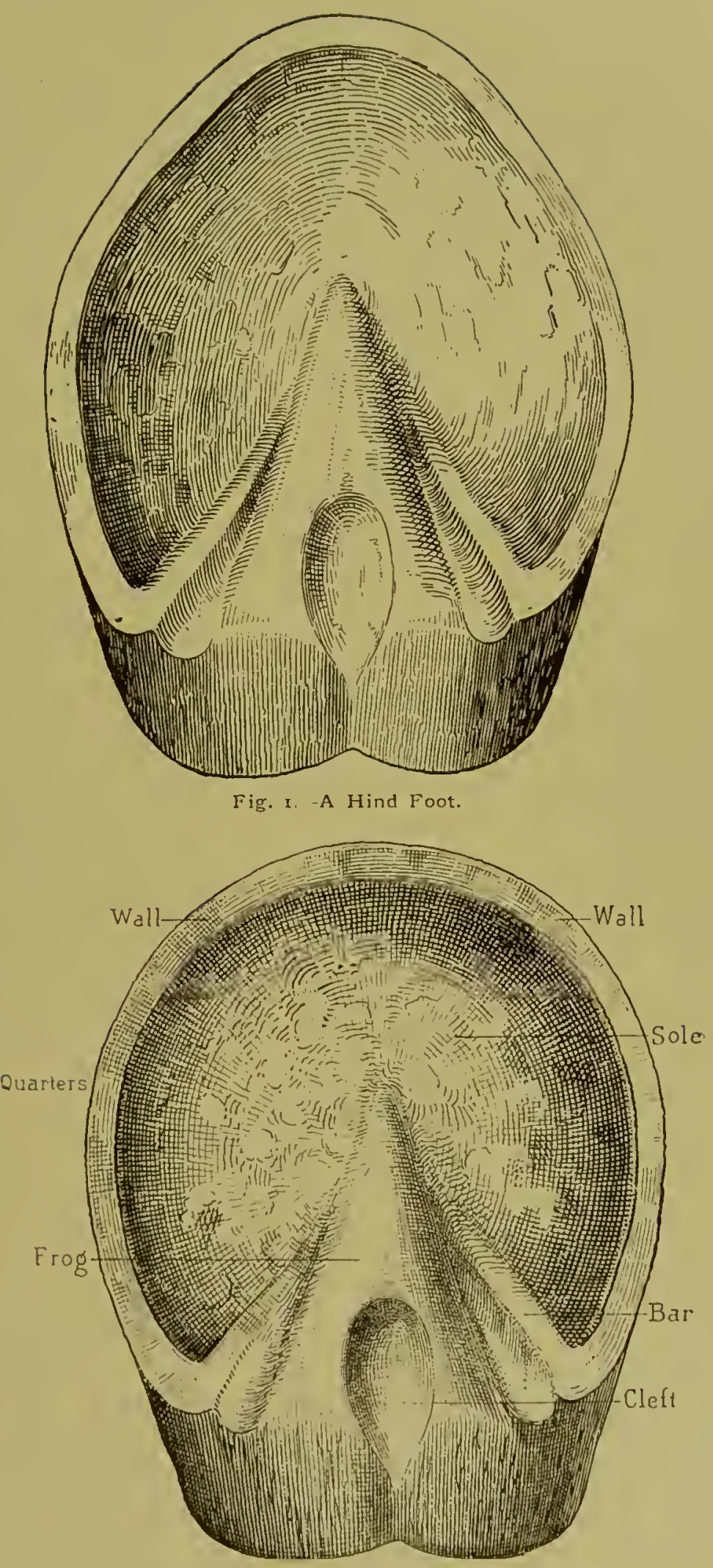

Fig. 2.-A Fore Foot. 
The hind feet should be proportionate in size to the fore, and then it is not of much practical consequence whether the whole are large or small.

The hoof varies greatly in shape even when sound and healthy. The popular idea is that a fore foot which is round and open is the best form. My observation leads me to prefer an approach to the oval. Too often the round foot has a flat sole, and it is always more liable to be bruised by the heel of the shoe. A distinctly contracted foot is usually the result of long-continued lameness, and this is the reason why narrow feet are looked upon with suspicion. If the narrow foot is natural to the horse it is as little likely to become unsound as any other. Looking at the hoof from the side, the slope of the front should be in the same direction as the slope of the pastern. Upright feet do not present this continuity of slope, and they generally have heels which are naturally high. It is well to mention this, as, when an attempt is made to reduce them to a theoretical standard of proportion by rasping, the sensitive foot is reached before the desired form is produced and lameness may be caused. The opposite form to this is a long sloping foot. The heels are low and the toe long, but usually the pastern also is long and sloping. Such a foot cannot be made a good shape without injury, and is therefore to be treated as a normal form.

Some hoofs have the toe turned out, some have it turned in. No attempt should be made to alter this by shoeing, as the twist is not merely in the foot but almost always in the whole leg. In nine out of ten cases the turned-out toe is accompanied by a turned-in elbow, and shoeing cannot alter such formation.

The quality of the hoof depends upon the breed of the horse and upon the soil and climate of the district in which he is reared. The Arab has a hard, flinty, strong hoof, the heavy draught horse a softer horn. Some hoofs are brittle and some "shelly," by which is meant horn with a tendency to break and crumble away. When 
defective quality of hoof is due to constitutional causes the farrier can do little to remedy it, but he must take care not to make it worse by submitting it to mundue pressure. Defects in the hoof are often due to bad shoeing, and then are mostly confined to the horn below the nail-holes.

\section{Divistons or the HoOF.}

Although to a casual observer the hoof appears as one continuous horny structure, it may easily be separated into three distinct parts by prolonged soaking in water. The division takes place so as to leave the sole, frog, and wall separate portions. These may now be considered.

The Wall is that portion of the hoof seen whilst the foot rests upon the ground. It covers the front and sides of the foot. It extends from the coronet downwards and slightly ontwards, so that its lower circumference is greater than its upper. The front portion shows its greatest height and obliquity, diminishing in these respects as it passes backwards. At the heels the wall is turned in upon itself, and passes forward towards the centre of the foot until it becomes lost in the structure of the sole. These turned-in portions of the wall are called the bars, and serve two purposes; they increase the bearing surface of the wall, and by embracing a part of the sole on each side, they afford an increased solidity to the union of the wall with the rest of the hoof.

'The bars act as buttresses, preventing the shrinking in of the heels. When they are cut aray the structural resistance to contraction of the hoof is destroyed. 'They should therefore be allowed to grow and retain their natural prominence.

'The lower border of the wall is the chiel hearing surface of the font. It encircles the sole, than which it is usually more prominent. In an overgrown foot it often extends some distance below the sole, and then shows on 
its inner side the horny laminæ which, within the hoof, afford attachment to the sensitive parts.

When excessive growth of the wall is reduced by rasping until the rall and sole are brought to a level it will be noticed-that the junction of the two is marked by a "white hine." This line of light hor"n, which connects the sole and wall, is often takco as at guide for the annount of hom to be remover. It is a dangerous guide, as many feet camnot safely be so reduced as to lning it into view over the whole bearing surface. In fact, it may be taken as a rule that the distinct appearance of the "white line" all round the sole is evidence that a foot has been over reduced.

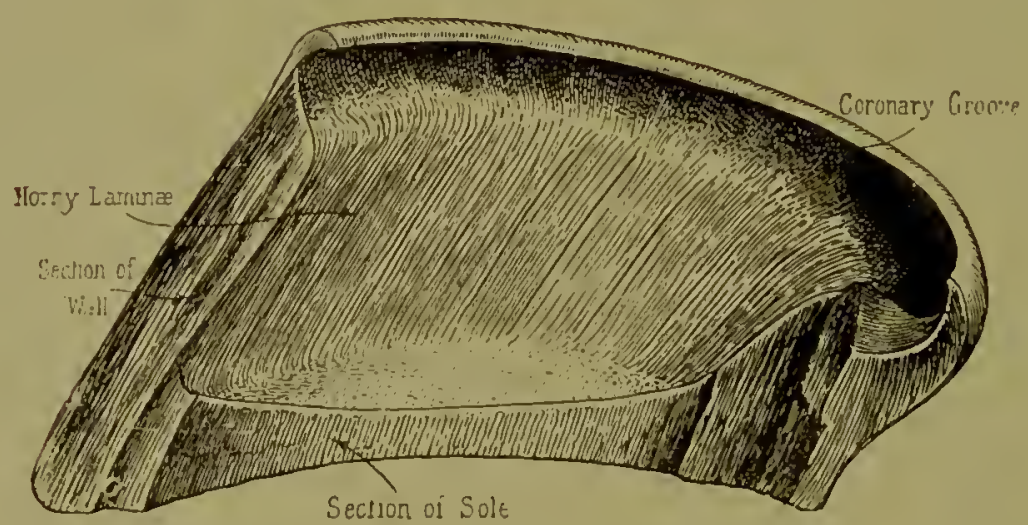

Fig. 3.-Half of a Hoof, showing the inside.

If we detach the wall, its inner surface is seen to consist of a number of thin, horly projections rumning parallel to each other from above downwards and forwards. These are called the lorny laminæ. They number from five to six hundred and correspond to similar processes on the sensitive foot. (Fig. 3.)

Round the upper circminference on the inside of the wall is a depression or groove presenting innumerable small pits or openings. This corresponds to a part of the sensitive foot called the coronary band, which will be noticed again.

A section of wall enables us to see variations in its 


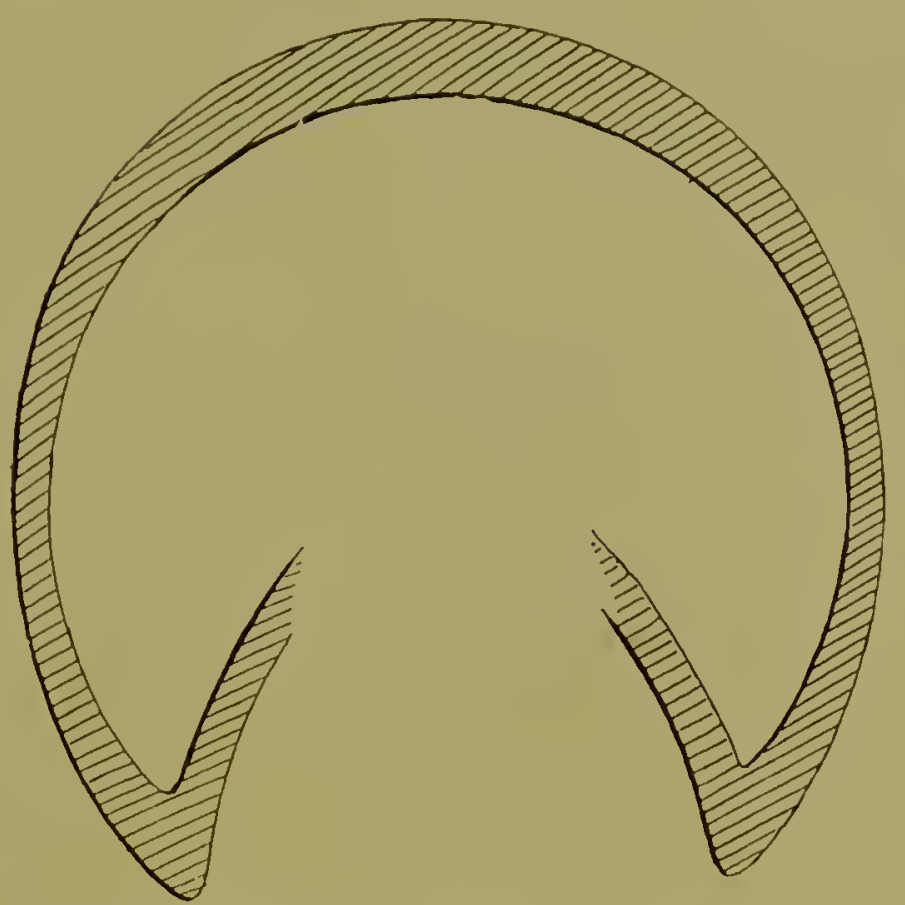

Fig. 4.- Transverse Section of Wall showing variation in thickness.

thickness. (Fig. 4.) It is thickest at the toe, becoming gradually thimner towards the heels; thins affording strength and solidity to resist wear at one part, as well as pliancy at another to ward off concussion.

The structure of the wall is fibrons, the fibres running parallel to each other, and with the same obliquity as that presented by the front of the wall. Although the wall varies in thickness from before backwards, it does not from above downwarls. It maintains the same thickness from the coronet to its lower circunference.

The layers of the wall are hardest externally, becoming softer as they approach the inner surface-a condition due to the onter layers being exposed to friction and evaporation. 'I'his is a simple and valuable provision of nature which should not be interfered with. The hard onter layer is best adlapted to withstand wear, and its density protects the deeper layers from eraporation. This maintains the whole wall at the degree of softness and 
toughness which best preserves elasticity and strength of horn.

The sole is that division of the hoof which forms the floor of the foot. It is situated within the lower border of the wall, and is slightly arched, so that on a hard, level

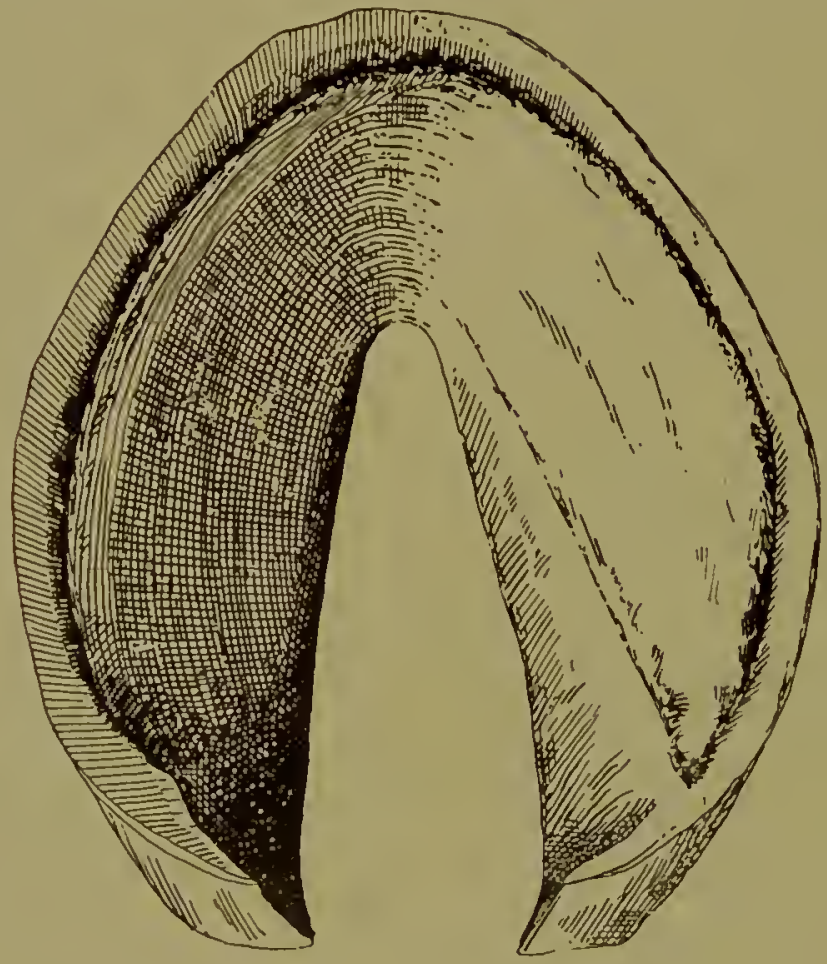

Fig. 5.-The Sole with Frog removed.

surface its central part takes no bearing. (Fig. 5.) Posteriorly the sole is divided by a triangular space into which the frog fits, and thus its continuation to the heels consists of two angular portions embraced between the bars and the wall. The unmutilated sole is throughout of neirly equal thickness, but a slight excess round the circumference gives firmer attachment to the wall. The inner surface presents a finely-pitted appearance, which is most miarked at the toe and round its border. 'The part immediately related to the frog shows few pits, and we shall find that the whole surface corresponds to the sensitive parts to which it is attached. 
The structure of the sole is, like the wall, fibrous; but the fibres are smaller. They run downwards and forwards in the same direction as those of the wall. The onter layers are the hardest and protect the deeper from injury.

The Frog is the smallest division of the hoof, and is a triangular-shaped body filling up the space left between the bars. (Fig. 6.) Its broad base is rounded and prominent.

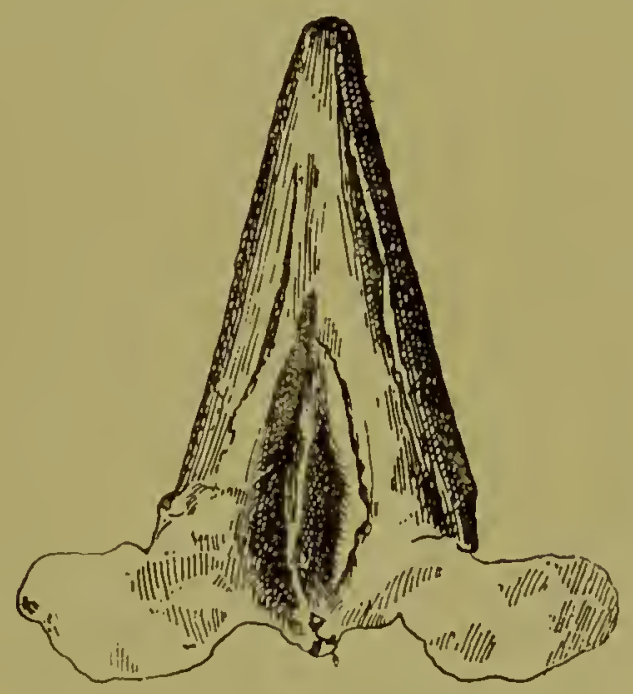

Fig. 6.-The Frog, detached from the Sole.

The point of the frog, much the harder part, extends forward to the centre of the sole. Though situated between the bars, the frog is only attached to their upper border, the sides remaining free and separate. Thus on each side is formed a deep fissure which permits the frog to expand laterally when compressed, without the entire force being continued to the sides of the foot. T'he frog is elastic, and when pressed upon must expand. If these spaces between frog and bars did not exist, the foot would be injured when the frog was compressed by the weight of the horse-either the sensitive parts within would be bruised or the heels would be forced apart. 
The centre of the frog presents a depression or "cleft," caused by the doubling in of the horn. Few shod feet exhibit it of natural appearance, and the term cleft, by implying a narrow deep fissure, lieeps up the false notion. The cleft should be shallow and rounded. It serves two purposes-it increases the mobility of the frog, and by breaking the regularity of surface affords a secure fonthold on level ground.

The prominence of the frog might lead a superficial observer to consider it a thick solid mass; and I believe this mistake is the canse of its too frequent mutilation. It is merely a layer of horn following the outline of the structures within, which are similarly prominent and

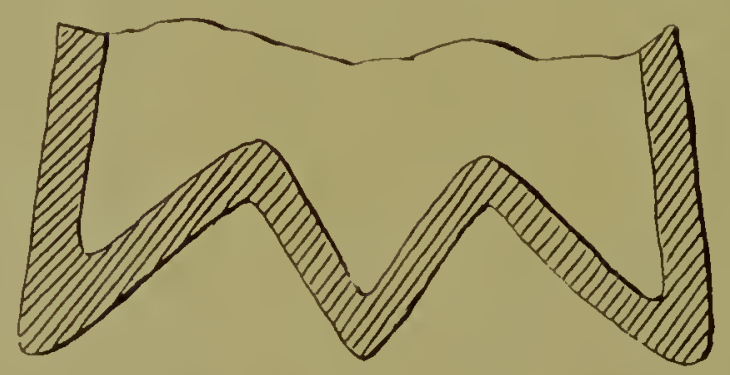

Fig. 7.--Section of Foot at point of Frog.

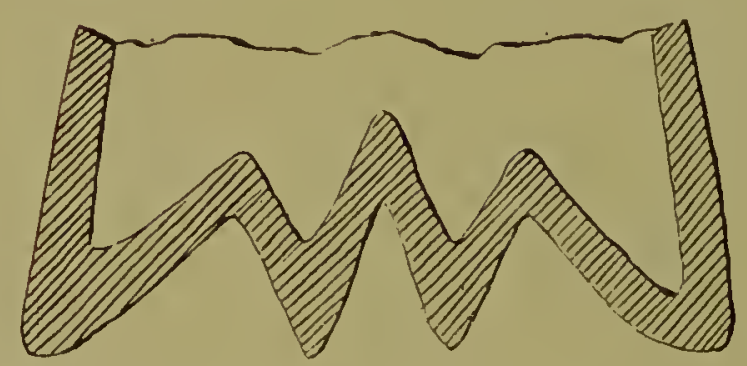

Fig. 8.-Section at Cleft.

irregular in surface. (Figs. 7 and 8.) The first diagram shows a section through the point of the frog, the second a section through the cleft.

The frog is fibrous, though not to such marked degree as the other portions of the hoof. Its chief qualities are elasticity and toughness. 
The Frog Band.-Covering the bulbs of the heels and apparently continuous with the structure of the frog is a light-coloured layer of horn which extends round the upper portion of the wall and encircles the junction of the loof with the hair. It is hardly visible on a dry hoof, but when the foot has been poulticed, or when a horse has been rumning in a wet pasture it is easily seen. In Figure 9 it is shown in connection with the frog, and in

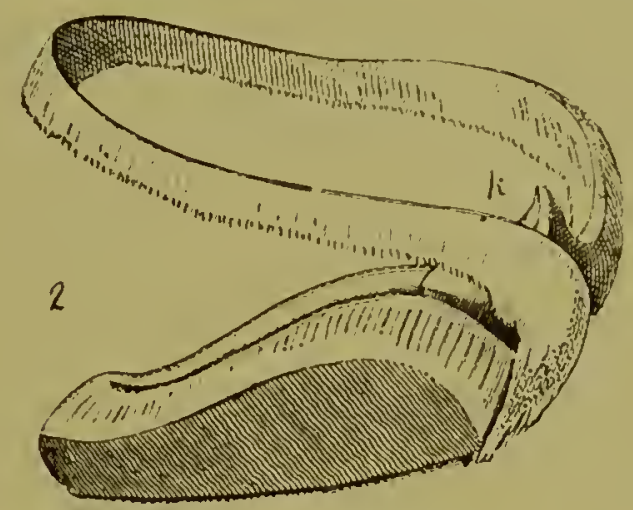

Fig 9.-The Frog and frog-band.

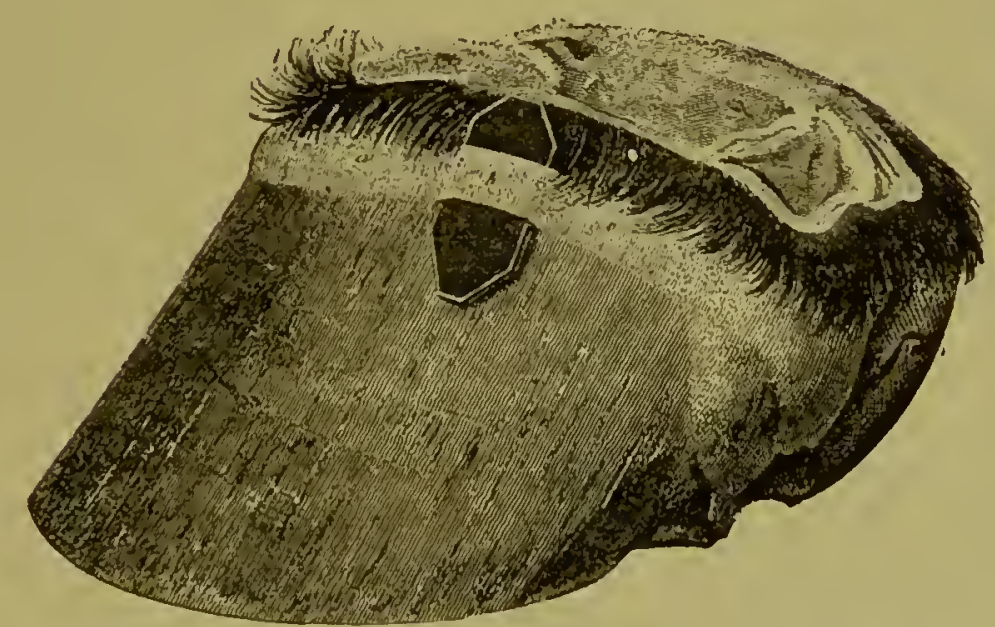

Fig. Io. - The frog-band detached from wall by a small wedge.

Figure 10 it is shown liuised from the wall. Both drawings give it the appearance of a narrow band but it is really not so. It may cxtend tor any distance down on the hoof but is worn away by attrition as it descends. 
This structure is secreted by special glands situate just above the upper edge of the wall, and forms an outer protecting layer to the junction between skin and loof. In structure it is something between skin and hor'n. It should not be rasped away. It prevents evaporation from the newly-secreted horn and is a continuous outer envelope of the hoof at its junction with the skin.

\section{The Sensitive Foot.}

If we macerate a dead foot in water for a week or two, the hoof may be removed entire without injuring the tissues within. In this way the sensitive foot or "quick" is exposed to view, and presents an exact counterpart of the inside of the hoof. The sensitive foot consists of a layer of fibrous tissue stretched over the bones and other structures which form the centre of the foot. It is plentifully supplied with blood-vessels and nerves necessary to its double function as the source of horn growth and as the tactile organ of the foot. Horn is, of course, not sensitive, although the slightest touch on a horse's hoof is recognized by the animal, and this foeling is due to the impression made upon the sensitive foot. In the living horse any injury to the "quick" causes the greatest pain, and although this sensitiveness is a serious disadvantage in disease, it is a most valuable provision in health, enabling the horse, even through a thick layer of horn, to recognize the quality of the surface upon which he may be standing or moving. It is this sense of touch -this tactile function-which demands that the sensitive foot should be so bountifully supplied with nerves.

Every farrier knows how profusely blood flows from any wound of the "quick"-evidence that the part is well supplied with blood-vessels. This full supply of blood is not merely for the ordinary waste and repair which takes place in every tissue ; it is to meet a special demand-to supply the material for the production of horn. The sensitive foot is the secreting structure of the hoof, and the source of the constant growth and repro- 
duction of horn. It corresponds with great exactness to the inside of the hoof, and as we have described the hoof in sections it may be convenient to follow that course with this structure, and to describe the sensitive frog, the sensitive sole, and the sensitive laminæ. We shall begin with the last.

The Sensitive Laminæ. - Corresponding to the horny leaves on the inside of the wall, the sensitive foot presents an arrangement of minute parallel folds which are called the sensitive laminæ. (Fig. 11.) Between these. when the hoof is on the foot, the horny laminæ rest, so that there is a kind of interleaved attachment which affords the very firmest connection between the wall and the sensitive foot. If the laminæ be laid bare in a living horse by removal of the wall, it is found that they have the porver to secrete a kind of horn, not a hard, fibrous horn like that of the wall, but a softer variety. This function is not very active in health or we should find that the lower edge of the wall was thicker than the upper; but it exists, and is very evident in some cases of disease.

In laminitis, the wall at the toe is often pushed forward out of position by a horny mass formed by the laminæ, and so we have the deformity of an excessive length of toe. In some cases of long continued sand-crack, the

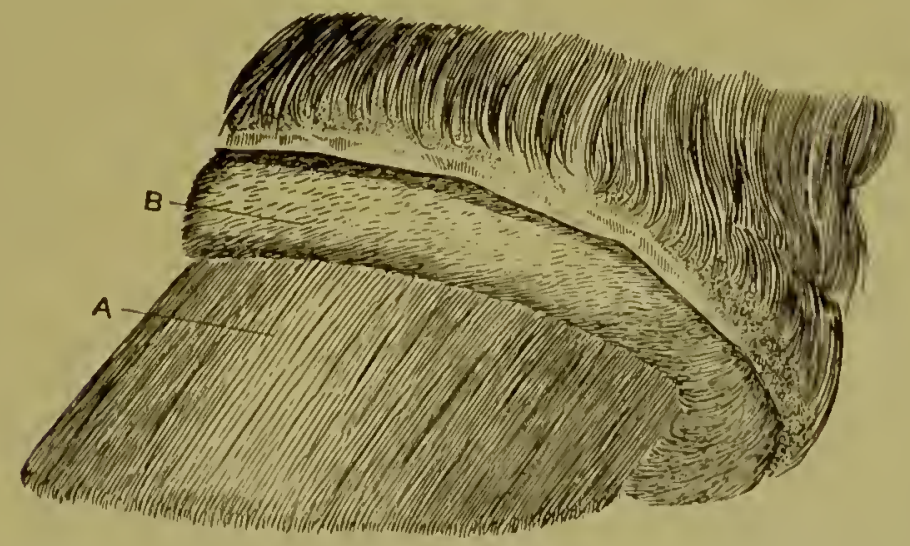

Fig. I1.-Foot with hoof removed showing at the upper part the Coronary band (B), and bclow the Sensitive Launina (A). 
irritation of the laminæ causes excessive secretion, and a hom tunnour results. The sensitive laminæ fulfil two functions; they offer a firm connecting medium for the wall, and they secrete horn. By the cruel experiment of removing the horny sole and frog of a living horse and then forcing him to stand on the maimed foot on a level surface, it has been shown that the laminæ are capable of alone supporting the weight of the animal. It has been argued from this that the laminæ always support the weight, and that the horse's foot may be described as being slung by the connecting lamine. This is not true. The frog and sole help to support weight, and the hoof acts as one continuous whole, each part taking its direct and proportionate share of the weight placed upon the foot. The sensitive lamine are not elastic, they are unyielding, and therefore allow no downward yielding which would inpose excessive pressure on the sole.

The Coronary Band.-(See B, Fig. 11.) The sensitive laminis do not cover the whole of the upright portions of the sensitive foot. There is, between their upper extremity and the line which separates the skin from the sensitive foot, a convex band which runs round the upper border of the foot, and is turned downwards and inwards at the heels. This is called the coronary band, and corresponds to the groove which we noticed on the inner side of the upper border of the wall. On its surface are innumerable small projections or papillæ which, in the living animal, fit into the openings on the groove of the wall. From each of these papillæ grows a horn fibre, and from the surface between them is formed a softer horny matterthe two products forming together the substance of the wall. The coronary band is, then, an important structure, being the source from whence the wall is produced. Upon the healthy condition of this band depends the soundness of the wall, and any interference with its integrity must lead to defects or deformities in the wall. 
The Sensitive Sole (Fig. 12) is that portion of the "quick" to which the sole is attached. Its surface is covered with papilla, like those on the coronary band, but much smaller, giving an appearance somewhat like the pile of vclvet. From these the horn fibres of the sole are formed, and a firm means of conncction is afforded for the floor of the hoof.

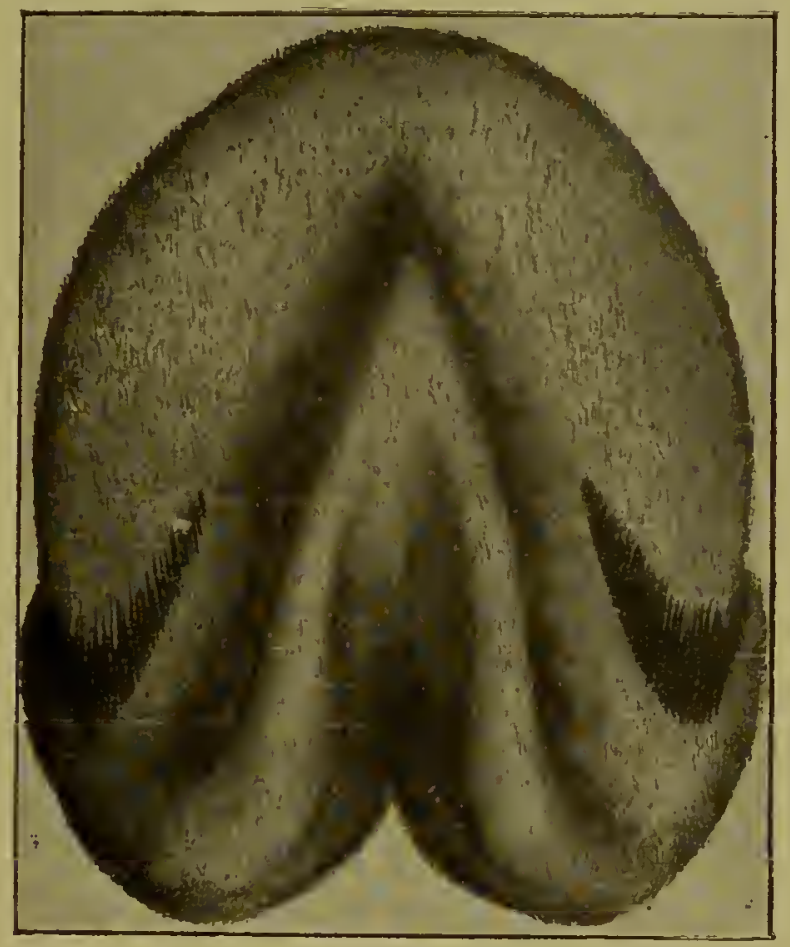

Fig. 12.-The Sensitive Sole.

The Sensitive Frog in structure resembles the sensitive sole, but its papillie are very much smaller, and the surface, therefore, is smoother. The imegular, prominent surface of the frog, with its cleft and the space at each side of it, is exactly reproduced on the sensitive frog, as might be expected, for the one is moulded on the other. 'There is one difference between the sensitive frog and the other portions of the sensitive foot which I may here inention. Tt is not attacher to the bones of the foot, except hy its point, but is situated between the two pos- 
terior branches of the cofftin bone, and has, as a basis, a mass of soft tissue which forms an important cushion or $\mathrm{pad}$, to be referred to later.

\section{Growth of Hoof.}

Like every other part of an animal body, the hoof is constantly changing. Wear and tear cause waste of the horn, which is replenished by growth. When wear exceeds growth the foot becomes denuded of horn, and lameness results. When growth exceeds wear, the hoof becomes disproportionately long, and some parts suffer by the overgrowth of others-for instance, whenever the heels are unduly high, the frog becomes small and weak. In a state of nature, the horse's foot lieeps itself of proportionate form. On hard ground, the hoof is worn away as quickly as it grows. On soft ground, it may, for a time, become overgrown, but this is rectified by the soft horn becoming fractured and broken off. In enclosed, cultivated grounds, the movements of the horse, even on grass land, are too limited to ensure a proportionate form of hoof. When horses are turned out without shoes, the feet should not be left to take care of themselves, unless the pasture is of large area and the time at grass extends for several months.

In a hoof which is overgrown-and all shod feet become overgrown in four or five weeks-there is apparently a greater excess of horn at the toe than elsewhere. This is due to the oblique direction of the wall at the toe, and to the fact that the horn fibres of the hoof do not grow down vertically, but obliquely forward. When the natural wear of the hoof is prevented, the effect of growth is to lengthen the toe and carry forward the bearing surface of the foot. Now; this bearing surface has a proper relative position to the limb above it. Therefore a disproportionate foot must injuriously affect both the action and position of the whole limb.

The rate at which the wall grows raries greatly in different horses, and is affected by external conditions. 
The good average wall grows nearly one inch in three months, and the whole hoof is replaced in from ten to fifteen months. The hoof grows more rapidly when a horse is actively exercised than when he is confined in a box. Febrile diseases check growth, and irregularities of the system cause the formation of ridges in the horn, each one commencing at the coronet and being carried down with the growing horn until the hoof is marked by a series of rings rumning transversely and parallel to each other. These rings are of themselves no detriment to a horse, but they mark irregularities of growth which may have been due to illness or lameness.

The growth of horn on a shod foot is affected by the bearing it takes. When a part of the wall takes no bearing on the shoe it grows quicker than that which does. We see this when a shoe is so fitted that the heels take no direct pressure on the shoe, also when a portion of wall is broken at the quarters, and again when, for any reason, a portion of the edge of the wall has been rasped away to prevent bearing upon some special spot. In all these cases, after the shoe has been worn a month, it will be found that the horn has grown more rapidly at the part where bearing did not take place, and, when the shoe is removed, the horn which was relieved of pressure may be found in apposition with the shoe.

The growth of horn cannot be accelerated by any application to its surface. If we desire to hasten growth of the wall we can do so by stimulating the part from which it is produced, i.e., the coronary band. A mild blister to the coronet causes considerable increase in the rapidity of growth, but no liniments applied to the surface of the wall affect its production in the least, thongh they may modify its condition and prevent dryness and brittleness.

The sole grows in much the same way as the wall, but it wears quite differently. It never becomes overgrown to the extent seen in some instances of the wall. The hard, firm structure of the wall, if not worn down 
by friction on roads or dry, hard surfaces, may grow to a great length. As a rule, when much overgrown, it splits in the direction of its fibres and becomes detached in broken fragments. The sole, when overgrown, has a tendency to become detached in flakes, and never very much exceeds its normal thickness without becoming dry and brittle, when the movements of the horse cause it to break up and to fall off.

The frog, when it takes a bearing on the ground, wears off in shreds. A frog which takes no bearing dries up, and sometimes a large, superficial layer is cast off. Though the soltest of the horny divisions of the hoof, the frog is able to withstand wear and tear as well as any of the others. Being elastic, and resting upon soft tissues, it is able to yield to any undue pressure and leave the firmer horn of the wall and bars to sustain the greater strain. The growth of the frog depends a great deal upon the form of the back parts of the wall. If the heel becomes overgrown the frog is removed from bearing and consequently wastes. High heels have always between them a small frog. On the other hand, low, weak heels have always a large frog, and the explanation is that the increased bearing thrown on the frog causes greater developinent.

Properties of Horn.-Horn is light, hard, tough, and elastic, properties most essential to its usefulness as a protector of the foot. Horn is porous, and absorbs moisture. Too much moisture in horn weakens it, and therefore it must be remembered that the natural protection against this is the hard outer layer of the hoof. When this layer is rasped off moisture is more easily absorbed, until the dry, hard surface is restored by cxposure and friction.

Horn is a bad conductor of heat, and thus an equally good protective against the effects of snow in some countries, and of hot, dry sands in others. With in sound, thick hoof, the application of a red-hot shoe produces 
very little effect on the internal structures, provided, of course, it remain in contact only a reasonable time. With a foot protected ly a thin layer of horn, fitting a red-hot shoe must be done quickly, or it may dimage the soft tissues.

\section{The Bones.}

So far we have only described the outer covering of the foot and the structure from which it grows and by which it is connected to the parts within. A little deeper examination is necessary to understand the mechanism of the whole organ.

If we divide into two lateral halves, a foot cut off at the fetlock joint, we have a section which should show the whole of the deeper structures. In the centre, we see the three lower bones of the limb-the pastcrn, coronet, and pedal. (Fig. 13.) On the front surface of these

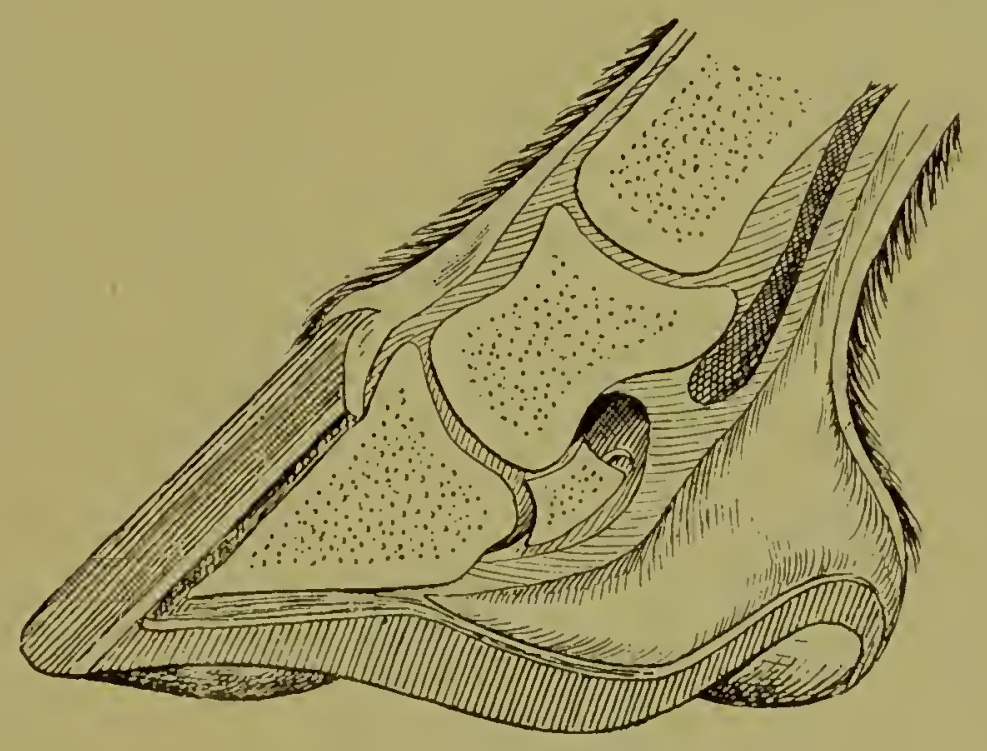

Fig. 13.-Section of Foot.

bones, we notice in teston or sinew which comos from above the knee and is fixed to the upper part of the podal bone. At the back of the bones, two very large tendons run down and are fixed on the last two bones. T'hese tendons are the structures through which the movements 
of the foot are made. They have in themselves no power of contraction, but they are connected above the knee, and in the hind leg above the hock, to porrerful muscles which possess the porrer of contraction. When these muscles contract the tendons are drawn up towards linee or hock, and so move the foot backinards or formards.

To permit movement of one bone upon another, the ends of the bones are suitably shaped, and covered with a layer of gristle or cartilage. To limit the movement and to hold the bones together, the ends of each bone are surrounded by ligaments, and thus we have joints formed. The pastern bone is altogether above the level of the foot, the coronet bone is partially within the hoof, and the joint betrieen it and the pedal bone is quite within.

The Pedal, often called the coffin bone (Fig. 14), is entirely within the hoof and fills the front part of the

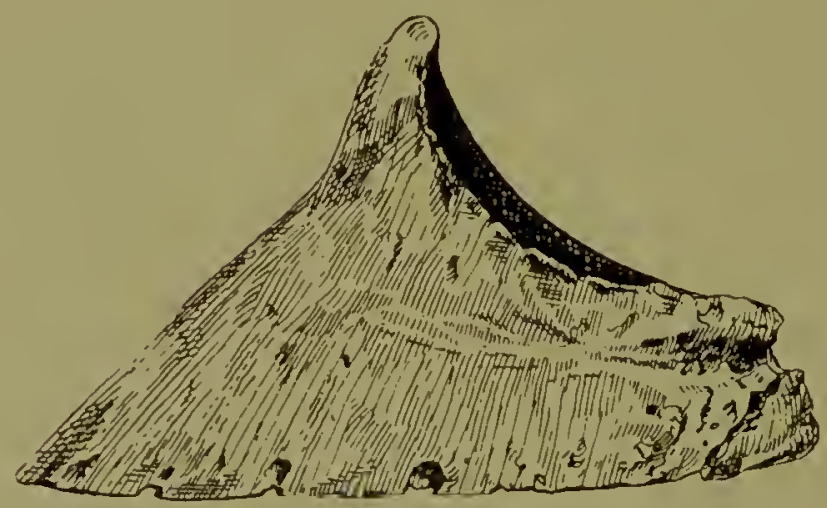

Fig. 14.- Side view of Pedal Eone.

horny envelope completely. It is a peculiarly shaped bone, being continued backwards by two projections which follow the course of the wall to a little beyond the quarter's of the foot. (Fig. 15.) From this point to the extremity of the heels, the wall is not supported by bone, but by strong plates of gristle, which are called the lateral cartilages. 


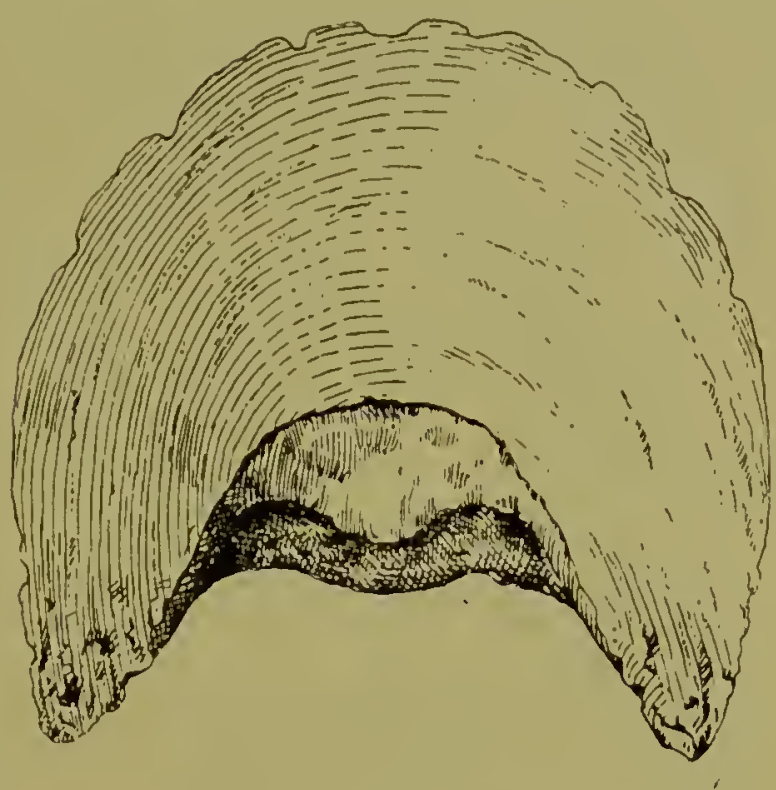

Fig. 15- Under surface of Pedal Bone.

The Navicular Bone is a small narrow bone placed transversely at the back of the cotfin joint. It is shomn in section in Fig. 13, and its surfaces are seen in Figs. 16, 17.

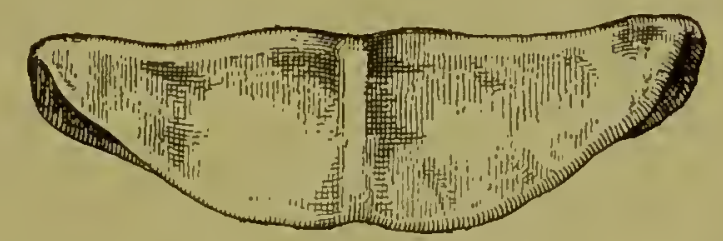

Fig. 16. - Navicular Bone. Back surfacc, over which the tendon plays.

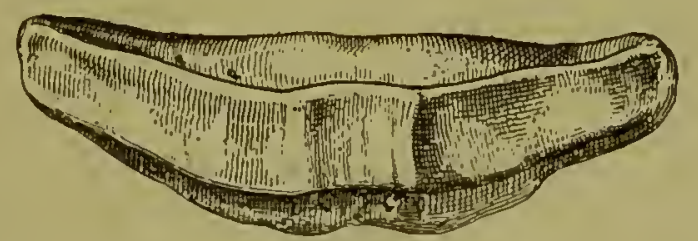

Fig. 17.-Navicular Bone. Joint surface for articulition with coffin-bone.

Over its posterior surfiace the back tendon passes on its way to be attached to the under surface of the colfin bone. Picked-up nails entering the font about an inch behind the point of the frog cause gruve injuries when they penetrate the tendon or reach the navicular bone. Perhaps 
a more correct idea of the position of the navicular bone will be obtained from a glance at Fig. 18 where it is shorn in position between the coffin-bone and the back-tendon.

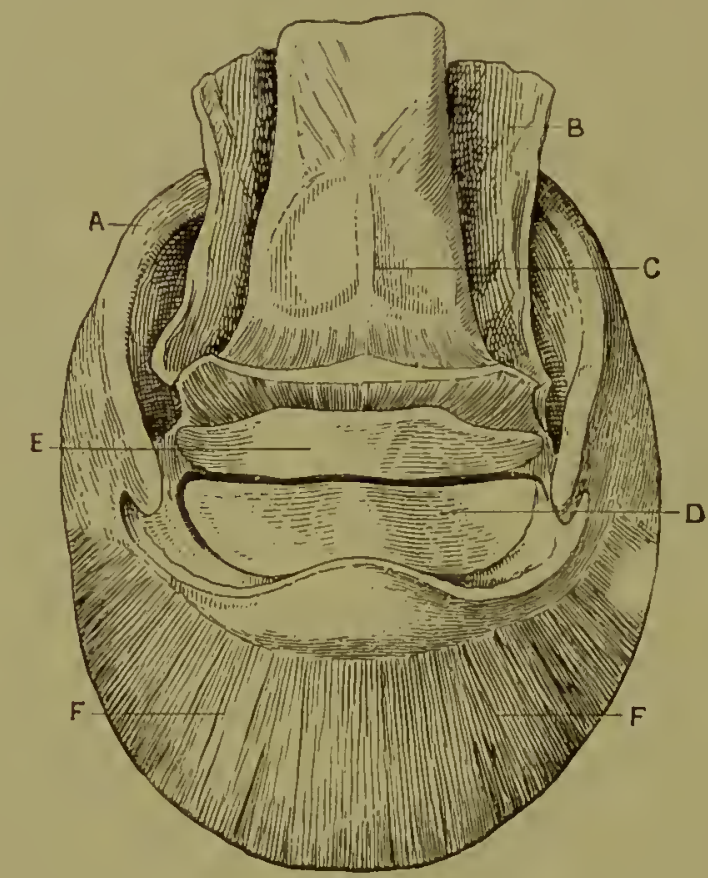

Fig. 18. Dissected loot.

sensitive lamina. D joint surface of coffin bone. E navicular bone.

C part of the back-tendon. B sheath of tendon.

A upper border of lateral cartilage.

T'HE ELASTIC S'TRT' ('TTRES.

The Lateral Cartilages are situated one on either side of the foot, partly within and partly without the hoof. They form the basis upon which the back part of the wall is moulded, and being elastic, permit a certain amount of movement in the posterior parts of the foot. (Fig. 19, 20.) If the colfin bone filled the whole hoof, the foot would be too rigid. With bone at the front portion, we have a fir'n surface for attachnent, and with cartilage at the back we have an equally finm attachment, but one that will yield to blows or pressure and thus better protect the internal parts. These cartilages extend above the level of the hoof, and may be easily felt in the living 
horse at the upper and back part of the coronet. (Fig. 19, 20) Between them, and behind the body of the coffin bone is a large space which is filled up by a mass of soft tissue, to which various names have been given, such as plantarcushion, frog-pad, \&c.

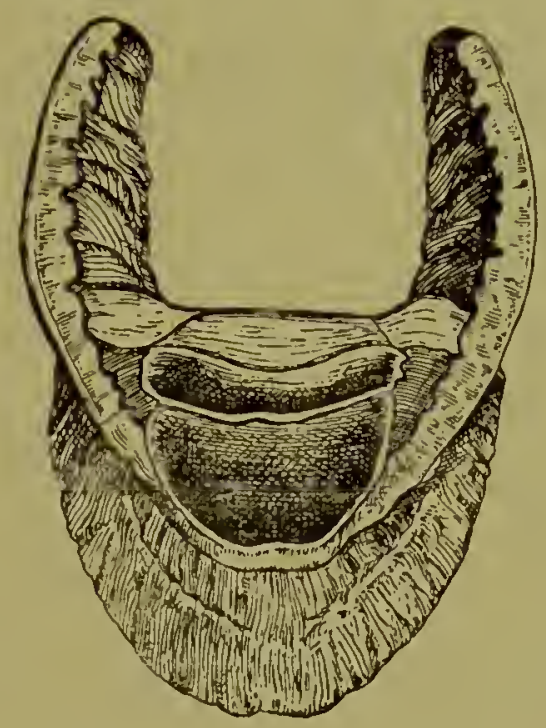

Fig. I9.-Coffin Bone and Lateral Cartilages seen from above.

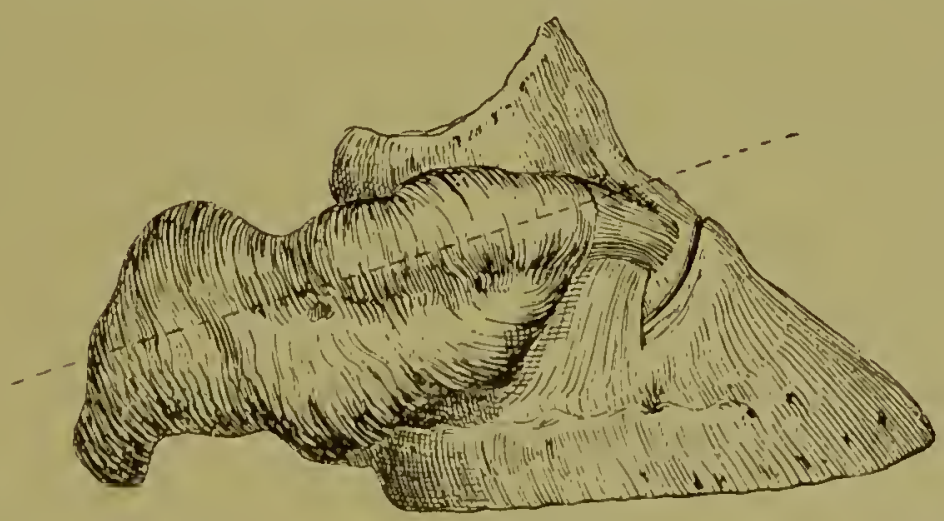

Fig, 20.-.The Lateral Cartilage.

The Frog Pad is the name under which we shall notice it. It forms the bulbs of the heels and is the soft basis upon which is spreat the sensitive frog. It extends from side to side of the foot between the two lateral 
cartilages, and fills up all the space within the hoof behind the body of the coffin bone. The structure of this pad may be described roughly as consisting of a network of fibrous bands, having the interstices filled up with elastic tissue. (Fig. 21.) Down the centre of the pad

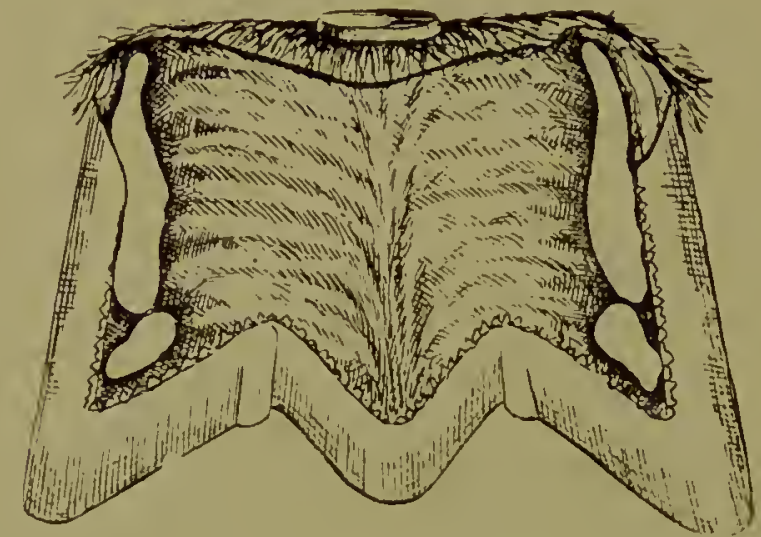

Fig. 21.-Section of F oot showing the Frog-Pad, at each side the cut edge of the Lateral Cartllage.

runs a vertical partition of inelastic fibres; from this, strong, fibrous bands pass to each cartilage, and so the whole of the back part of the foot is tied trgether. The heels and quarters may be pressed together to some extent, but they are prevented from being forced asunder by the fibrous comnections of the frog-pad. During progression, the downward movement of the coronet bone is provided for by this soft pad, and so is an upward movement of the frog, when excessive bearing is placed upon it.

The frog-pad serres other purposes besides those we have just referred to. It is essentially a cushion or pad to prevent jar or concussion, and it also play's an important part in the action of the foot, as we shall see later on.

The Coronary Cushion or Pad is nnother mass of tissue of a similar nature to the frog-pad. It is siturted just above the upper border of the hoof, and gives to the coronet its prominence and elasticity. At 
this part of the foot there is an enormous number of small blood-vessels and nerves, and the coronary pad formus not only a base for these to rest on, but a necessary protection for them. If, instead of this elastic bed, they were placed merely between the skin and the hard bones and tendons of the part, they would be injured by every slight bruise. Even with this cushion, we have, in practice, very many serious conditions following bruises of the coronet.

Blood-vessels of the Foot.-It is not necessary to describe the course of these vessels. All we need remember is that every part of the tissues within the hoof is very plentifully supplied with blood, and that the flow of blood is most rapid when the foot is in action. In a dead foot, from which the blood has escaped, a certain amount of movement of the bones within the hoof is easily effected. In the living foot, when every vessel is filled with blood, no such movement takes place. The blood in the ressels forms a sort of water-bed, which assists in preventing concussion and which distributes evenly over the whole organ the pressure applied when weight is thrown on the foot. In stndying the dead foot with a view to understanding its mechanism, we must not lose sight of the difference which resnlts from having in one case the blood-vessels empty, and in the other-in the living animal-the blood-vessels full.

\section{The Foot as a Whole.}

The details given of the structure and uses of each separate part of the foot will, it is hoped, be sufficient to enable us to understand the form and action of the organ as a whole.

No one part of the foot is of greater importance than another; each is dependent for its highest development and soundest condition upon the integrity of neighboring parts.

A weak wall allows of the flattening and spreading of 
the sole, whilst a weak sole permits contraction of the wall. Overgrown heels cause wasting of the frog, but low, weak heels are usually accompanied by excessive derelopment of frog.

The special function of the foot is to sustain the weight of the animal whilst standing or moving. The horse standing squarely on all four feet rests his weight chiefly on the lower circumference of the wall. On level ground, the sole. on account of its arched form, takes no direct bearing, but if sole and wall be sound, a proportion of all pressure applied to the wall is transmitted to the sole. So, also, must all weight imposed on the arch of the sole be transmitted, through its abutments or union with the wall, to the wall. If the sole be so thin that it yields to pressure, then its proper action is destroyed, and instead of acting like an arch and supporting weight imposed on it, it yields, and injury results. The arched form of the sole indicates that it was not intended to take a direct bearing on hard ground. On in soft surface, the edge of the wall sinks and the whole under surface of the foot takes a direct bearing. Pressure of the sole on the soft surface does no harm, because it is diffused evenly over the whole of the sole. We take advantage of this when the wall is diseased or injured, and we desire to throw on the sole a larger share of weight. We turn such animals out into a soft field, or stable them on sand or saw-dust. Any system of shoeing founded upon the true form and action of the foot must recognize the arch, and not endeavour to force the sole to take a bearing for which it is not adapted. There is only one part of the sole which should act as a bearing surface, viz., that outer border which is firmly joined to the wall. This part-the abutment of the arch-is destined by nature to take a bearing, and through it the whole of the sole supports its share of weight.

The frog takes a bearing on the ground, but it has a weight-sustaining function quite secondiry to the harder and firmer parts of the hoof. It is formed of a softer 
horu, and it has above it only soft tissues which permit yielding. The frog, then, when weight is placed upon it by the standing horse, recedes from pressure and leaves the heels (wall and bars) to sustain the primary weight. Wall, sole and frog, each take their share in supporting weight, but this function is distributed over them iu different degrees, and it is fulfilled by each in a varying manner. During progression, the foot is repeatedly raised from and replaced on the ground. It has not only to support weight, but to sustain the effects of contact with the ground at each step, and the effects of being the point of resistance when the body is carried forward and the foot is again raised from the ground.

What part of the foot comes first to the ground? Many different answers have been given to this question. It has been said by some that the toe first touches the ground; by others, that the foot is laid flat down; and by a few, that the heel is the first part to come in contact with the ground. Fortunately, it is not now necessary to argue this question on a purely theoretical basis. Instantaneous photography has shown that on level ground, at all paces, the horse touches the ground first with the heel. This fact gives significance to the structural differences we find between the front and back portions of the foot. At the back part of the foot, we have the wall thinner than elsewhere, we have the moveable and elastic frog, the lateral cartilages, and the frog-pad. We have, in fact, a whole series of soft and elastic structures so arranged as to provide a mechanism best adapted to meet shock and to avoid injury by jar. Whilst drawing heavy loads, or ascending or descending hills, the horse may vary his action to suit the circumstances, and then we have the exception, which proves the rule-then we have somctines the heel, sometimes the toe brought first to the ground.

At the time when the foot first touches the ground, the $\operatorname{leg}$ is extended forward and the pastem is in the same oblique position to the shank as when a horse is 
standing. This obliquity of the pastern is another safeguard against concussion, and it renders impossible the first contact with the ground at any point other than at the heel. As the leg becomes straightened, the weight of the body is imposed upon the foot, but the greatest strain arrives just before the toe leaves the ground, for then there is not only weight to sustain, but the friction to be borne which results from the toe being the fulcrum upon which falls the whole effect of the muscular effort necessary to raise and carry forward the body of the animal. The front part of the foot is structurally well adapted for its use. It presents the thickest and strongest part of the horny covering; and, as an inside basis, it has the unyielding coffin bone. Thus we have at the toe strength and rigidity; at the heels, strength and elasticity.

Another important point in the action of the foot is implied by the question-does it expand when weight is thrown upon it? The principles of horse-shoeing require that this question should be answered. There are those who say that the foot does not alternately expand and retract as weight is placed upon or removed from it. There are others who assert that the expansion of the foot is an important natural function that must be provided for in any system of shoeing. It is agreed by most observers that at the upper border of the hoof, more particularly at the heels, expansion does occur. It is when we come to the lower border of the foot that the statements are most conflicting. Ordinary measurements taken at this part with calipers, or by tracings on paper, of the foot when raised from the ground and when resting upon it, show no variations in the width of the foot. These methods of measurement are not sufficiently delicate to be trustworthy. Experimentalists, Lungwitz in Germany and F. Smith in this country, have used an apparatus by which the slightest variations are detected by electrical contact, and the results are very interesting. These experiments show that in a well- 
formed, healthy foot the hool, throughout its posterior two-thirds, does expand to pressure, and perhaps that the areh of the sole is slightly flattened. This expansion is, however, comparatively slight-about equal to the thiekness of a sheet of writing paper-and may practically be disregarded in eonsidering the best methods of shoeing sound feet.

One result of these experiments is to show what an important part the frog plays in the foot, and also how the aetion of one part depends upon the eonditions of others. When the frog rests firmly on the ground and weight is plaeed upon the foot, expansion occurs, especially at the upper or coronary border of the hoof. When the frog does not toueh the ground and weight is imposed upon the foot, eontration oeeurs. The explanation of this difference seems to be as follows. When weight is placed upon a foot, the coronet bone is depressed upon the soft mass of the frog-pad. With a sound frog taking a bearing upon the ground, the frogpad cannot deseend, and the eompression to which it is therefore subinitted causes it to bulge laterally and so expand the back of the foot. When the frog does not reach the ground, and weight is plaeed upon the frogpad, there is nothing to prevent it yielding downwards, and in so doing, the fibrous band eomneeting together the two lateral eartilages of the foot is depressed and the eartilages drawn together; hence the contraetion of the foot. No better illustration could be given of the unity of all parts of the foot, and how one or many parts may suffer if the structure or funetion of one be defeetive.

There is one more movement of the hoof whieh is possible and which must be referred to, as it has been made the basis of a grave error in shoeing. I have said the baek part of the foot is elastie and yielding. If you examine a shoe, so applied to a loot that an ineh or more of its extrenity has no contact with the hoof, you will find that, when weight is rested on that foot, the horn yields downwards and connes in contact with the shoe. 
This simply demonstrates that, when there is nothing to support it, the horn at the heels may be forced downwards. It is not a nommal action, and in an unshod foot cannot occur on a level surface. The effect of this downward movement of the heels is to put a strain on the horn of the quarters. A shoe so fitted as to permit this evil is in common use, and no fault is more serious than thus forcing an unnatural action upon the hoof at every step. With unintentional irony, this piece of bad work has been called " easing the heels."

In concluding this chapter, I would just repeat that the natural bearing surface of the horse's foot is the lower edge of the wall and that portion of the sole immediately in union with it; that the arch of the sole should not be in contarct with the ground; that the frog ought to have a bearing on the ground, but ought not to be so prominent as to unduly share in sustaining weight. This natural bearing surface, is what wo want to utilise in shoeing. We put on a shoe merely to prevent excessive wear of the hoof. If we can protect the wall, the frog can take care of itself, and we have only so to apply our shoe that we do not damage any useful structure or interfere with any natural function.

Noтk- -No person is expected to learn the structure of a foot entirely from this description. He must obtain two feet cut off at the fetlock joint. One he should soak in water till the hoof can be pulled off. The sensitive foot is then visible and the inside of the hoof ; with these before him, the drawings and descriptions in this chapter will be of great assistance. The second foot he should have sawn vertically down the middle through the point of the toe, and again across the quarters, so as to show the inside of the font from two different points of view ; this will afford a view of the relation of parts. 


\section{Chap'Teli III.}

\section{Prepalation of the Foot.}

The cheap wisdom of the muateur is often expressed in the remark " the shoe should be fitted to the foot, not the foot to the shoe." Like many other dogmatic statements, this is only the unqualified assertion of half a truth. Foot and shoe have to be fitted to each other. There wre very few horses whose feet do not require considerable altcration before a shoe can be properly fitted to them. As a rule, when a horse arrives at the forgc, the feet are overgrown and quite out of proportion. In a few cases - as when a shoe has been lost on a journeythe foot is worn or broken and irregularly deficient in horn. In either instance, the farrier has to make alterations in the hoof to obtain the best bearing surface before he fits a new shoe. The clain often made for some novel inventions in horse shoes, "that they may be fitted and applied in the stablc by a groom or stableman," is evidence of a sad misunderstanding of the art of horseshoeing. If shod feet always remained of the same shape, replacement of shoes would be a very easy matter, but they nevcr do. The living foot is constantly changing, and therefore the man entrusted with fitting shoes to it must know what its proper form should be. When he finds it disproportionately overgrown, he must know how much horn to remove-where to take away and where to leave alone. He must not carry in his head a theoretical standard of a perfect foot, and attempt to reduce all feet to that shape. He must make allowance for varietics of feet, and for many little diffcrences of form that present themselves in practice. He has, in fact, to prepare the foot for in shoc, and it is just as 
important to do this properly as it is to prepare a shoe for the foot. To fit a shoe to a foot which has not been properly prepared may be even more injurious to the horse than " to fit the foot to the shoe."

The general principle to be followed is-to remove superfluons horn, to obtain is good bearing surface for a shoe, to bring all parts of the loof equally to proportion. A good foot so prepared, when the horse is standing on level ground, should show, when looked at from the front, both sides of the wall of equal height; the transverse line of the coronet should be parallel with the line of the lower border of the hoof, and the perpendicular line of the leg shonld cut those lines at right angles. (Fig. 22.) When looked at from the side, the height of the heels and the toe should be proportionate. When looked at from behind, the frog should be seen touching the ground. On lifting the foot, a level bearing surface wider than the wall should be presented, extending from heel to toe all round the circumference of the hoof; within this level border, the sole should be concave, strong and rough.

In Fig. 2.2 is shown the foot on its ground surface and from the side. The parallel lines are quite arbitrary, but assist in explaining how the proportion of the foot is to be attained. Both sides of the foot are of the same height. The bearing surface just meets the middle line. All the lines at coronet, heel and toe are at right angles to the perpendicular line. The side view shows the proportionate height of heel and toe and the slope of the wall in front. Compared with Figs. 27 and 28, deviations from proportion are seen.

These conditions are not attainable with all feet, but the prudent farrier does the best he can under the eircumnstances. It is easy to make the frog touch the ground by over-lowering the heels, but this is only introducing one evil in attempting to avoid another. Some feet have naturally a long toe with an excessive slope of the front part of the wall. To hide this defect, a fiurrier 
maly "stump up" the toe and leave the heels too high, but he does so at the expense of the horse's foot. Each

A
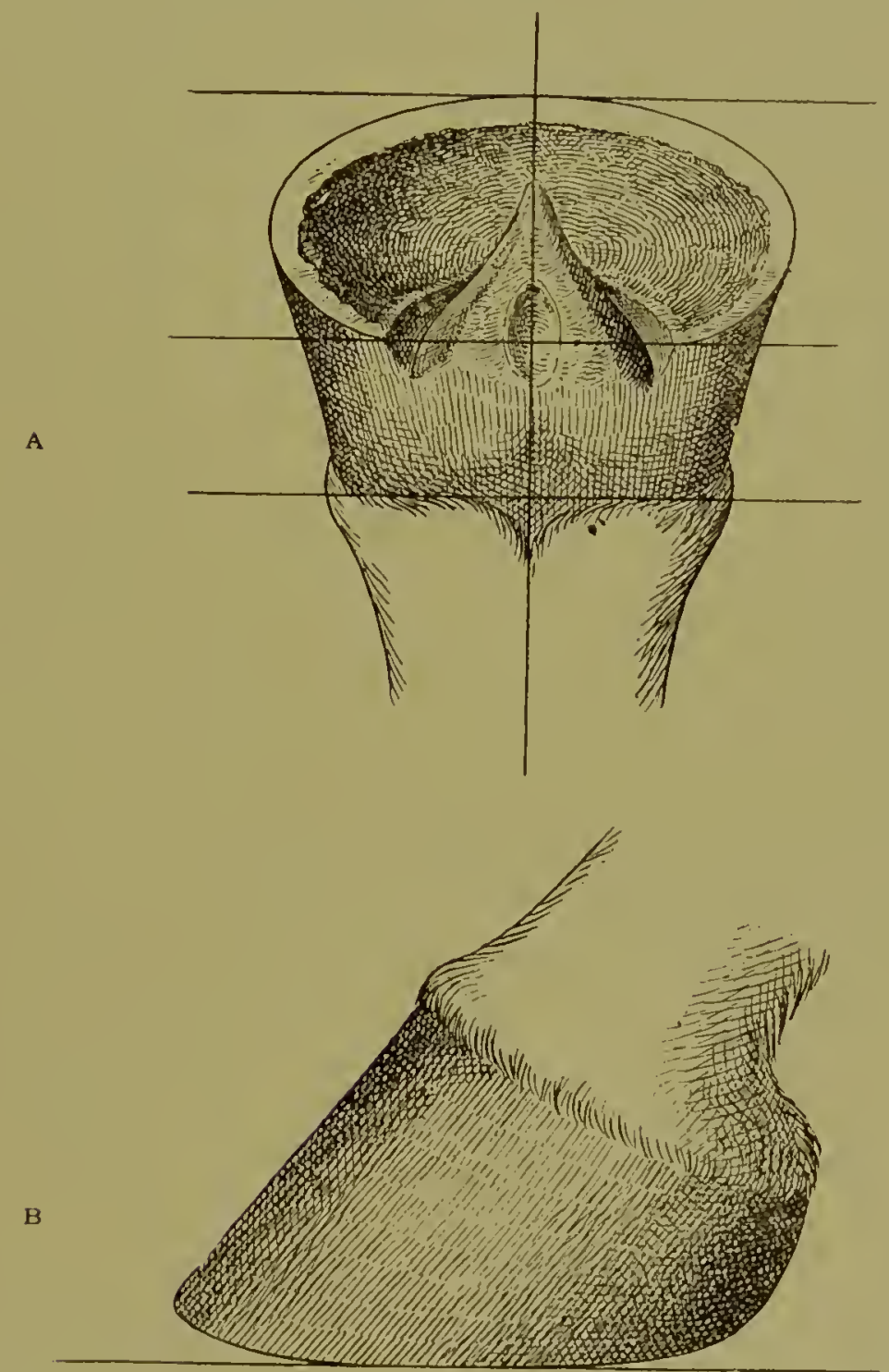

Fig. 22.-Showing proportionate foot; ground surface and side view.

foot requires treating with full knowledge of the form best adapted to its natural formation, and most capable of carrying a shoe. 
The Instruments used to prepare a foot for shoeing are a rasp, a drawing knife and a toeing knife.

The rasp is the most indispensible. It should be sixteen inches long, proportionately broad, and one part of it should be a file-surlace. 'T'he shorter, narrow rasps do not afford all the advantages a larier should possess to enable him to do the best work. To strike an even, all-round level bearing surface on a hool, al farrier requires a large rasp, just as a joiner must have a large plane to prorluce a level-surface on wood. Harm may be done hy the careless use of a rasp, and a bearingsurfice sproiled by the over-reduction of horn at one place. This fault may be acreravated by attenpts to mend it, if such attempt talic the form of lurther reduction of the whole hool on a loot where horn is deficient.

The drawing linile is a comparatively modern instrument, which replaced a tool called the buttress. A drawing knife is formed with great skill for the purpose of paring out the concave sole of the hoof, and has done infinite ham. In the days which have now almost passed away, when it was thought the proper thing to make the hoof look clean, smooth and pretty, the drawing knife was the chief instrument in the preparation of the foot. Now, when nearly all men know that the stronger the sole and frog of the foot cin be preserved, the better for the horse, this linife is less used-and the less the better. The doorman, preparing a foot for the fireman to fit a shoe to, should not use a linife at all. The man who fits the shoe requires a knife to remove occasional little prominences of horn which are liable to cause uneven pressures or which are in the way of a properly fitted shoe-ius, for instance, the edge of the wall to make way for a clip, or the angle of sole at the heel to prevent uneven pressure by the shoe.

The toeing knife usually consists of about a foot of an old sword-blade. T'his knife is held and gruided by one hand of the farrier, whilst with the other it is driven through overgrown horn by the hammer. Skilfully 
nsed, it is unobjectionable, and for the large, strong hoof of heary dranght horses, it saves a great deal of time and labour. For the lighter class of horses it is mnnecessary, and for wak fect with a thin horn corering it is dingerous.

The toeing knile camnot leave a finished level bearing smrface, and its work has to he completed by a fer strokes of the rasp. A farrier should, therefore, never attempt to remove all the superfluous horn with the knife; he shonld leave some for the rasp, so that in producing the final level surface, no encroachment upon the necessary thickness of covering horn need be made.

The Overgrown Foot, such as we find on a healthy horse that has retained a set of shoes for some reeks, or that has been without shoes on a surface not hard enomgh to canse sufficient wear, is quite unfitted to receive a shoe. It must be reduced to proportions. In Fig. 2:3,

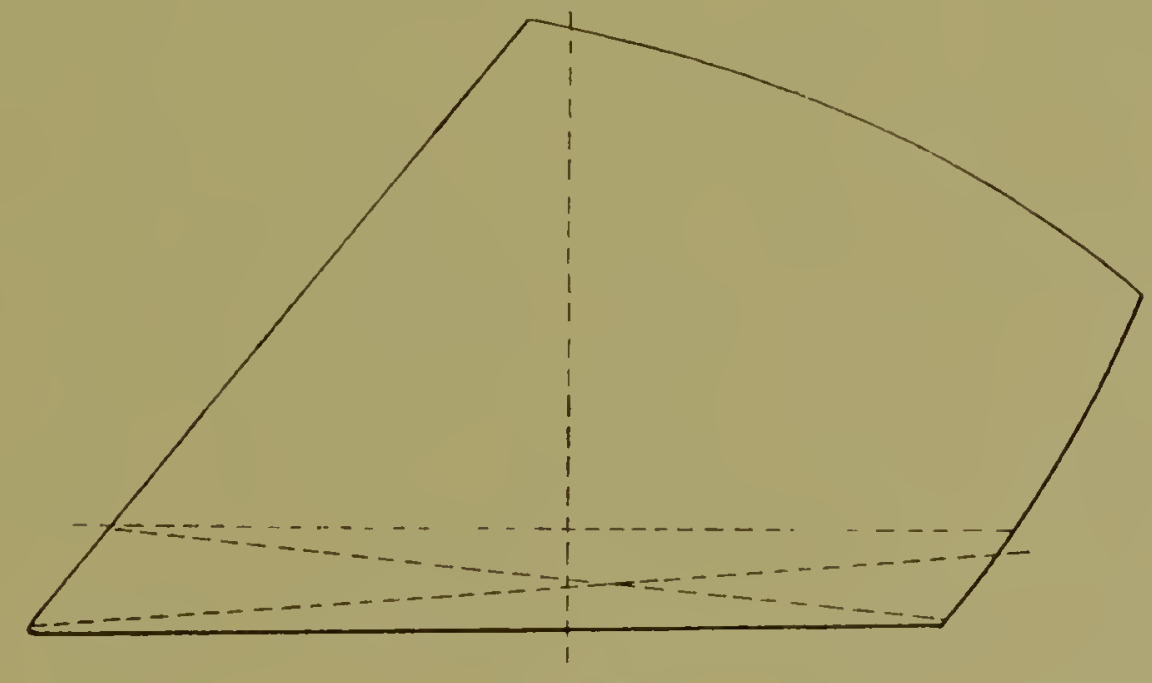

Fig. 23.

I have attempted to show diagrammatically a side view of an overgrown hoof. The dotted lines at tho base. show two effects of lowering one pat mote than mother, although both attain a level surface. In Fig. 26, wo see the rosult of ovel:-lowering the heels, and in Fig. :5, of 
leaving them too high. It may also be noticed that these conditions affect other parts of the foot; in fact, not only other parts, but the whole font, and even the relative position of the foot to the leg. If we compare the proportionate foot, Fig. 24, with the diagram Fig. 26, it will be seen that by over-lowering the heels, the slope of the front of the foot is increased, that the bearing surface from heel to toe is slightly increased in length, and that if the dotted perpendicular line be accepted as showing the direction through which the weight of the body passes, lowering the heels tends to put an increased proportion of weight on the back parts of the foot. If we compare Fig. 24 with Fig. 25, we see the effect of leaving the heels too high. The bearing surface from heel to toe is shortened, the slope of the wall at the toe is made less, and more weight is thrown upon the front parts of the foot.

Now, these alterations in both cases affect not only the form of the foot, but its relative position to the leg, and as the bones of the limb above are a series of levers connected by muscles and ligaments so placed as to be most efficient for movement, it is evident that alterations of the foot must affect the action of the limb. (Compare Figs. 24, 2.5 and 26.) In the unshod horse roaming about, there is a natural automatic return to proper relative position whenever it has been temporarily upset. A long toe is worn down and high heels are reduced to their proper level by friction. Not so a foot protected by an iron shoe. Wear is stopped, and a disproportionate hoof becomes more and more disproportionate. Temporary alterations of the position of the font do little harm, because they are permitted, within a margin, by the movement of joints and by the elasticity of muscles. When, however, an alteration of position is continued for many weeks, it tends to become permanently fixed, and may thus do a great deal of harm, which is not traced to its real canse, because the effect is slow and gradual. It is important, therefore, to remember that 


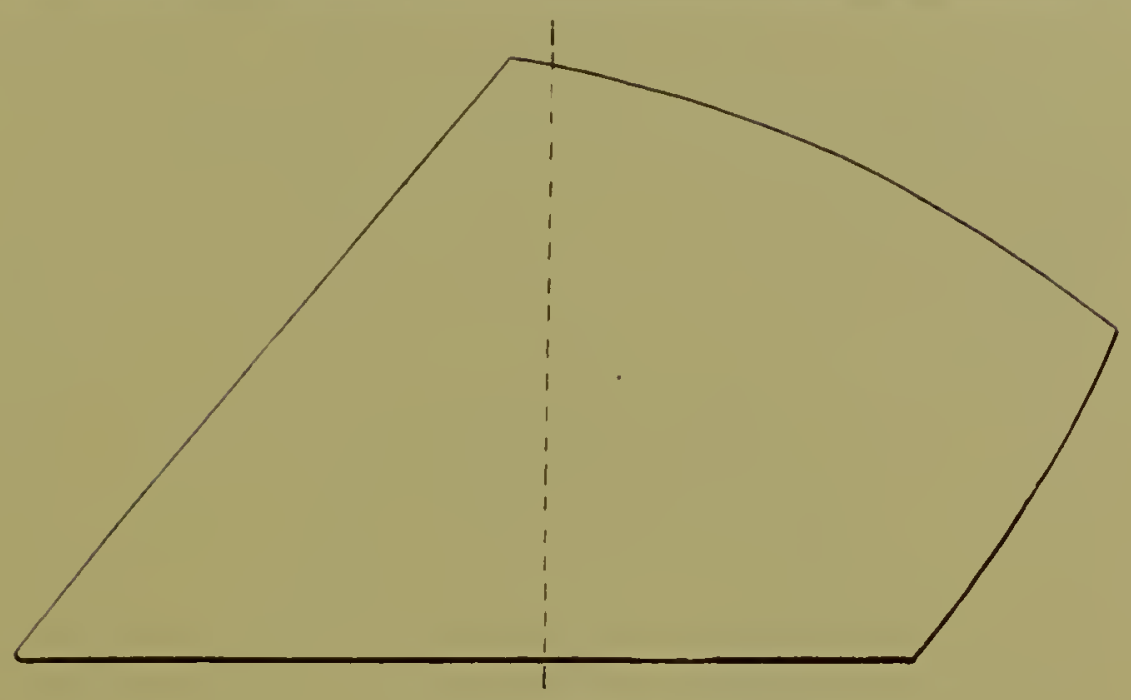

Fig. 24.-A proportionate Hoof.

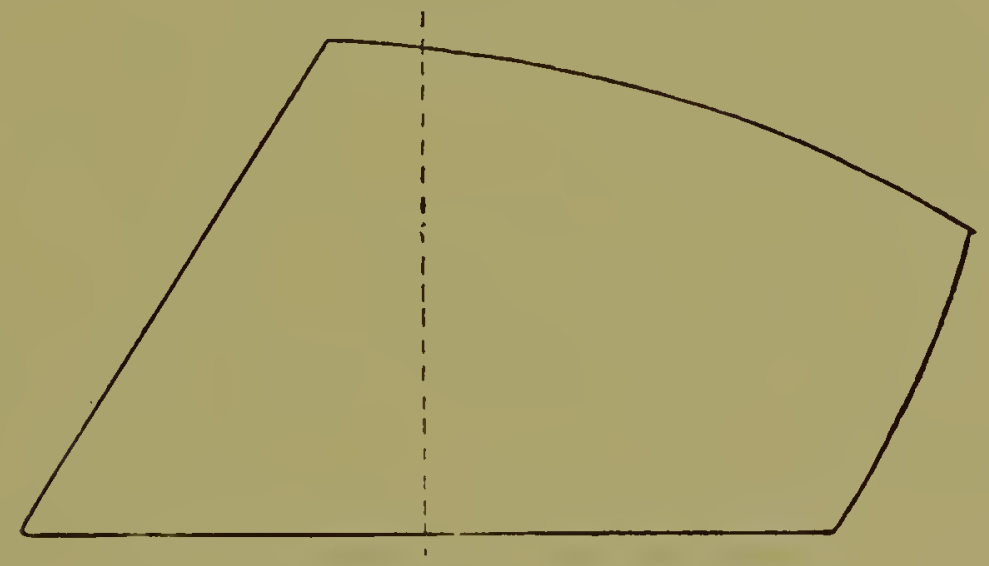

Fig. 25.-A disproportionate Hool-heels too high.

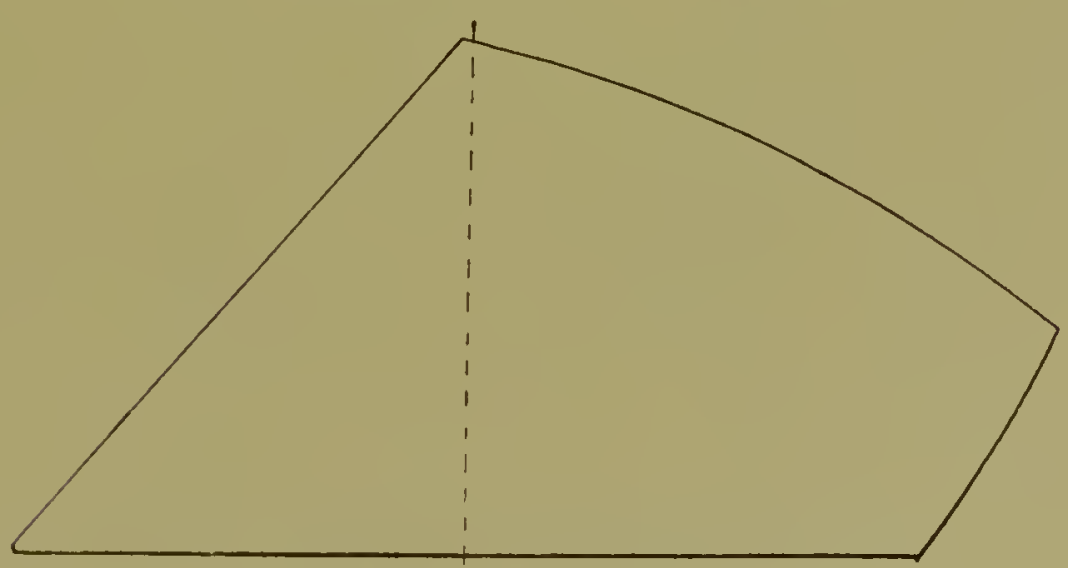

Fig. 26.-A disproportionate $\mathrm{H}$ oof-heels too low. 
the proportion of the hoof is to be maintained, not only becanse it is necessary to the well-being of the foot, but becanse it affects the action of the whole limb. 'Too long a toe may canse a horse to stumble, and it must always increase the strain on the back tendons during progression. Heels too high prevent the frog from taking its proper bearing on the ground, and thus cause a loss of function in the back parts of the foot. An excessively high heel has a tendency to throw the knee forward and to straighten the pastern.

It is impossible to lay down any hard and fast rule 'to guide a farrier in maintaining the proportions of heel and toe, when reducing an over-grown hoof to proper form. Feet differ much in their natural formation; some are high-heeled and some low, some are straight in front, some very much sloped, some are narrow and upright, others round and spreading. In Fig. 27, the heels are too high, and the bearing surface does not reach the transverse line at the heels. The side view shows the excessive height of heels, and the slope of the wall in front too upright. Great assistance is afforded the farrier in judging whether he should remore more horn from heel or toe by the appearance of the under surface of the foot. When the heels are much above the level of the frog there is an indication for their lowering. When the nall and bars are about flush with the angle of sole between them, there is, as a rule, no more horn to spare at that part. The length of the toe may be usefully gauged by the condition of the junction between wall and sole. When the sole is sound and strong, all the wall above its level-wall unsupported by sole and showing on its immer aspect marks of the horny laminæ-may be rasped down so that a firm bearing surface is obtained, consisting of wall and sole.

In Fig. 28, the bearing surface at the heels is below the line marking a proportionate foot. The toe is too long and projects beyond the transverse toe line. The side view shows the low heel and the corresponding 
excess in the slope of the wall in front. The lower transverse line in each figure does not represent the ground, but is added to make clearer the height of heels and length of toe.

A
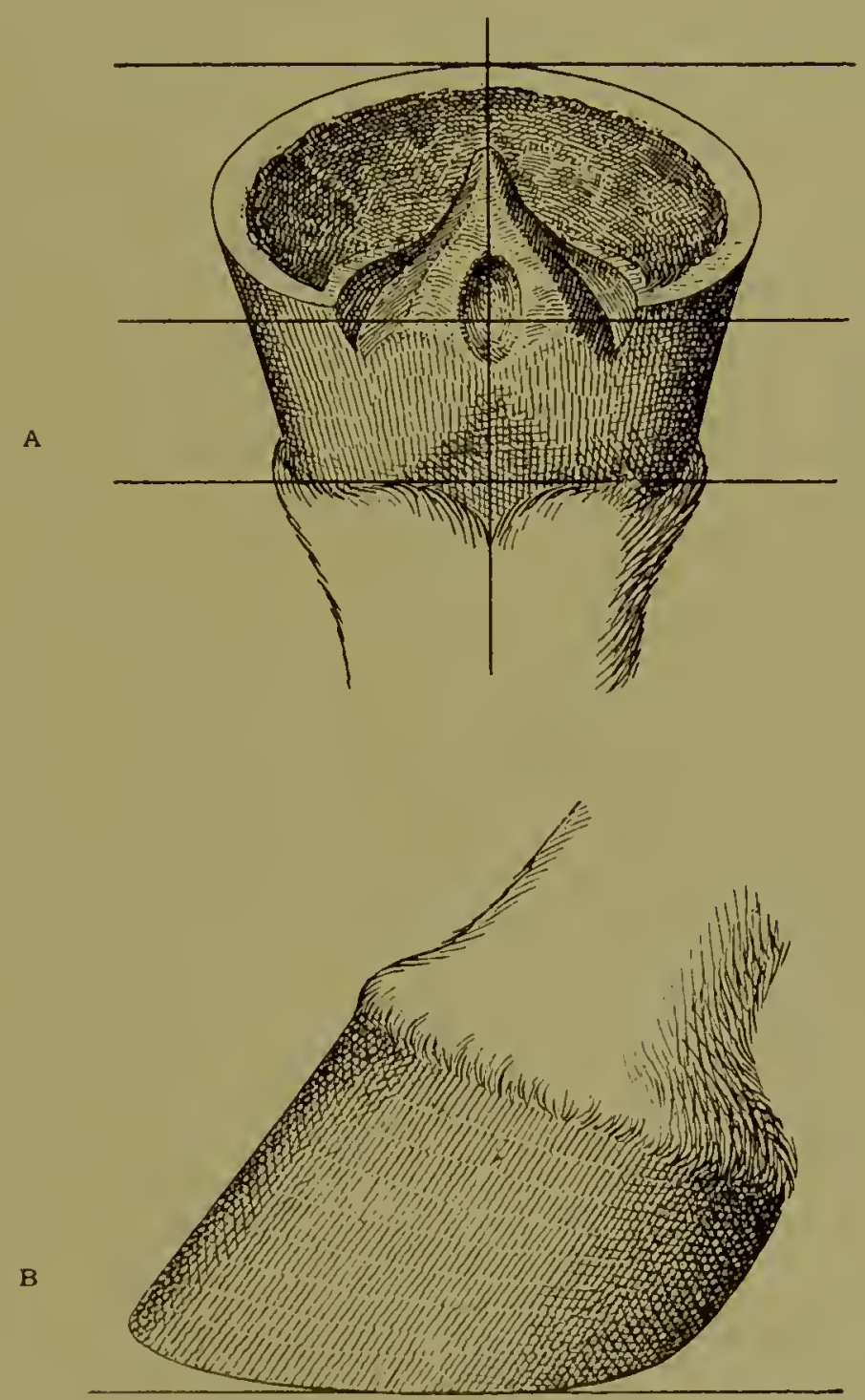

Fig. 27-Heels high-under surface and side view.

Important as it is to maintain the relative proportions between the lront and back parts of the foot, it is perhaps even more important to preserve the balance 
between the two sides of a foot. Both sides must be left of equal height. If one side be higher than the other, a disproportionate amount of weight is thrown on the lower side, and more or less strain is put upon the liga-

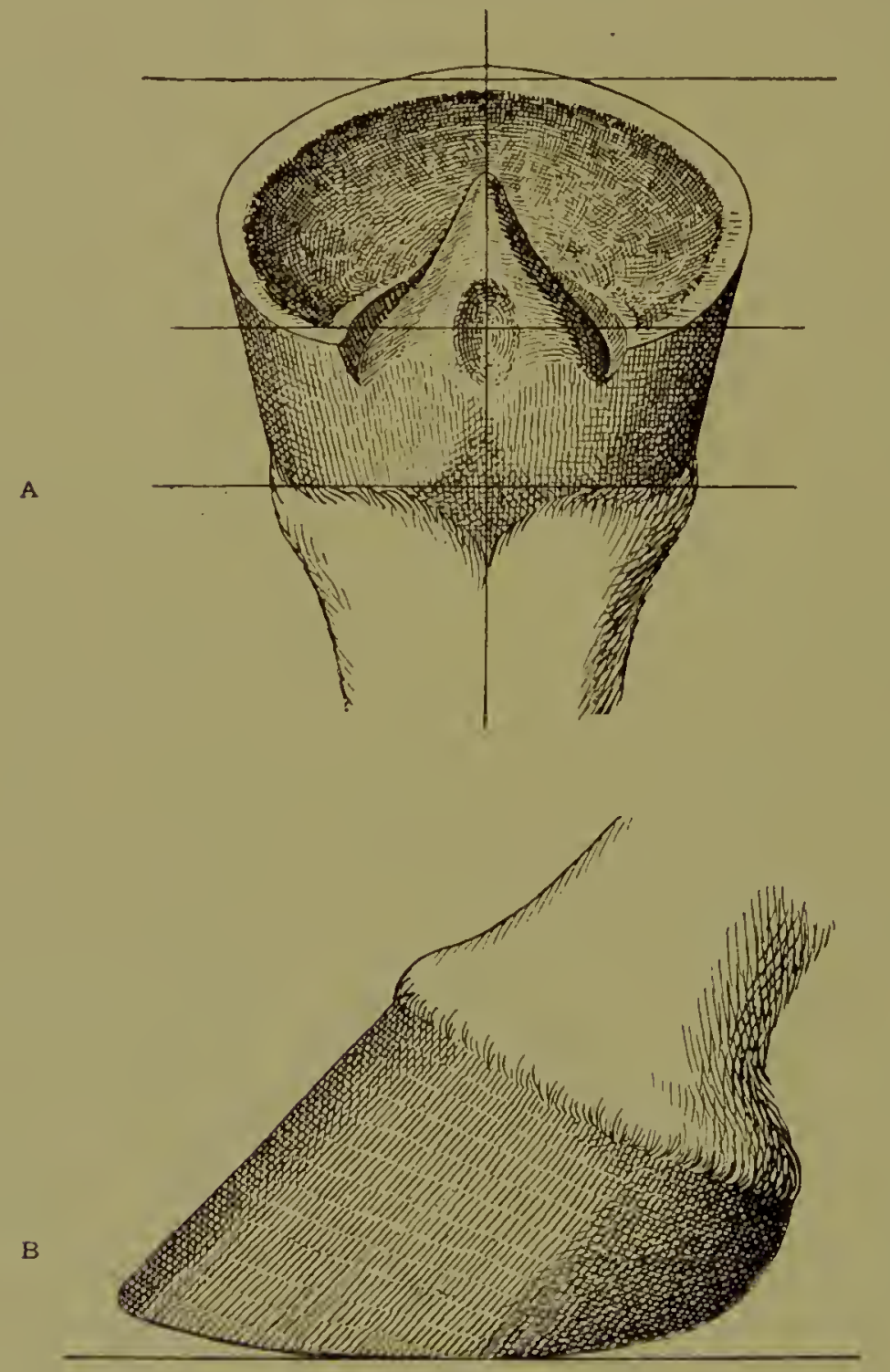

Fig. 28. - Heels low toe long.

ments of the joints above. In the Figs. 29, one limb is shown with both sides of the hoof even, and the straight line of the limb cuts squarely across the transverse line 
of the bearing surfaee of the foot. In the other limb, one side of the hoof is too high, and, in the preparation lor shneing, only that side will require attention.

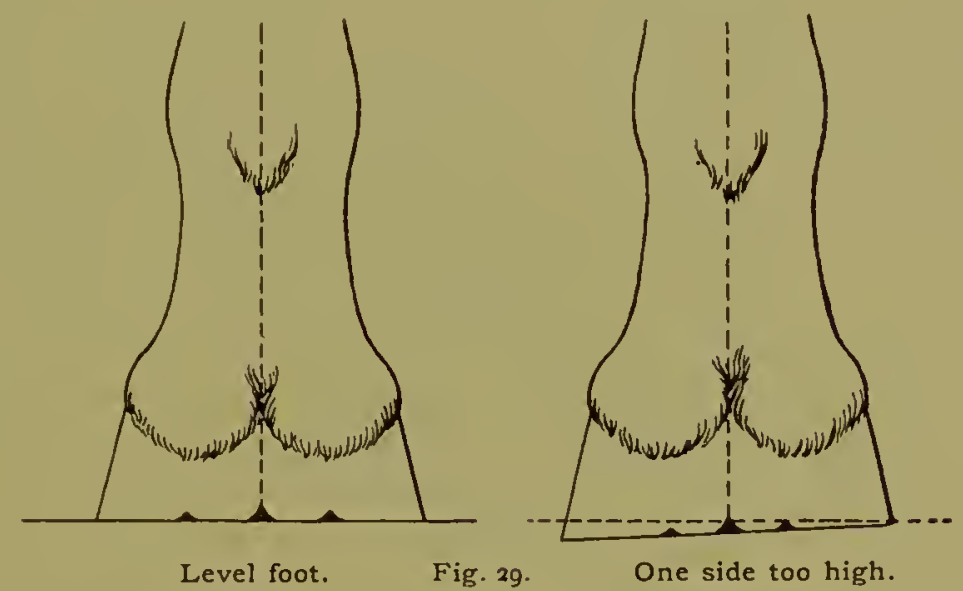

Through eonstant negleet of this point, some feet beeome more or less permanently twisted-and the twist necur's at the coronet. The ground surfaee of a foot or a shoe always tends to remain at right angles to the direction of the limb, and when the sides of a hoof are allowed to remain of unequal height, the higher side presses the soft tissues of the coronet upwards. As the hoof grows from the eoronet, the side thus inereased in height is not so notieeably uneven at the lower border of the wall as at its upper, and it cannot be restored to its proper form, exeept by months of careful attention and slight over-lowering at eaeh shoeing. The diagrams (Figs. 30 and 31) represent vertical sections through a foot from side to side. One shows the wall uneven at the base, the other shows it uneven at the coronet.

Pecularities in the formation of a limb sometimes cause an apparent error in the relative position of the foot. 'Thus we have horses that turn their toes in, and those that turn their toes out. The eause of this twist takes place at the upper part of the limb, and it will be found that when the toes turn out, the elbow turns in, and vice versa. The larrier can do no good to this forma- 
tion, and attompts to alter it or disguise it by derices in shoeing are only injurious to the foot,-little deceptions worthy of a horse-coper.

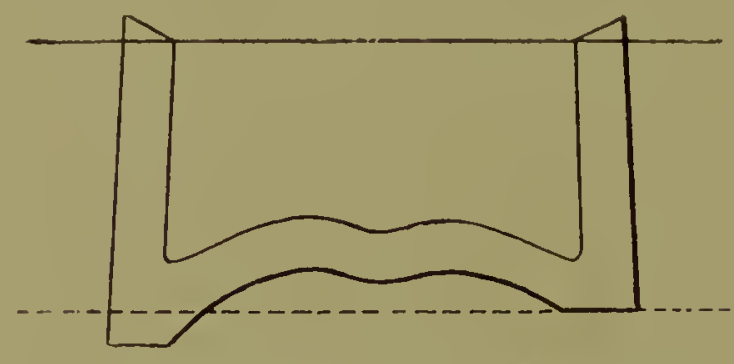

Fig. 3o.-Uneven at Ground Surface.

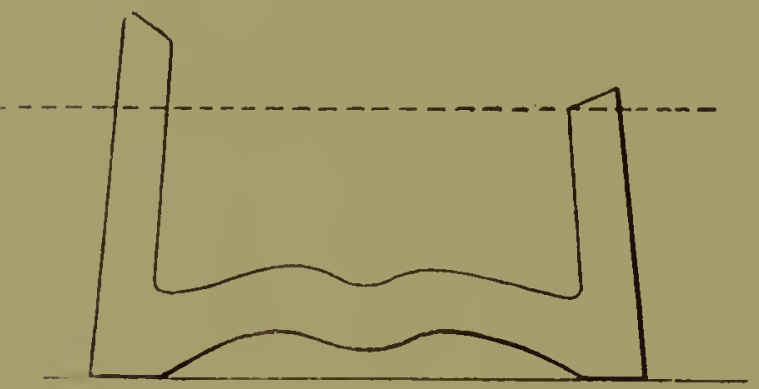

Fig. 3r.-Uneven at Coronet.

A Good Bearing Surface is the primary object aimed at in preparing the foot for a shoe. 'The relative position of the limb to the font and the proper proportions of every part of the foot are matters to be borne in mind whilst the farrier is directly forming the bearing surface for a shne. A good bearing surface must be even, level, on sound horn, and as wide as can be obtained, to give stability to the shoe. It should not be limited to the wall. If, without orer-reduction, the use of the rasp leaves a firm portion of the sole as a level surface continuous with the lower edge of the wall, the best of bearing surfaces is obtained. (Fig. 32.) The bearing surface should be level from heel to toe. and no part of it can be singled out either as unfit to bear weight or as specially capable of enduring undue pressure. No broken or disensed horn should be used as bearing surface for a shoe. The broken horn should be removed 
and the diseased horn must, if not entirely removed, have so inuch of its border eut or rasped off as will prevent contact with a shoe.

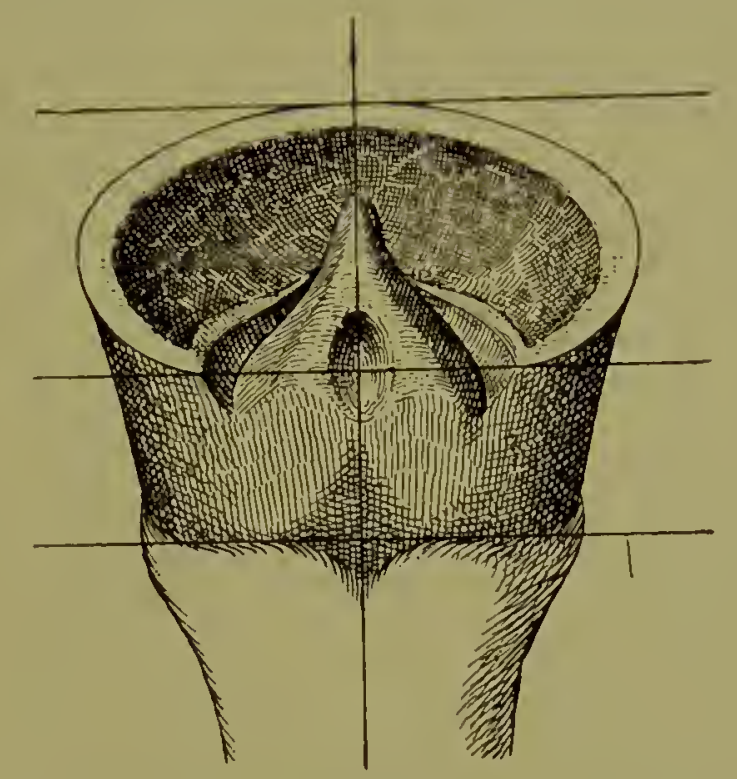

Fig. 32.- A proportionate Foot with a good bearing surface.

After forming a level bearing surfaee with the rasp, the shar'p outer border of the wall is lightly removed with the file, so as to prevent splitting of the horn. The onter surface of the wall should not be rasped, for it affords protection to the reeper layer of hor'n. The harder the outer layer of horn is kept, the tougher and firmel is the whole thiekness.

The Sole and Frog require very little attention. No sensible farrier now puts himself to the unnecessary trouble of eutting away horn that is wanted for protection. It was not the practical farrier that introduced the stupid "paring and cutting " that ruined horses' feet for nearly a century. It was the theorists, who taught expansion of the wall and descent of the sole as primary necessities in the function of a foot, who must be credited with all the evils resulting from robling the sole and frog of horn. When a horse is shor with an iron shoe, 
the wall cammot wear, and therefore it has to be artificially reduced at each shoeing. But the shoe does not interfere with the wear of a frog, and the farrier may safely leave that organ entirely to take care of itself. To some extent, the shoe does interfere with the natural wear of the sole, and, therefore, any flakes of horn which have been prevented by the shoe from detaching themselves from the sole may be removed. The best way to remove these is with the buffer. The sole should not be pared out. I mean not only that the horn should be left strong, it should not be pared with a drawing linife, even if only a harmless surface layer be removed. The effect of leaving the sole of a shod foot with a smooth, level, pared surface is to stop its natural method of throwing off more or less broken flakes, and to cause it to retain that which is half loose until it is removed in one great cake.

A portion of the sole that requires a little special care in preparing for shoeing is the angle between the wall and the bars - the well-known seat of "corn." This must not be left so as to come in contact with the shoe. It is not to be "scooped" out, but it should be reduced distinctly below the level of the wall, so that when the shoe has been in position for a week or two, there is still no contact between the horn of the sole and the iron at that point.

Level or Adjusted Surface? The bearing surface of a hoof inust, of course, be exactly adapted to the surface of shoe intended to be applied. Presuming that the best surface for a shoe is one level from toe to heel, I have insisted upon the necessity of a level bearing surface on the foot. There, are, however, exceptional cases in which a level shoe is not used, and then we must alter the foot accordingly. Horses that wear the toe of a shoe out of all proportion to the rest of the iron may be beneficially shod with a shoe turned up at the toe. To fit such a shoe the hoof surface must not be made level; it 
must be rasped away at the toe and rounded off to follow the line of the shoe. In the three diagrams (Fig. 33) is shown- $(a)$ side view of a foot prepared to suit the turned-up shoe at the toe, (b) a level line to fit a level shoe, and $(c)$ a form olten indopted on the Continent, to

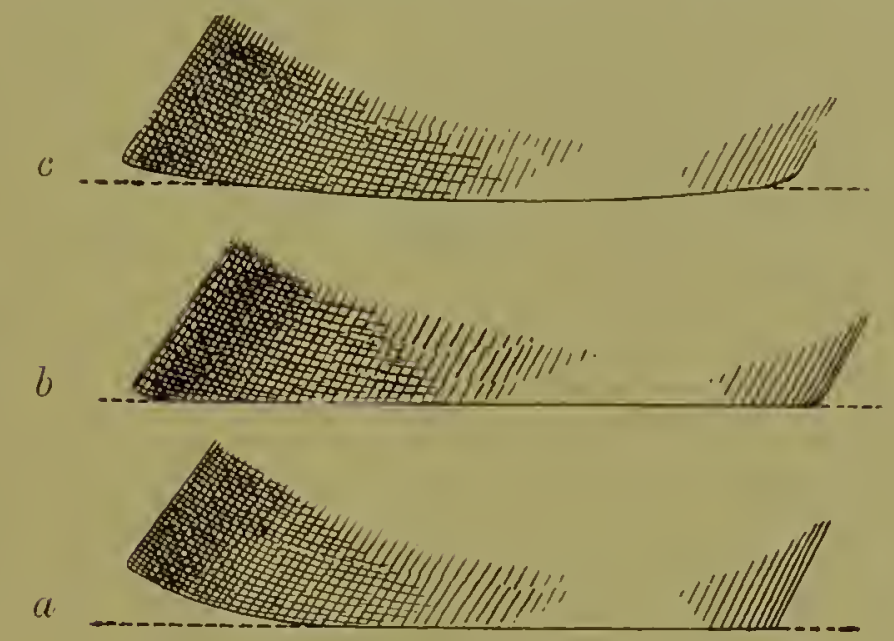

Fig. 33.-Three forms of Bearing Surface.

suit a shoe fitted with a slight curve throughout. This adjusted shoe is designed to imitate the shape of the worn -surfaee of an old shoe or to some extent the worn surfaee of an unshod foot. Every farrier knows how many horses go better after a level shoe has been worn a few days than when first applied, and it is argued, with reason, that the greater ease is due to the shoe being worn to the form offering least resistanee to the movement of the foot in locomotion. I have nothing to say against this form of shoe and the neeessary form of foot surfaee for it, exeept that it is more diffieult to make than the ordinary level one. When adopted, the curve of the foot should be obtained not so much by overlowering the toe and heels, as by leaving the quarters higher.

\section{Faults to be AvoIned.}

Fig. 34 shows a hoof in whieh shortening of the toe has been effeeted not by reducing the ground surfaee of the wall, but by laspling away the wall in front of the 
toe. This should not be done with any good foot, but it may be adopterl with feet having an unnaturally long toe and no superfluous horn on the under surface. A "stumped-up " toe is very ugly, and it weakens the hoof in front.

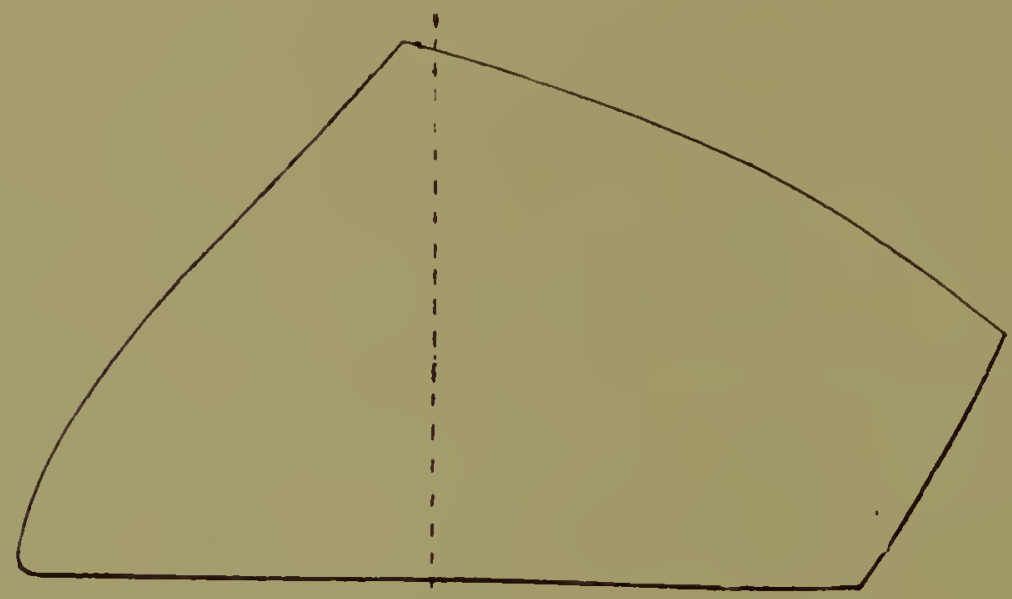

Fig. 34.-A "stumped-up " toe.

Uneven Bearing Surfaces are easily produced by a careless use of the rasp. One side of the wall may be made lower than the other, one heel may be reduced more than the rest of the foot, or one side of the toe may be unevenly reduced. In Fig. 30, the foot presents an uneven surface which not uncommonly results from careless work. The parts over-reduced are those most easily reached with a rasp. The near foot suffers at the outside heel and inside toe. A left handed farrier rould injure the feet in just the opposite positions.

Another fault results from holding the rasp untruly. If we suppose the inside heel of the near foot to be under preparation, and the farrier inclines his rasp too much inwards, he leaves the wall at the heel lower than the sole within it. On such a foot, a level shoe rests upon the sole instead of upon the wall, and a bruised heel soon follows. 


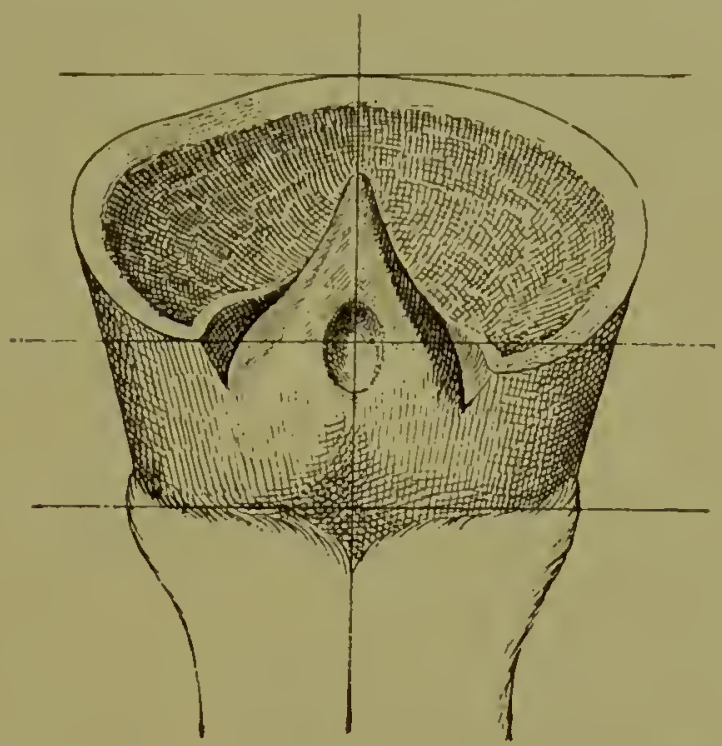

Fig. 35-Uneven Surface, over-lowered at Heel and Toe.

Paring away the Sole to produce a deep, concave appearance has another evil effect in addition to that before pointed out. It removes the horn just within

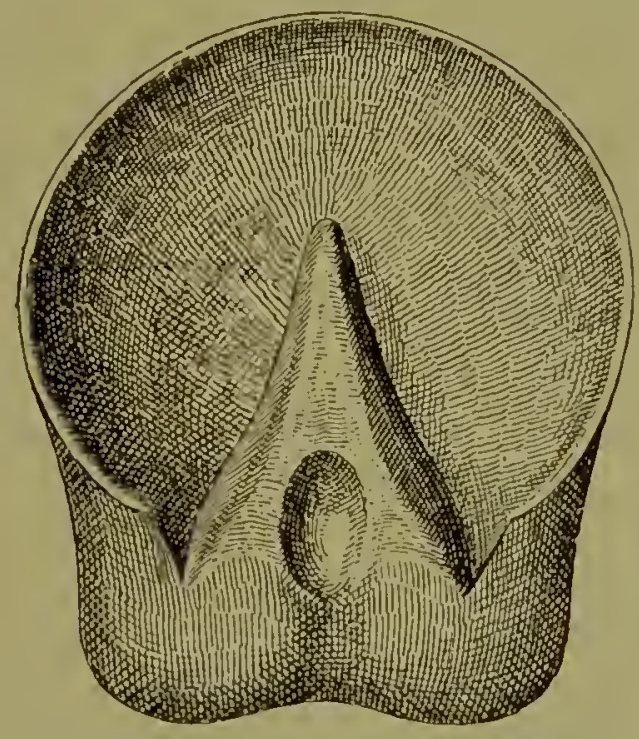

Fig. 36.-A Pared-out foot; bars destroyed and bearing surface for shoe reduced to a narrow ridge.

the border of the wall, taking away the natural support, and leaving as bearing surface for a shoe a narrow ridge instead of a strong flat surface. Fig. 36 shows this fault, 
and it must be remembered that the ridge may be left as thin as a knife edge. Such a ridge cannot sustain the weight of the horse, and when it yields, the shoe also yields, the clenches are raised and the shoe becomes loose.

Excessive Rasping of Wall.-The best farriersthose most proud of their work-have a great temptation to use a rasp too freely to the outer surface of the wall. The hoof gets rough or, it may be, ridged, its appearance is improved by being made smooth, and it is only human to turn out work which is clean and neat. Owners and grooms are rather inclined to forget the claims of the horse when judging shoeing, and the result is that some harm is done by excessive rasping. A strong foot does not suffer much, but its strength is preserved by leaving the hard outer surface intact. Rasping off an outer layer of horn favours evaporation and hardening of the underneath layer, and the toughness so desirable is to some degree replaced by hardness and brittleness. Excessive rasping below the clenches is even more injurious than rasping above them. The wall, between its bearing surface and the clenches, has to withstand the contact of the shoe and the perforation by nails. It should be the toughest and strongest part, and, therefore, should not be rasped more than is necessary to lay down the clenches and finish the fitting. Unfortunately, the neatest work is done by fitting a shoe "close" and then rasping off any protruding horn. This is bad for the foot, as it weakens the wall and spoils the bearing surface at each shoeing. The worst offender's in this direction are dealers, who sacrifice everything to appearances and insist upon shoeing being neat at all hazards.

Opening the Heels is one of the gravest faults a farrier can be guilty of. It consists in cutting away the extremity of the wall at the heel and generally a slice off the side of the frog at the same time. The effect is to produce an appearance of width at the back of the footto make what is called " $a$ fine open foot." Fig. 36 
show's a loot which has been injured in this way. The wedge shaped opcning which results has many objectlions. It hrealis the continuity of structures at the heels, it removes horn unnecessarily, it weakens the foot, and, when the wall is interfered with, it shortens the bearing surlace for a shoe. The bearing surface at the back of the foot is perhaps the most important of any afforded by the wall. 'The longer the bcaring surface is at the heels, the more the base for sustaining wcight is brought under the leg, and the bettcr the position for supporting the body. All removal of hom that shortens this surface is injurious.

Over-Reduction of Hoof is always a fault. It is true, a carefully fitted shoc on a foot so treated may do no harm for a time. Too much horn should be left rather than too little. A strong covering of horn is a protection against many mistakes in the fitting or form of a shoe applier to a foot. So long as a hoof is everywhere strong enough to sustain pressure and afford bearing, weight is evenly distributed throughout the whole foot. When the horn is thin, it yields to an uneven pressure, and damage is done to the foot, even if immediate lameness is not induced. 


\section{Chapter IV.}

\section{Foals and Unshod Feet.}

Injury to horses may result from want of attention to their unshod feet. At first sight, this statement would appear to suggest that the hoof, in its natural condition, was unable to take care of itself. This is not so. When horses without sloes are really in a state of nature they have extensive pasture grounds and unlimited freedom of motion. Growth and wear of hoof are balanced, and so the foot is preserved in a proportionate shape. Over-wear of horn causes the horse to rest his tender foot, and growtl soon brings about a balance. Over-growth cannot take place so long as constant wear accompanies the free movement of the animal.

The injury referred to is due to excessive growth of horn, which takes place on the feet of loorses that are confined in stables or small paddocks where natural use is insufficient to preserve the balance between growth and wear. Excessive growth of horn causes disproportion in the form of a foot, and ill-formed feet soon react injuriously upon the limb. All hor'ses' feet, as they grow, become long at the toe, and thus the bearing surface upon which the leg should firmly rest, is carried too far forward from the vertical line of the limb. This injuriously affects the joints and tendons of the leg. Over-grown feet are always too high at the heels, and thus the frog is removed from its proper bearing on the ground, with the consequence that it wastes, loses its function and permits contraction of the hoof. Excessive growth of hoof may also leave one side of the wall higher than the other, a condition which, especially in 
young horses, may cause a more or less permanent twisting of the foot on the leg.

The reaction of the limb to distorted forms of hoof and the injury to intemal parts of the foot from disproportionate growth of hoof are more serious in young animals than in those of maturer growth. The tissues are more plastic, more easily moulded to external conditions and more likely to suffer permanently from interference with their functions, than are the tissues of animals in which development has ceased.

The ease with which the foot and leg react upon each other in young animals permits attempts being made to improve the form of defective limbs and to prevent some defects from becoming greater. If one side of the hoof be higher than the other there is a tendency for the long bones above the foot to be thrown out of the perpendicular. If the inside of the hoof be the higher, the fetlock is thrown outwards and any tendency to knock-knees would thus be opposed. If the outside of the hoof be the higher, the fetlock is thrown inwards and thus a tendency to bowleg may be counteracted. All disproportions of the foot affect the leg in greater degree up to the first joint, but the effect does not cease there. It is to a lesser degree imparted to the bones above so that even the position of the knees and hocks may to some extent be modified by the form of the foot. A colt with well formed limbs only requires that his feet should be kept proportionate. A colt with defective conformation requires the foot putting into a form which may counteract the defect. To do this is a work of time, and as the hoof is constantly growing and liable to accidental injuries, a shoe must be affixed so that the desired effect is maintained. For the good of the hoof it is kept proportionate, but the shoe is made higher on one side than the other. In this way a force, slight but constant, is directed so as to counteract the tendency of the limb to develope an irregular conformation. 'The relative proportions of the toe and heel may also be modified to produce effects upon the limb. When the front 
pasterns are excessively oblique a shoe thick at the heels tends to prevent increase of the defect. When the linees are thrown unduly forward, a shoe thick at the toe will assist in bringing then back to the desired position. When the hocks are turned excessively inwards the use of a shoe with the inner binch hishost will counteract the condition, whilst the use of a shoe with the outer luanch highest will have a tendency to throw the joints closer.

When shoes are fixed upon the feet of animals at grass it is too often forgotten that growth of horn goes on whilst wear has ceased, and that a disproportionate foot must be produced in a few meelis. No shoes should remain on feet mole than five weeks without removal. T'hen the hoof should be reduced witl a rasp to its proper proportions and the shoes may be re-applied.

The necessary interference with somnd feet which are simply overorown is vely slight. No cutting or paring of frog or sole is required. All that is wanter is a judicions use of the rasp to the lower border of the wall, so that heels are not allowed to lift the frog from contact with the ground, so that the toe is not of such almormal length as to strain the joints and tendons of the leg; and that both sides of the hoof are nuantained of an equal height.

Stud horses, from want of exercise and oxcessive foeding, are predisposed to disease of the feet. I anuinitis is a frequent cause of lameness and even of death in stallions, and in mares at foaling tince. It would be wrong to say that this disease is directly due to neglected, disproportionate feet, but in nearly every case these conditions accompany the disease, and, according to theil extent, aggravate it. I feel certain that mole altention to the preservation of the natural form of hoof wonld modify the violence of many cases, even if it did not prevent their origin.

In all horses which are prevented by their surromdings from wearing down the hoof naturally, especially in young, growing animals, a little periodic attention to the hoof would ensure better conformation and nuore 
healthy feet and limbs. As a rule, it is the more expensive class of horse that is bred and reared in stables or in contined pastures where overgrowth produces roischice. 'lhe greater, then, the conomy of intelligent core of the foot in such conditions. Were it possible to always trace effects to their causes, it wonld often be found that round joints, straight pasterns and bent knees directly resulted from neglect of the feet in unshod young horses. 


\section{Chapter V.}

\section{The Form and Manufacture of Shoes.}

Horse-shoes are made either by hand or machinery. In this country most are hand-made-the front shoes from new bar-iron, and the hind from old shoes welded together and drawn out under heavy hammers, Probably no method of working iron gives such good results as this in producing a hard, tough shoe that will withstand wear. The custom of the trade is to keep a stock of shoes suitable for all the regular customers. From this stock are selected sizes and forms, which are then specially fitted for each foot.

Various materials have been tried in the production of horse-shoes. Leather, compressed and hardened, has been tried, and failed. Vulcanite was experimented with unsuccessfully. Paper, or more correctly, a compressed papier michí, has also been tested, but proved unsatisfactory. Steel has been pretty largely tried in many different forms, but it is difficult to temper. As nearly all shoes are applied immediately after being fitted, they have to be rapidly cooled in water, and steel treated in this way is made so hard that, if the shoes do not break, they are dangerously slippery on most paved streets. As a material for shoes good malleable iron has no equal. It can be obtained in bars of various sizes to suit any form and weight of shoe, and the old shoes made from it may be worked up over and over again.

The chief objects to be attained in any particular pattern or form of shoe are-that it be light, easily and safely retained by a few nails, capable of wearing three weeks or a month, and that it afford good foot-hold to 
the horse. All shoes should be soundly worked and free from flarvs.

The first shoes were doubtless applied solely to protect the foot from wear. The simplest arrangement would then be either a thin plate of iron covering the ground surface of the foot, or a narrow rim fixed merely round the lower border of the wall. Experience teaches that these primitive forms can be modified with advantage, and that certain patterns are specially adapted to our artificial conditions. A good workman rcquires no directions as to how he should work, and it is doubtful if a bad one would be benefited by any written rules; but it should be noted that a well-made shoe may be bad for a horse's foot, whilst a very rough, badly-made one may, when properly fitted, be a useful article. To make and apply horse-shoes a man must be more than a clever worker in iron-he must be a farrier, and that necessitates a knowledge of the horse's foot and the form of shoe best adapted to its wants.

Weight of Shoes.-The lighter a shoe can be made the better. Weight is a disadvantage we are obliged to put up with to obtain wear, for the frequent removal of shoes is only a little less injurious to the hoof than working with none at all. It is not to be understood that the heaviest shoe gives the most wcar; on the contrary, a heavy shoe may have the iron so distributed as to increase the rapidity of wcar, and a shoe of half the weight properly formed may last longer. It is no uncommon thing to find worn-out shoes still weighing more than a new shoe which will, on the same horse, give a longer period of wear. When a horse wears his shoes out very rapidly, the indication to the farrier is not simply to increase the weight, but to see if he can obtain more wear by altering the form and distributing the iron in a different way. A tired horse wears his shoes much more rapidly than a fresh and active one. Continued slipping wcars awny a shoe ont of all proportion to the work done 
by a horse having a firm foot-hold. These two different eonditions may be partially due to the shoes, for a heavy shoe tires the leg, and broad flat shoes favomr slipping. Some horses wear one speeial part of the shoe exeessively -as a rule, either at the toe or the heel-and this is better met by turning up the worn part out of the line of wear than by thiekening it and so inereasing weight. Besides, a heavy shoe requires a greater number or a larger size of nails to retain it seeurely in position, and this is a disadvantage. It has often been asserted that a horse "goes better " in a heavy shoe than a light one, and that this is due to the heavier shoe aeting as a protection to the foot and warding off eoneussion. If the term "goes better" merely means that he lifts his foot higher and eonsequently bends his knee inore, I do not deny the assertion. The reason of this is not that the horse feels less eoneussion and therefore gnes freer. It is an exaggeration of the natural movements, due simply to the horse with weight imposed on his feet having to use the museles of his arms more to lift that weight. The same thing ean be brought about by tying bags of shot on to the hoof, which is done to cultivate "action." The healthy foot requires no artifieial aids against eoneussion, but when a font beeomes tender from bad shoeing it may sometimes be relieved by adding to the substanee and weight of a shoe.

The following are about the avernge weights, per shoe, of horses standing 16 hands high :

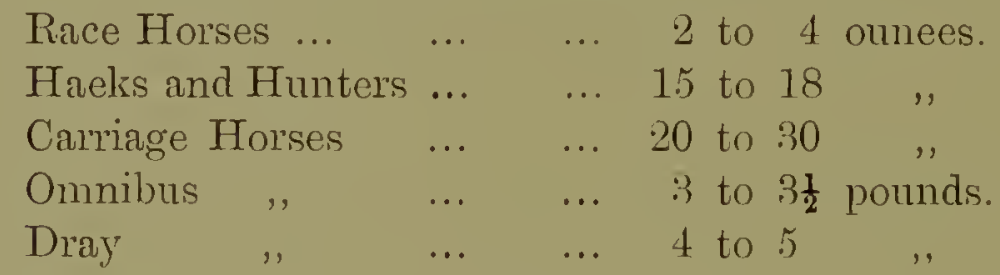

Thickness and Width of Shoes. - To obtain the neeessary amount of wear from shoes they must be inereased either in thickness or midth, and it will assist us in estimating the relative value of these conditions if 
we shortly consider thcir advantages and disadvantages. I may say at once that no sound foot requires a wide shoc merely as "cover" or protection for the solc. Defcctive soles may sometimes require protection, but sound ones never, and we may therefore put aside entirely all claims made for width of shoc under pretcnce that it gives a valnable protection to the foot. A shoe should be as wide as the natural bearing surface of the foot, so that it may occupy the wholc of the space offered by naturc as useful for bearing. Even when it is wider no harm is done until the width is such as to afford a lodgement for stones, ctc., between the concave sole and the web of the shoe.

A thick shoe raises the foot from the ground and thus remores the frog from bcaring - a very decided disadvantage. It also requires the larger sizes of nails to fill up the deep nail holes, and very often renders the direction of the nail holes a matter of some difficulty.

The widtl of a shoe may beneficially vary. It would be widest at the toe, to afford increased surface of iron wherc wear is greatcst. It should be narrowest at the lieels, so as not to infringe upon the frog, nor yet to protrute greatly beyond the level of the wall. The thicliness of a shoe should not rary, unless, perhaps, it be reduccd in the quarters. Heel and toe should bc of the same thickness, so as to preserve a level bearing. Excess of thickness at the tocs puts a strain on the back tendons, whilst excess at the hcels tends to straighten the pastern.

The Surface of Shoes.-Therc are two surfaces of the shoe which claim attention, one which is applied to the foot, and another which rests on the ground. The form of thesc surfaces may be varied greatly, but of comrse the foot-surface presents much less neccssity and less opportunity for altcrations tham the ground surface. 'The foot-surface of a shoc must be formed in accordance with the requirements of the horse's foot, and no other 
consideration should be allowed to materially modify it. The ground-surface may be altered to suit the tastes and prejudices of the orrner as well as the requirements of the horse and the peculiarity of roadways.

The Foot=Surface.--It is quite obvious that the surface of the shoe upon which the hoof has to rest should be regular and even; that it should not consist of hills and holes and grooves and ridges. I should not have mentioned such a very evident matter, but that in large towns, the cheaper and poorer classes of shoeing com-

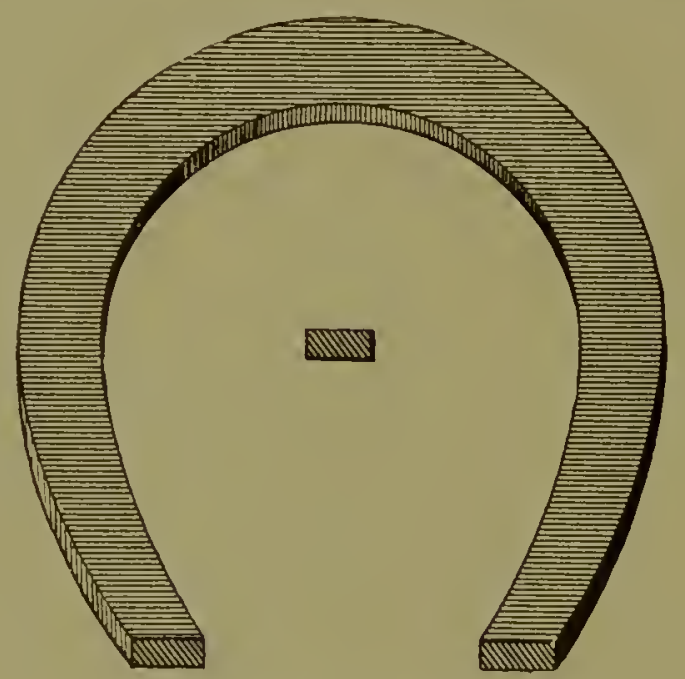

Fig. 37.-A level, llat bearing-surface.

monly possess this very fault. When shoes are made from thin, wide, old iron tyles they are "buckled" on one surface, and to hide this the farrier puts that side to the foot so that it is not noticed until it causes damage. There are three or four forms of foot-surface adopted by farriers, all of which have distinctive features, and some of which have very grave evils. There is the plain flat surface, which is given to all narrow shoes, to hunting shoes, and to some heavier and wider shoes. So long as the sole is healthy and arched this is a very good form. All hind shoes have a flat foot-surface, and most fore shoes might have it with advantage. It utilizes the whole of the natural bearing surface, and must of necessity 
afford a firmer basis lor the foot to rest upon than a more limited surlace. The fore feet are not so constantly arched in the sole as the hind. Sometimes they are flat and occasionally convex. If a shoe be intended for use on all feet-on feet with convex and flat soles as well as those properly formed-a wide flat foot surface would often cause injury by pressing unevenly upon the sole. To avoid this injury in less than five per cent. of feet, and to save the trouble of keeping in stock shoes of different forms, the flat foot-surface of liont shoes lias been replaced by a bevelled or "seated" surface. (Fig 38.)

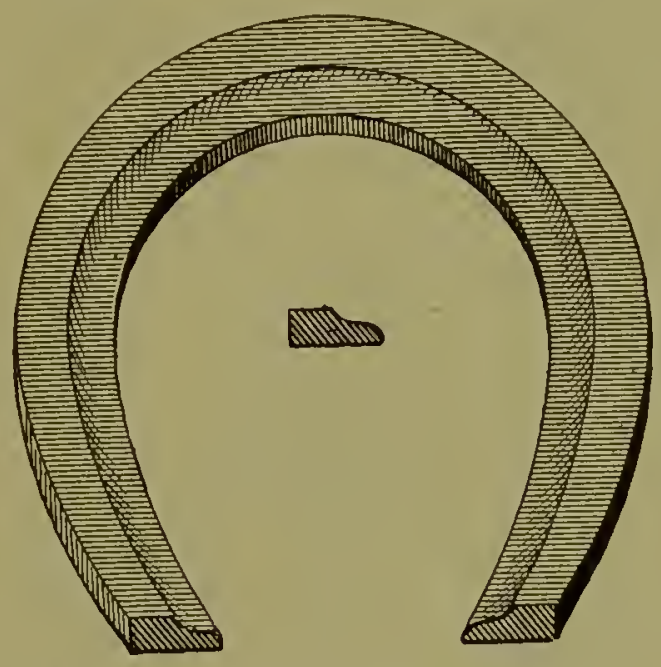

Fig. 38.-A " seated" bearing-surface.

This form is very widely used. It consists of a narrow flat surface next the outer circumference of the shoe, about equal in width to the border of the wall; and within that, of a bevelled surface, sloped off so as to avoid any pressure on a flat sole. This " seated " surface is not positively injurious, but it linits the bearing to the wall, and neglects to ntilize the additional bearing surfice offered by the border of the sole. If shoes were to be made all alike no shoe is so generally uselul and safe as one with a foot surface of this form, but it is evident that when the sole of the foot is concave there is 
nothing gained by making liall the foot-surface of the shoe also concave.

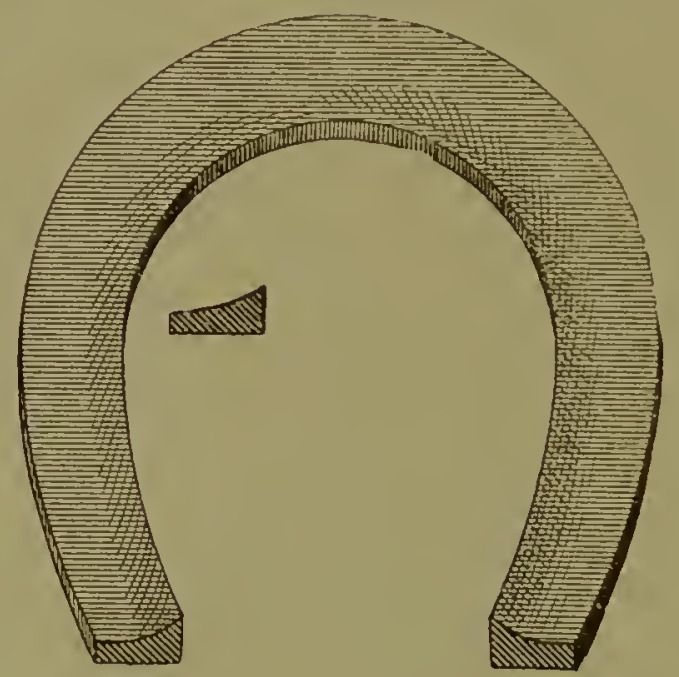

Fig. 39.-Foot-surface sloped outwards.

There are two otlier forms of foot-surface on shoes. In one the surface slopes gradually from the outer to the inner edge of the shoe, like the side of a saucer. In the other the incline is reversed and runs from the inner edge downwards to the outer. The last form is not often used, and was invented with the object of spreading or widening the foot to which it was attached. The inventor seemed to think that contraction of a foot was an active condition to be overcome by force, and that expansion might be properly effected by a plan of comstantly forcing apart the two sides of the foot. The usual result of wearing such a shoe is lameness, and it achieves no good which camnot be as well reached by simply letting the foot alone.

The foot-surface which inclines downwards and inwards like a saucel, acts in an exactly opposite way to the other. The wall cannot rest on the outer edge of the shoe, and consequently falls within it, the effect being that at every step the horse's foot is compressed by the saucer-shaped bearing. This form of surface (Fig. 40) is frequently seen, and is at all times bad and umecessary. Even when maling a shoe for the most convex sole, it is 
possible to leave an outer bearing surface, narrow but level, which will sustain weight without squeezing the foot.

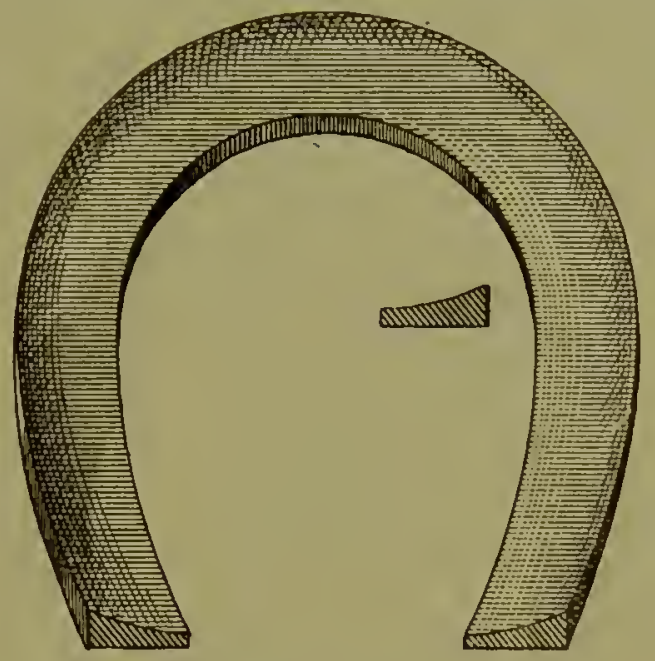

Fig. 40.-Foot-surface sloped inwards.

At the heels, the foot-surface of all shoes should be flat-not seated-so that a firm bearing may be obtained on the wall and the extremity of the bar. No foot is

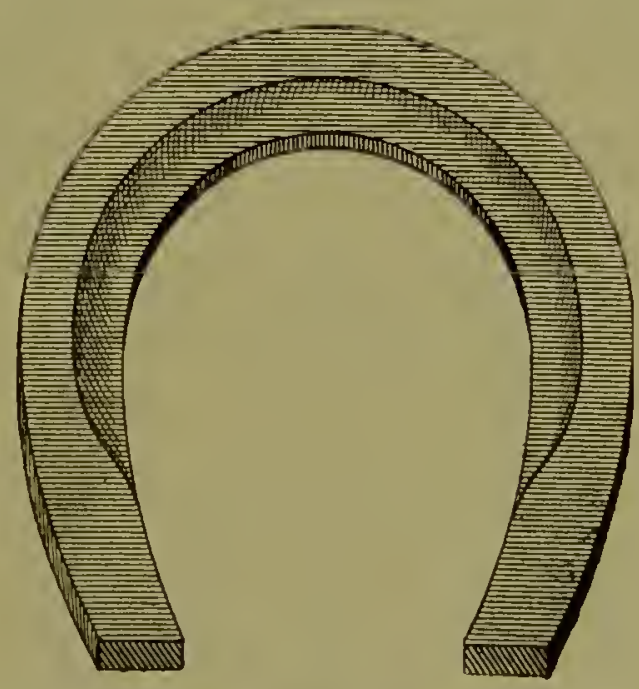

Fig. 41.-Foot-surface level at Heels.

convex at the heels, therefore there is no excuse for losing any bearing surface by seating the heels of a shoe to avoid uneven pressure. Fig. 41 rather exaggerates the "unseated" portion of shoe. 
The Ground=Surface.-As I have said, this may vary indefinitely. Sometimes it is a plain, flat surface, broken only by the holes made for nails or by the "fullering" which affords not only space for the nails, but some grip on the ground. When a shoe is fullered, the groove made

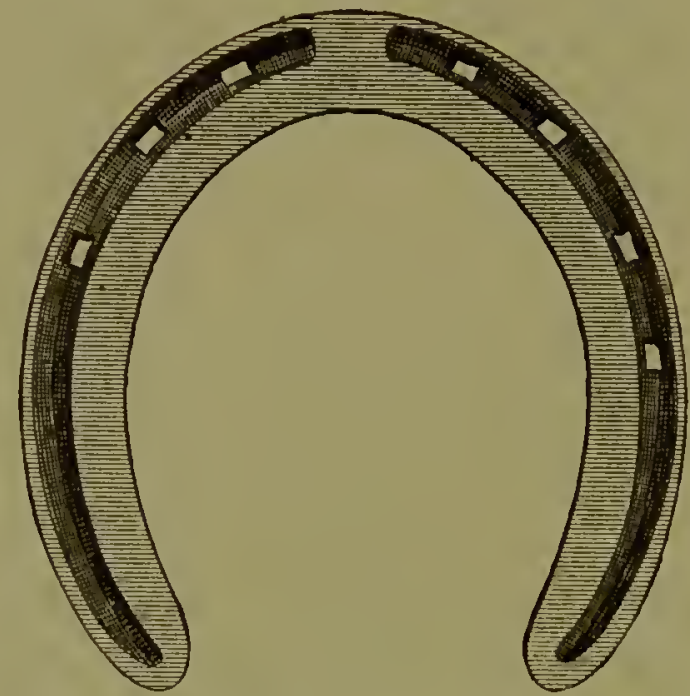

Fig. 42.-Shoe showing portion at toe unfullered.

should be deep, so as to let the nailhead well down, and wide, so as to afford room for giving the nail a proper direction. If the fullering be continued round the toe of

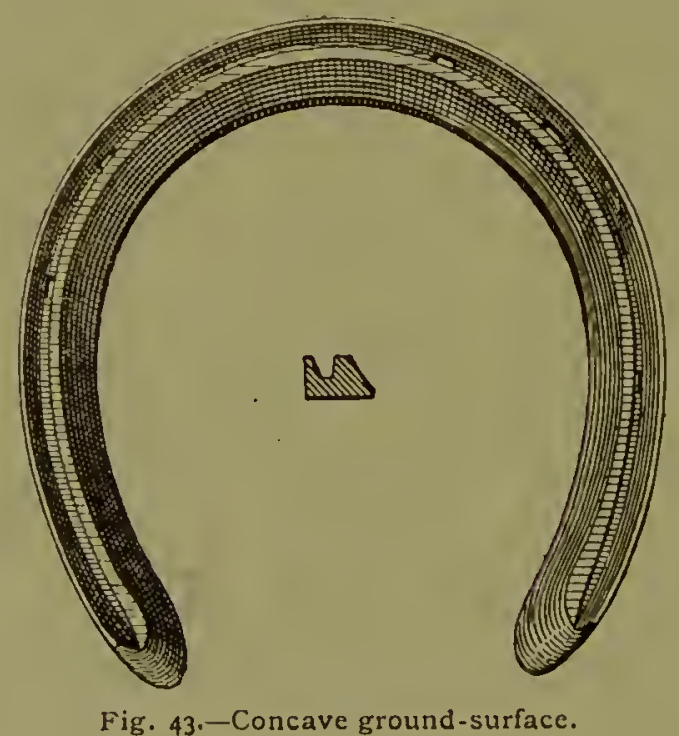


a shoe by a good worknilli, neatness is given, but when a clip is drawn, the iron is so reduced that some wear is silcrificed. If only an inch at the toe be unlullered, the solid iron affords more wear just where it is wanted. (Hig. 42.)

'T'he concave shoe, often described as a hunting shoe, presents in very different ground-surface from that just referred to. It rests upon two ridges with the fullering between, and on the inner side of these the iron is suddenly sloped off. (Fig. 43.) This shoe is narrow and flat on the foot-surface, and is specially formed to give a good foot-hold and to be secure on the hoof.

A Rodway shoe has two parallel grooves and three ridges on its ground-surface. The outer groove carries

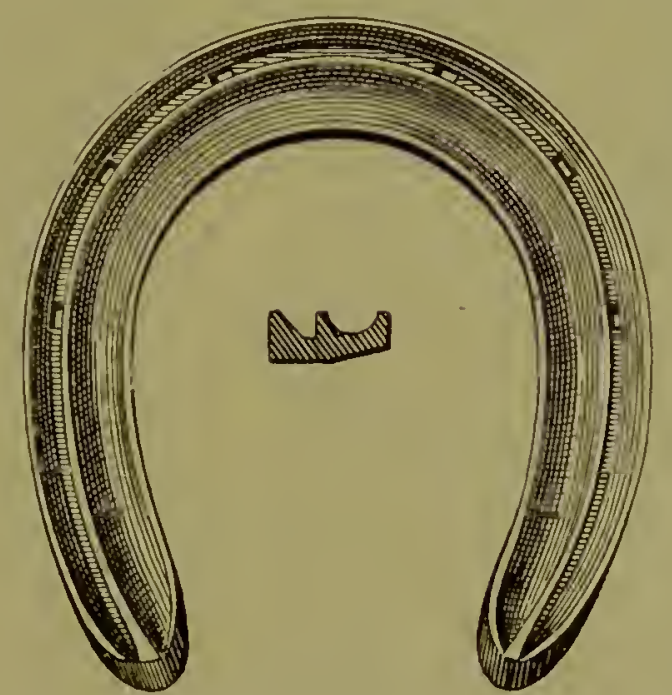

Fig. 44.-Double-grooved ground-surface. (Rodway.)

the nails, and the inner groove lightens the shoe and increases the loot-hold. It is not the number of grooves or ridges that prevents slipping; it is the absence of a continuous flat surface of iron, and the existence of irregularities which become filled up with sand and grit. A four-grooved shoe has no more anti-slipping properties than a threc-grooved, and a one-grooved shoe is as good as cither, although it cannot stand the same amount of wear. 
Transverse ridges and notches have also been tried as ground-surfaces for shoes, bnt offer very little, if any, better grip than the longitudinal grooves. Their great disadvantage is that they cannot be made deep enough withont weakening the shoe, whilst, if shallow, they are worn out before the shoe has been long in wear.

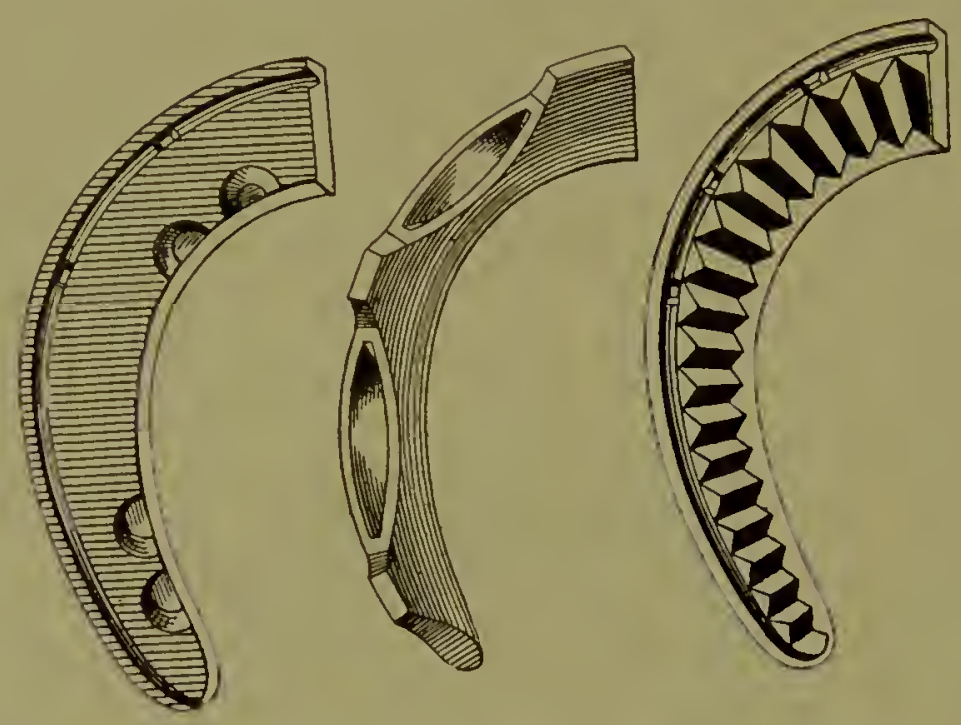

Fig. 45--Ground-surfaces, notches, projections, ridges.

A Calkin is the name given to the extremity of a shoe when turned down at the heels. Calkins are used on most hind shoes and, in some parts of the country, on fore shoes. They are supposed to be the most convenient and effective means of giving good foot-hold. This supposition is correct when a horse travels on soft ground or on streets so paved that a space is left between each conrse of stones. They are of very little use on asphalt or wood pavement and not much more use on rollermade macadam. With light, modern carriages and level modern roads, calkins are quite unnecessary, and better means of giving foot-hold may be substituted. It is it fact that horses, when shoes are new and calkins proninent, do their work without slipping, and that when the calkins are worn down, the horse moves with less confidence and security. This does not prove that calkins 
are neeessary. It numst be remembered that horses possess a power of adapting themselves to circumstanees, but having learned to rely upon any artificial assistanee, they are the more helpless, for a time, on its withdrawal. Calkins assist the horse for a time, but after the eallin is worn clown, the horse is in a worse position than if he had never become accustomed to its assistanee. Of course, on soft ground, especially grass, ealkins afford a firmer grip than any other contrivance. On the other hand, their constant use lifts the frog out of bearing and eauses it to waste, thus spoiling the action of the natural provision against slipping. Level shoes on the hind feet promote sound, prominent frogs, and give firm foothold for all light horses. Even ommibus horses, now that the vehicles are supplied with effective foot-biakes, may advantageously be worked without callins. On country roads, especially when the distriet is hilly or the load is heavy, calkins may be requisite, and must then be made to do as little harm as possible.
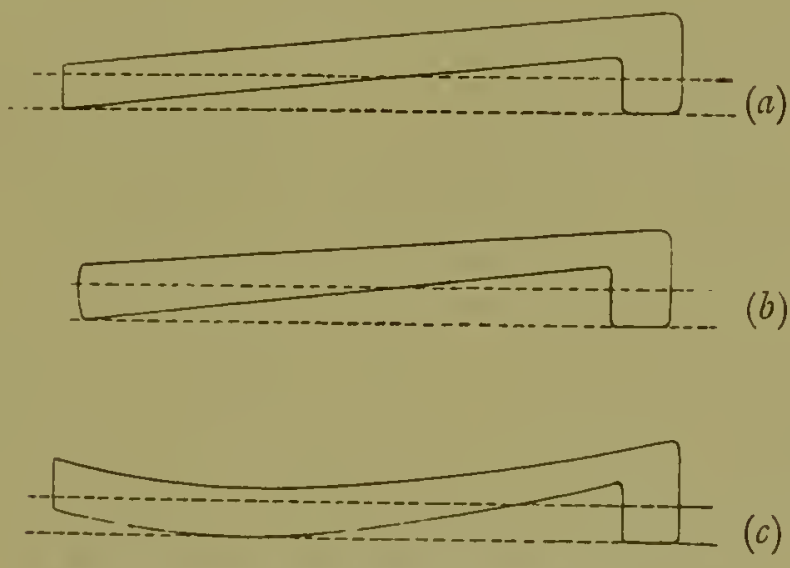

Fig. 46.-The dotted lines show the effect of wear and its relation to the shape of the shoe.

'T'he wear of a shoe is affected by the height of a ealkin: The more the heel is raised the greater the amount of wear ut the toe. Many shoes when worn out at the toe, show very little effeets of weur at other parts, and the question arises how best to inerease the wear of the shoe without increasing its weight. In Fign. 46, throe diagrans 
are presented, in which dotted lines show the effect of wear. At (a) the shoe is of even thickness throughoutfrom heel to toe-and the line of wear shows that when the shoe is worn out a great amount of iron remains. At (b) the quarters of the shoe are made thimner and the toc is made thicker, so that with no increase of weight but by a better distribution of the iron, increased wear is provided for at the part where it is most required. At $(c)$ is shown a shoe similar in form to that at (b) but differently fitted. The toe is turned slightly upwards, and the result is that a larger portion of iron is brought into wear. In the case of very hard-wearing horses, that scrape out the toe of the ordinary shoe in ten or fourteen days, this form of fitting adds considerably to the durability of the shoe, and so preserves the foot from the evil of too frequent removal of shoes, whilst avoiding any increase of weight. Without calkins, wear is more evenly distributcd, and the toe is not worn away disproportionately to the rest of the shoe.
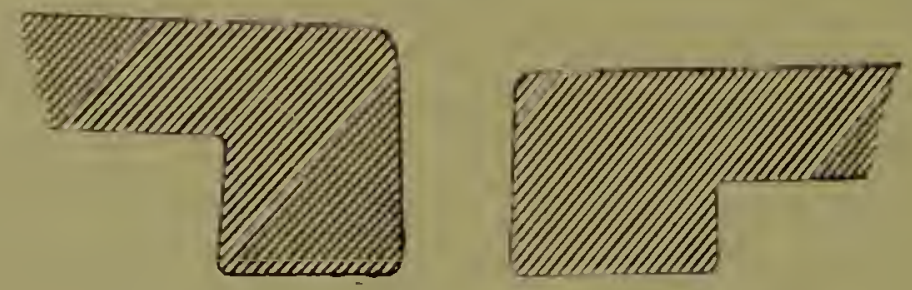

Fig. 47.-Two calkins -the low square one preferable.

A calkin throws the leg and foot to some extent out of their proper position. A very high calkin is not only objectionable, it is unnecessary. Not much prominence is required to afford a catch or stop. Excessive height is usually given to meet wear', and this can bc obtained equally well by increasing the width and breadth. I, therefore, recommend that when callins are used, they should be low, squarc and broad. The further under a foot the calkin is placed, the greater is the raising of the heel, therefore calkins should always be accompanied by a long shoe. The further back a calkin is placed, the less it interferes with the natural position of the foot. 
Calkins render a horse liable to tread the opposite foot, and the higher and sharper the callin, the greater the injury inflicted. To avoid this injury, the inner heel of a shoe frequently has no callin, lunt is made at the sane level as the outer by narrowing and raising the iron at the heel, forming what is called a wedge heel. This is not an advisable for'm of shoe, as it has on the inner heel a skateshaped formation, most favourable to slipping, and on the outer a catch-an arrangement tending to twist the foot each time the catch takes hold of the ground. If calkins are used at all, they should be of equal height and on both heels of the shoe.

In Scotland and in the North of England, heavy horses are shod, fore and hind, not only with callins, but also with toe-pieces, and the owners assert that the horses could not do the work without them. That horses do similar work in the South without callins and toe-pieces rather shalies one's faith in the assertion, but it must be remembered that nearly all paved streets in the North have a division left between the rows of stones in which the toepiece finds a firm resisting surface. I believe also that the average load drawn is greater in the North than in the South. One thing in favour of toe-pieces must be acknowledged-they, with the callins, restore the natural position of the foot and preserve the level of the shoe. On the larger draught horses, the toe-pieces permit a lighter shoe to be used, as the portion of iron between heels and toe need not be thick to resist wear. It only requires to be strong enough to support weight, and much less iron is therefore used.

The heavy diny horse of the North, shod with toe-pieces and calkins, is never worked at a trot. In London, all horses are trotted - a proceeding which reflects discredit upon the intelligence of the managers.

I must mention another objection to callins. They increase the tendency to "cut," and many horses will cease "cutting " after calkins are removed and a level shoe has bcen adopted. 
Nails and Nail-Holes.--It is necessary to consider these together, as they are dependent on each other. Shoes were first nailed to the feet by flatheaded nails, and prolal)ly it was a long time before the wedge-headed nail was thought of. When the nail hear fits into the nail-hole, it may retain the shoe till it is worn as thin as a penny, but if only the shank of the nail enters the shoe, the head is soon worn off and the shoe becomes loose. Within the last twenty years the horse-shoe nail trade has been revolutionized by the introduction of machinery. Machine-made nails are now almost entirely used, and the three or four leading brands are as near perfection as were the very best hand-made. Practically there is no fault to find with them, and as they are ready-pointed for driving, they save time and labour in the forge. 'They are made in various sizes, and numbered from 2 to 16. Only the very best iron can be used to produce good nails. Nothing is dearer than bad nails, which cause injury to the foot and loss of shoes.

A good nail should present certain forms of head, neck and shank. The head should not be too broad at the top or it may hecome fixed in the nail-hole only by its upper
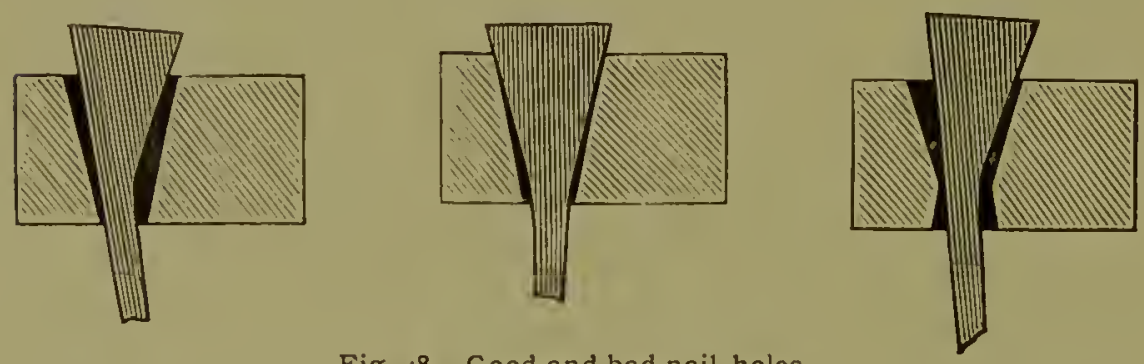

Fig. 48.-Good and bad nail-holes.

edge, as shown in the middle diagram (Fig. 48), and when the shoe has had a few days' weal, the nail loses its hold, and the shoe is loose. The neck should not be too thick, as it is then liable to press on the sensitive foot or to breali the wall. The shank should not be too wide or too thick. The point should not be too long or too tapered, as this leaves insufficient metal to form a good clinch. 
There are two methods of putting nail-holes into shoes -by "fullering" and by "stamping." A stamped shoe is one in which the nail-holes are merely punched at certain distances, so as to leave four-sided tapcred holes of the exact shape of a nail-head. A fullered shne is one having a groove round the circumference through which the nailholes are punched. Both processcs, when woll done, admit of nails bcing driven in the hoof with equal safcty and ease.

Whether stamped or fullercd, there arc a few more important points to remember about the nail-holes. The wall is not of the same thickness throughout, but becomes thinner towards the heels. 'The inner side of the foot is also somewhat thinner and more upright than the outer. The safest position, then, for the nails is in the front half of the foot, but should this position not present sound horn, they may be placed further back. 'The danger of placing nails near the heels is due entirely to the greater risk in driving them through the thin horn. There need be no fear of interfering with expansion.

The distance of the nail-holes from the outer edge of the shoe shonld depend upon the thickness of the horn of the wall, and therefore be greater in large shoes than in smaller, and greater at the toe than at the heels of the same shoe. When the nail-holes are all near to the circumfercnce of the shoe (Fig $49 \mathrm{~B}$ ) they are described as "fine"; when they are all placed far from the edgc (Fir. $49 \mathrm{~A}$ ) they are called "coarse." When the nail-holes are too "fine," a nail is liable to split the horn, and has to be driven high up in the wall to obtain a firm hold. When the nail-holes are too "coarse," the nail in driving goes dangerously ncar the sensitive foot. The evils of coarse and fine nailing depend a great dcal upon the method of fitting the shoes. When shoes arc fittcd full to the foot (when the onter circumfercnce of the shoe is greater than the circunfercnce of the wall) "coarse " nailholes are brought to about their best position. When shoes are fitted close (i.e., when their outer edge is brought 
within the border of the wall), "fine" nail-holes are brought to their best position in relation to the foot. It need hardly be added that the fit of a shoe ought not to lee subject to the position of the nail-holes, but that these should be properly placed, so that fitting be guided only by the requirements of the foot.

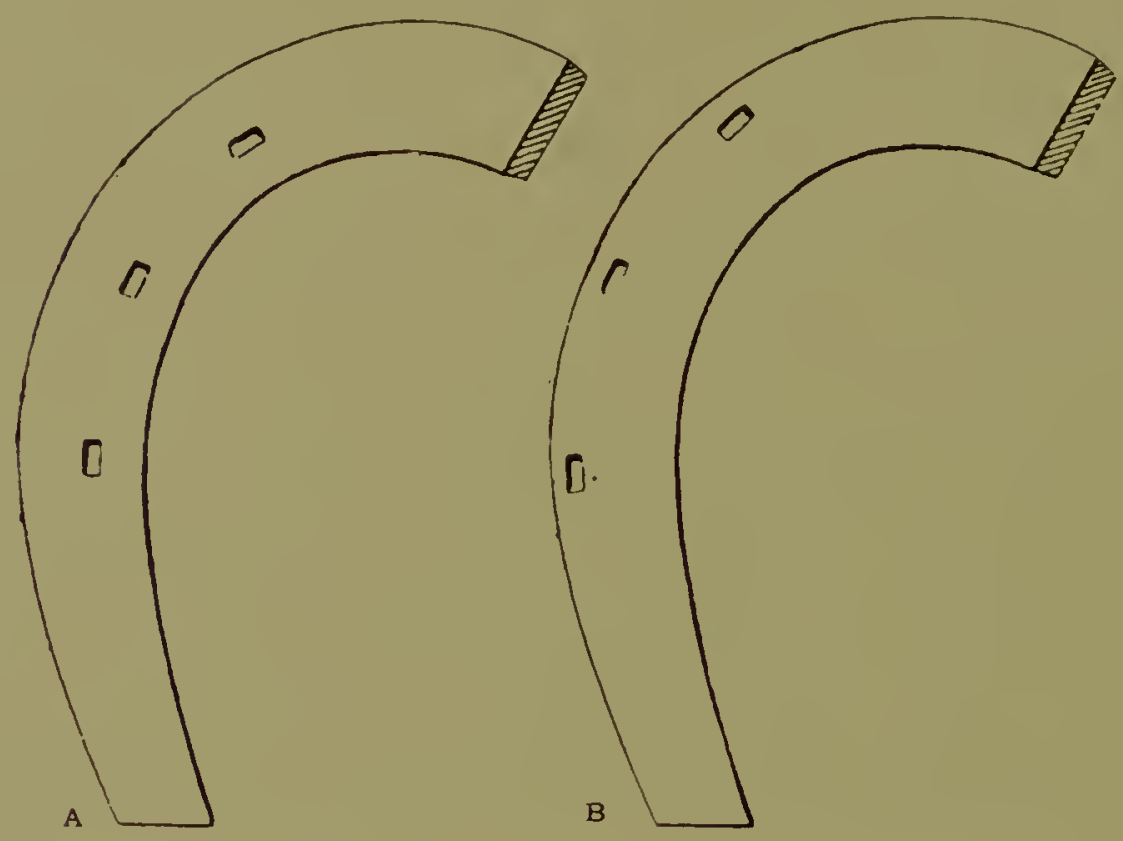

Fig. 49.-Wrongly placed Nail-holes (A too coarse, B too fine).

Each nail-hole, when properly placed-neither too coarse nor too fine-should be punched straight throngh the shoe and not inclined either inwards or outwards, except at the toe, where the slope of the wall is followed by slightly pitching in. When a fuller is used, the groove made should be wide; then the farrier has more command over the direction of the nail. If the nail-hole be much pitched in, the nail must take that direction and is liable to wound the foot. If the nail-hole be pitched out, the nail is prevented from taking sufficient hold of the horn.

The position and direction of the nail-hole controls the passage of a nail through a shoe and into the hoof. The man who drives a nail is usually blamed for laming a horse, lout in most cases it rould be more just to blame 
the man who makes the nail-holes or fitted the shoe and so rendered safe driving difficult or impossible.
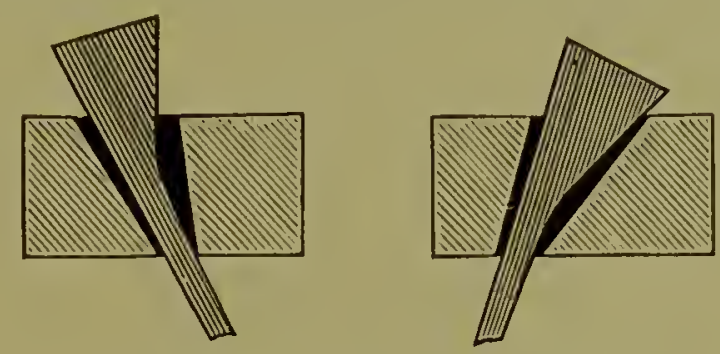

Fig. 50.-Nail-holes " pitched" in and out.

Each nail-hole should be as far as possible from the other-say, from an inch to an inch and a half apart. When the two front or toe nail-holes are put too far back, the whole are crowded, or the last are pushed back too near the heels.

For small shoes, four or five nail-holes are sufficient. Medium-sized shoes should have from five to seven, and the heavy shoes of big draught horses must have eight. The number of nail-holes need not always be increased in proportion to the size of the shoe, because as the weight of shoe is incrensed, so is the size of the nail, and an extra strong nail may take the place of additional ones. The fewer nails in a foot the better, but as a properlyplaced nail does no harm, and as the loss of a shoe may be very serious, it is better to have one too many than one too few.

Machine- made Shoes. - Horse-shoeing is distinctly an art requiring special skill for its proper performance. It is also one of the most laborious of all skilled trades. Anything which lightens mechanical toil tends to improve the mental and artistic qualities of the workman, and all applications of machinery which lessen the heavy manual labour of the farrier may therefore be looked upon as improvements. Machinery has lightened the labour of shoe-making in two ways-by supplying various patterns of grooved and bevelled iron in bars, which only 
require cutting into lengths and turning round to form a shoe, and also by making shoes all ready to be fitted to the foot. Machinery has not yet turned out a shoe as good and durable and well finished as the best workman can produce by hand, but it can produce many forms of shoes as good for all practical purposes, and it has this

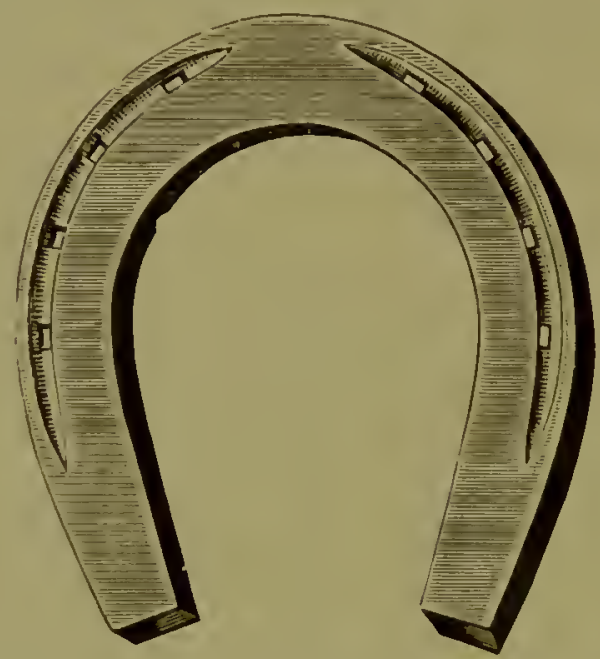

Fig. 5I.- Machine-made Shoe-Fore-foot.

advantage-all are alike. Bad workmen make bad shoes, but a machine, once able to produce a good model,

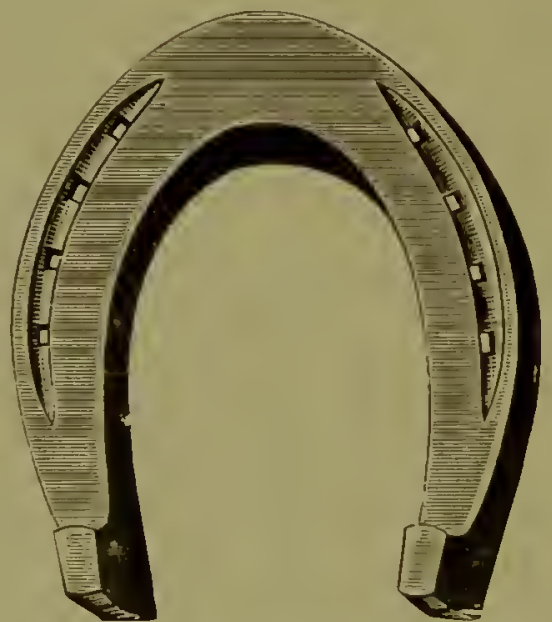

Fig. 52,-Machine-made Shoe-Hind-loot.

can repeat it exactly, therefore machine-made shoes of a proper pattern are superior to all but the very best hand- 
made shoes. Economy, of course, is on the side of the article produced by machinery, and all large firms keeping their own farriers find a great saving by buying the ready-made shoes. Under conditions when shoes must be fitted without a fire, as in coal mines, or in the case of armies during a compaign, the machine-made article has the advantages of regularity of form and a true level bearing surface.
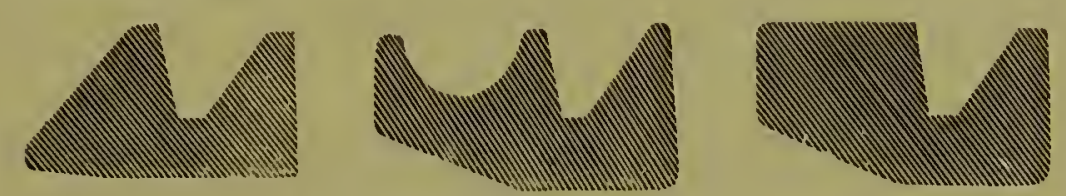

Fig. 53.-Sections of rolled bariron.

In little shops where often only one man is at work, either machine-made shoes or prepared bar iron offer great conveniences. The prepared bars can be bought seated on the foot-surface and with a single or double groove on the ground-surface. Very narrow bars suitable for tips, "Charlier," or light hack shoes are now widely used, and a special bar-flat on the foot-surface, concave to the ground - can be obtained which only requires cutting into lengths and turning round to form a first-class hunting-shoe.

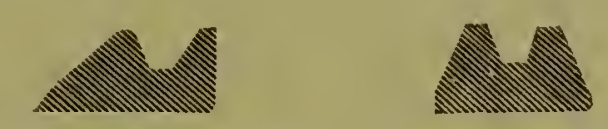

Fig. 54.- Section of light pattern bar iron.

Both prepared bars and machine-made shoes must be judged by their form and by the material used in their manufacture. Some are better than others, but all have to contend with a large amount of trade prejudice which has little basis, except in the matter of the hind shoes; here machinery has not yet reached perfection. 


\section{Chapter VI. \\ Selection of Shoes.}

In practice, a farrier is too seldom consulted about the form of shoe most suitable for the horse. The custom is to apply whatever form the horse has been wearing, and only to venture an opinion as to alterations when asked by the owner. It would be foolish to alter the plan of shoeing which was found suitable and satisfactory, unless for very good reason. It is equally foolish for a man who knows nothing about the art to send orders to the farrier and to treat disobedience of these orders as a crime ranking between heresy and revolution. In a large majority of cases the farrier knows more about the shoe and shoeing than the owner of a horse, and for the more ignorant man to order the other is simply an exhibition of conceit.

When the selection of a suitable shoe is left to the workman, he takes into consideration the work required of the horse, the form of the feet and the wear of the old shoes. The old shoes indicate not only whether a horse is a light or a heavy wearer, but what parts of the shoe are most worn, and thus enable provision to be made against excessive or irregular wear. The form of the feet shows not only what size of shoe is requisite, but also what special weakness or strength is to be encountered. It is also necessary to note the condition of the fetlocks, heels and knees, which may show signs of "brushing," "over-reaching," or " speedy-cutting." According to all these indications, a shoe is selected suitable for the horse and the kind of work on which he is employed.

For the different classes of horses there are wellknown forms of shoe which present some special adrantages :- 
The Race Horse, when in training, may be shod with a very light shoe, but on the turf he requires the lightest contrivance capable of protecting the hoof and affording grood foot-hold. The ordinary lacing plate answers these requirements. It may be made in a "crease" or from specially prepared bars which are already grooved and only require cutting into lengths and turning round. The plate is about one-third of an inch wide by one-eighth thick. The foot-surface is flat, the ground-surface fullered and concave. The best bars are made of mild steel.

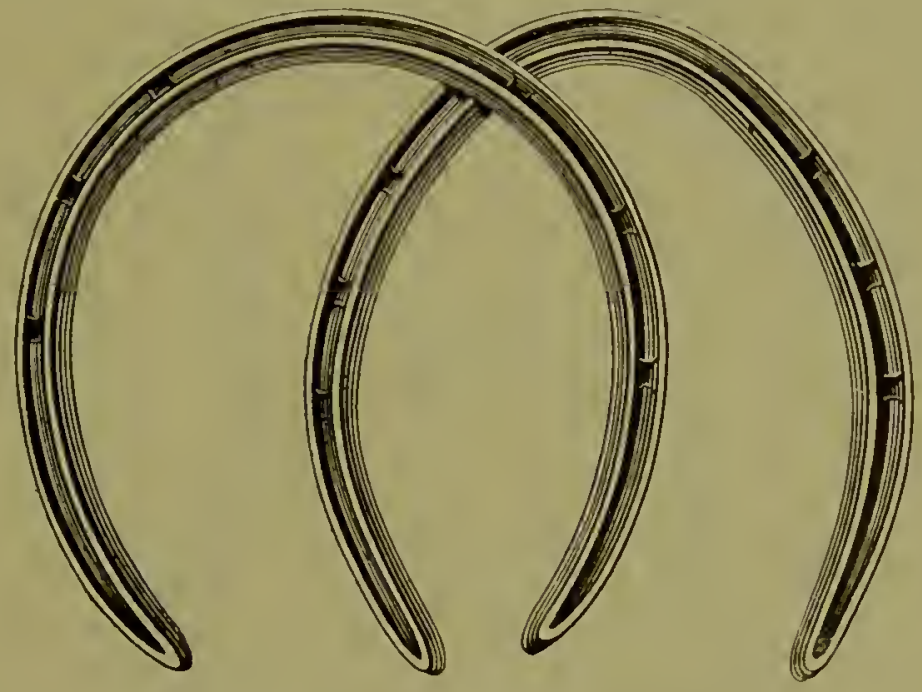

Fig. 55,-Racing Plates-Fore and Hind.

The front plates are fitted close and short so as to avoid any chance of contact with the other feet. The nails are very small and may be placed further back than usual, so as to increase the security of the shoe. The hind shoes may be turned down at the heels to form two small callins or, if it be preferred, only one on the ontside.

Steeple=Chase plates are made on the same pattern but stronger, so as to avoid the possibility of becoming twisted through contact with obstacles on the course. 
82

THE ART OF HORSESHOEING.

Hunting Shoes must have sufficient strength to wear three weeks or a month. They must be secure on the foot, afford good foot hold, and not interfere with the

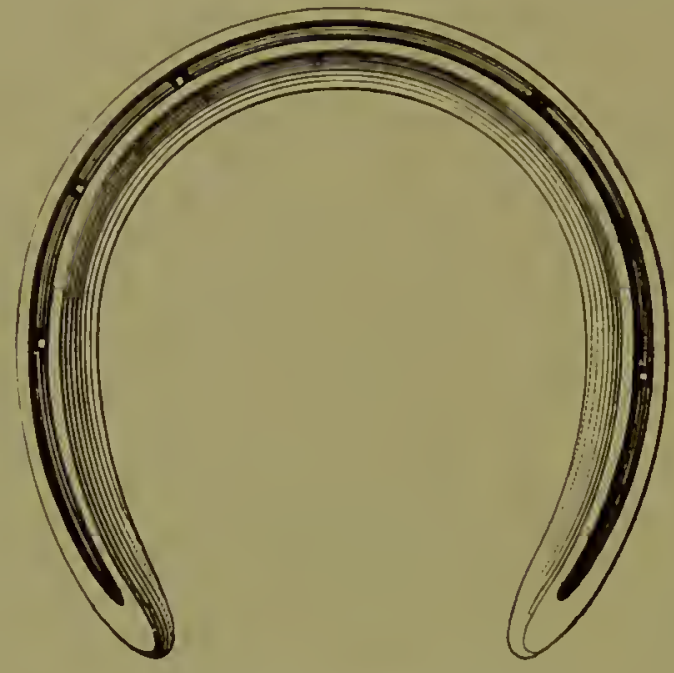

Fig. 56.-Hunting Shoe-Fore.

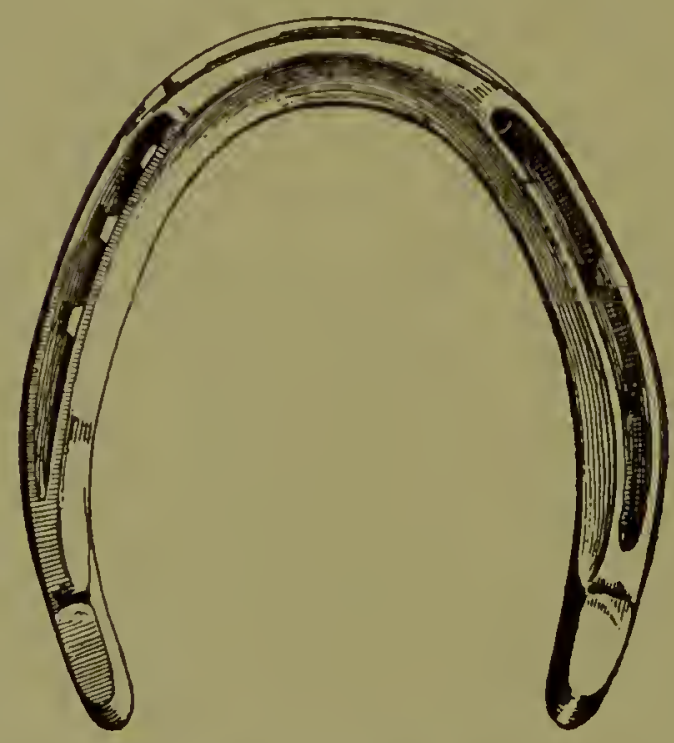

Fig. 57 --Hunting Shoe-Hind.

other feet or limbs of the horse, when galloping or jumping. The best form for both fore and hind shoes is the narrow, concave pattern almost universally employed in hunting districts. It is flat on the foot surface and so affords no lodgment for stones between it and the sole. 
The front shoe is fullered and concave on the groundsurface, attached with six nails and supplied with a toe-clip. It is fitted close and short. Often hunters' shoes are too short and the heels are filed off to a point, almost like a lead pencil. If the shoe is fitted close and an eighth of an inch shorter than the bearing-surface, nothing more is desirable. If, also, the points of the hcels

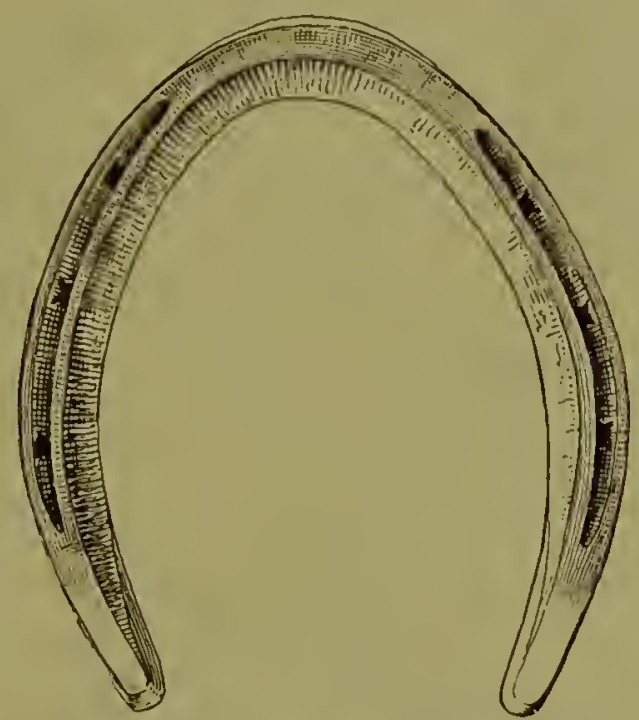

Fig. 58-Hunting Shoe (Hind)-another form.

be filed to a slope equal to that of the heels of the foot, perfect safety is attained, with the best bearing-surface. The hind shoe is also fullered and concave on the groundsurface. Unless the horse is guilty of "brushing," the shoe may have two small square calkins. To guard against over-reaching the heel of the front foot, the concave form is almost sufficient; but sometimes horses in jumping hit the back tendon of a fore leg with the toe of the hind shoe. To ensure the greatest safety the hind toe of a hunting shoe should be rounded and supplied with two toe clips. (Fig. 57). A very convenient bar iron is now sold, rounded on its upper surface. 'This only requires fullering at the sides, leaving the toe untouched, to make a perfect shoe for hunters. 
84

THE ART OF HORSESHOEING.

Hacks, being used on hard roads, must have heavier shoes than hunter's but the shape may be similar. There is not the same necessity for the concave form in front, so a narrow, double-grooved (Rodway) shoe may be employed.

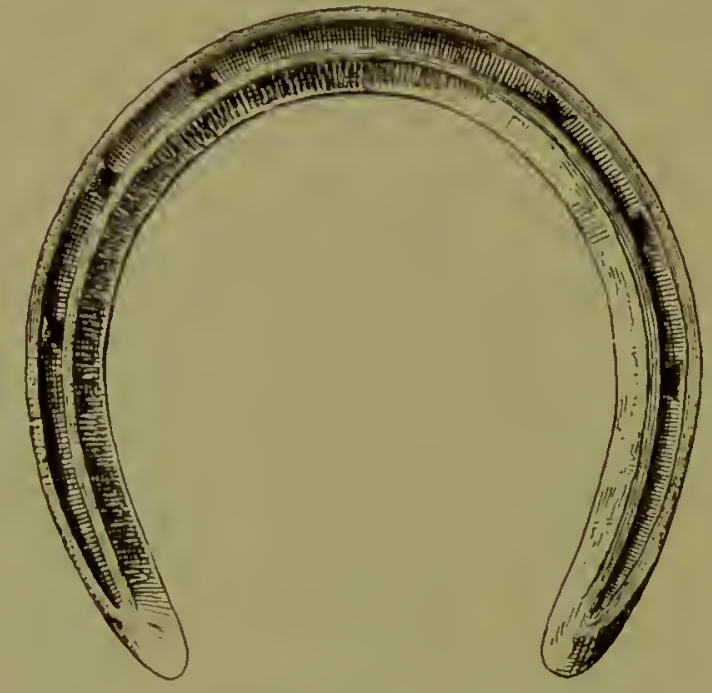

Fig. 59. -Hack Shoc-Fore.

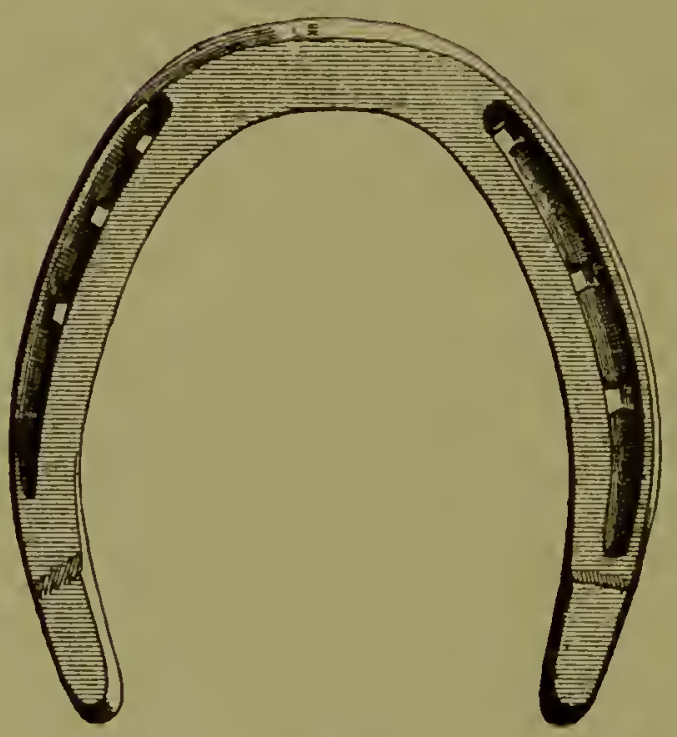

Fig. 60.-Hack Shoe -Hind.

There is not the same danger of over-reach so a wider flat shoe may be used on the hind feet and the clip may be at the toe. For ordinary riding purposes a horse does not require extraordinary precautions against the fore shoe 
being struck or torn off by the hind, and therefore hackshoes may be fitted longer and the heels be cut off at a more abrupt angle. On hard roads calkins do not take the hold they do on grass, and so there is no special necessity for calkins on the hind shoes of hacks. I think the square-toed hind shoe looks neat on a hack but it should not be used if the horse "brushes." (Fig. 60.)

Carriage Horses. The narrow, light shoes we have been describing do not afford sufficient wear for carriage work. For front shoes there is no better form than the double-grooved shoe known as "Rodway's." The grooves are rolled in the bar and it is, therefore, easy for a farrier to make the shoe single-handed or merely with the assistance of a boy. This shoe affords good foot-hold, is light and durable. The foot-surface is seated and therefore it may be safely used on flat feet.

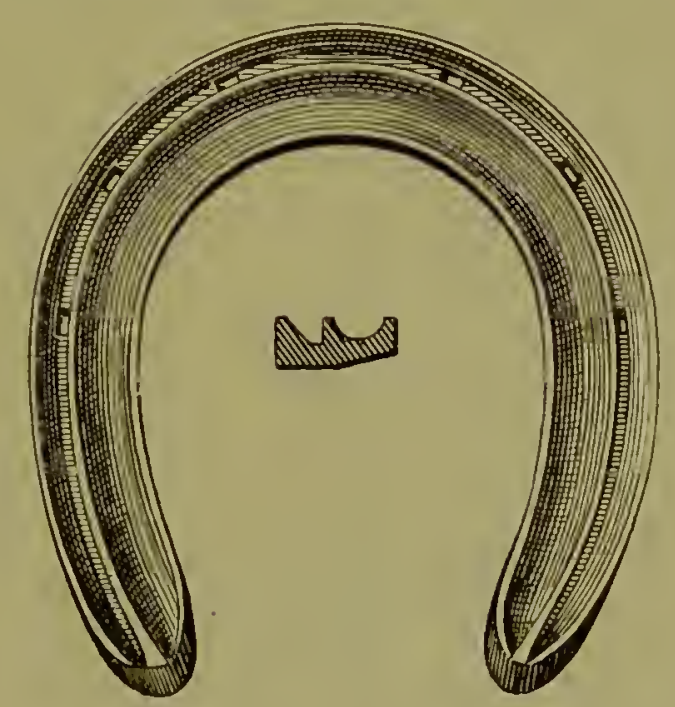

Fig. 6r.-Carriage-Fore Shoe-Rodway.

Carriage horses need have no callkins on hind shoes unless used in heavy vehicles. When callins are used, one on each heel is best. T'he clip should be at the toe and if there is a tendency for the shoe to shift its position, owing to the peculiar action of the horse, a quarter-clip may be 
drawn on the outside. This is seldom wanted and always ugly. When callins are used there is no reason for

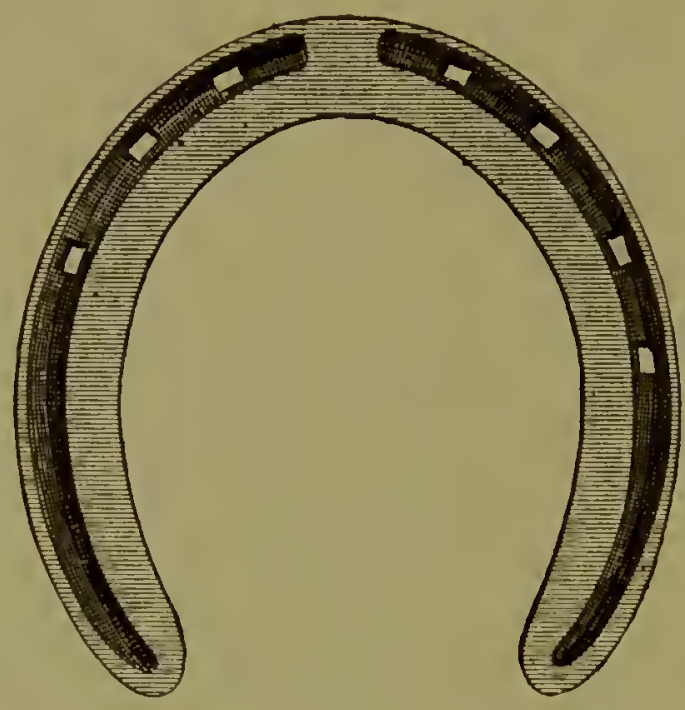

Fig. 62.-Carriage-Fore Shoe.

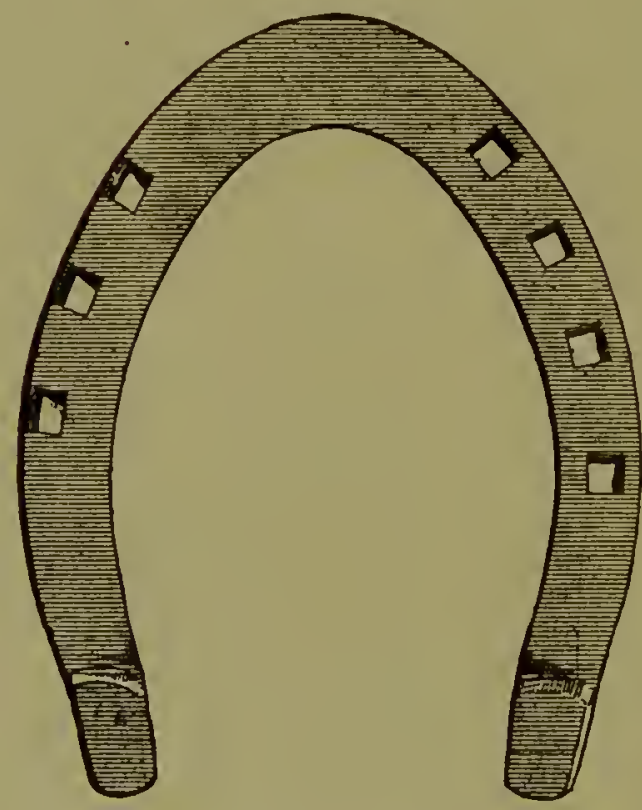

Fig. 63.-Carriage-Hind Shoe.

fullering a hind shoe, and the nail-holes may then be stamped-a process easier to do and affording a little more wear in the shoe. 
Omnibus and Van Horses. Strength to resist wear is the chief feaure of this class of shoe. A shoe too heavy is, of course, an evil as it tends to produce leg-weariness.

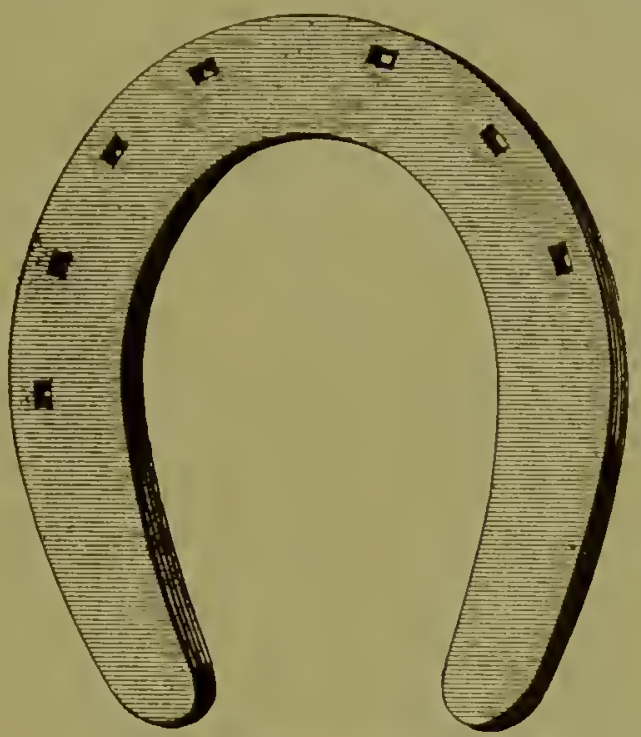

Fig. 64.-Omnibus-Stamped Fore Shoe.

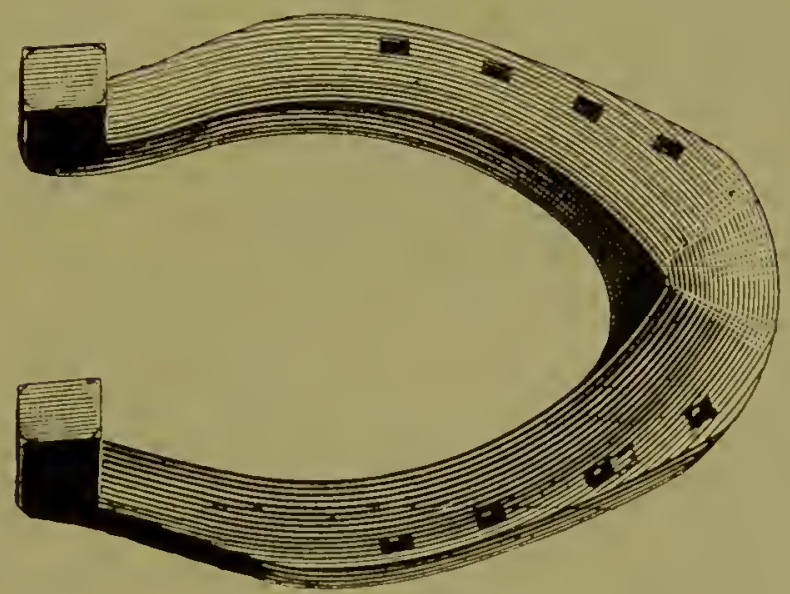

Fig. 65--Omnibus-Hind Shoe.

A shoe too light is also an evil as it wears out in a few days, and the frequent repetition of shoeing damages the hoof. Horses show immense variations in the wear of shoes, due to their different forms of action. A shoe which will last three or four weeks on the miljority of a stud of horses, doing similar work, will be scraped out in 
eight or ten days by some of the animals. These hardwearers require special notice and should have special shoes made for them. Those who scrape out the toes before the rest of the shoe is much worn should be tried with a shoe turned-up at the toe before increasing the weight of iron. Those horses that wear the shoe level are difficult to deal with, and usually can only be supplied with a durable shoe by increasing the weight of iron or by the use of steel.

When this class of shoe is fullered the toe should be left solid. Hind shoes, with calkins, may be stamped. As all omnibuses have good foot brakes there is no necessity to draw calkins on the hind shoes. Shoes last longer without calkins, horses are less liable to "cut" their legs, and the level shoe gives greatly increased duration in those cases where the toe is specially worn. An extra strong Rodway shoe-unseated on the footsurface and rolled out of mild steel--would make a most useful and durable shoe for omnibus or light van work.

Heavy Draught Horses. The heavy holse has not

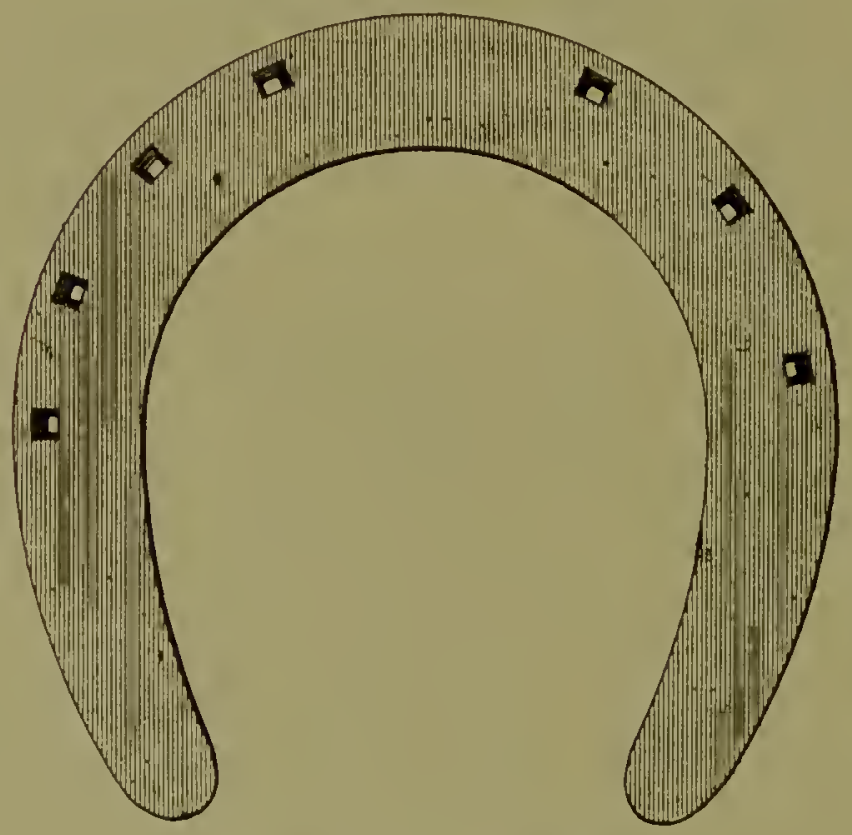

Fig. 66.-Heavy Horse -Fore Shoc. 
only to draw loads but frequently to back them, and therefore he must have callins on the hind shoes. The front shoes may be plain, level and stamped. The strain on the

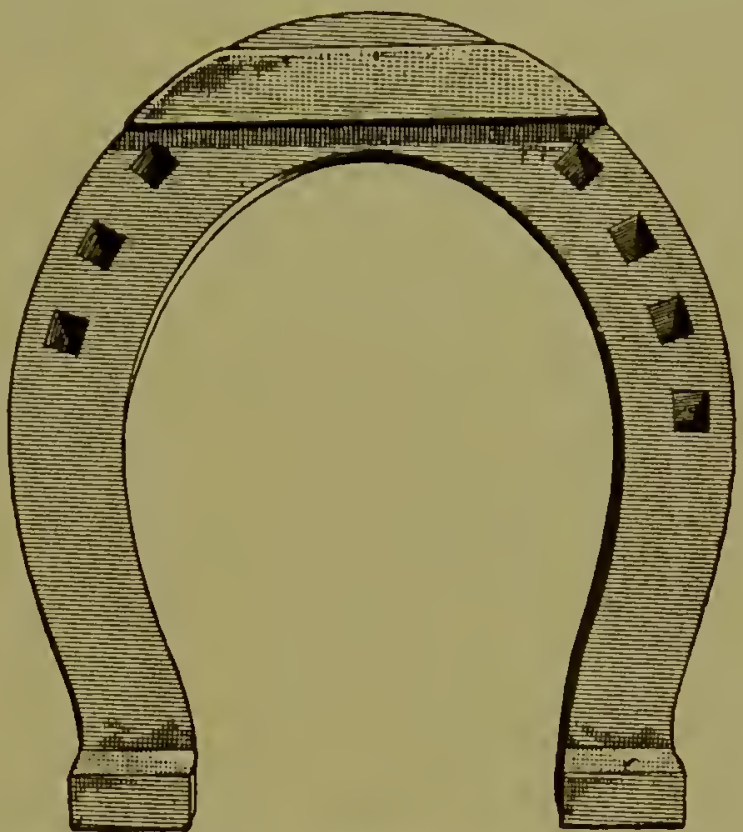

Fig. 67--Heavy-Horse-Fore Shoe, Toe-piece and Calkins.

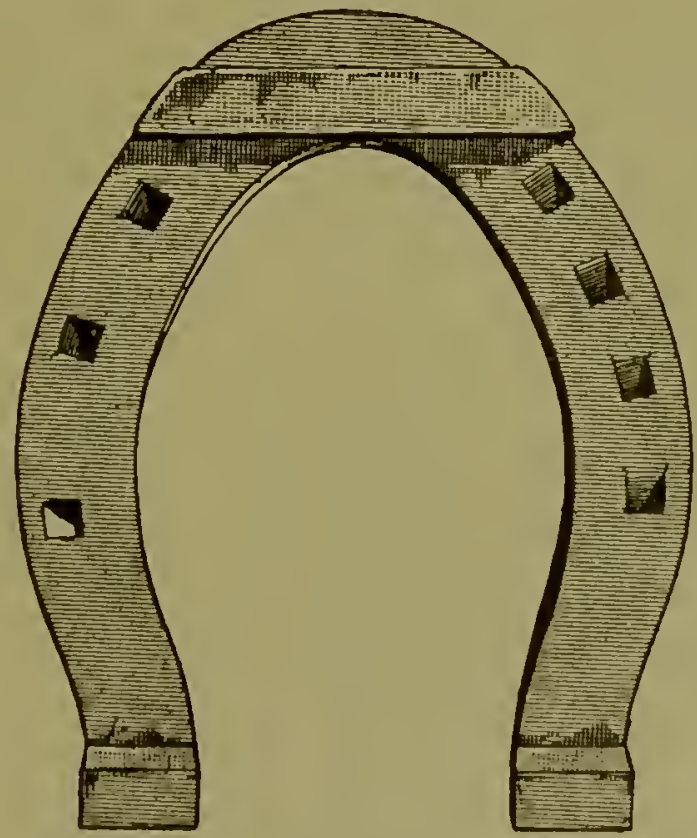

Fig. 68,-Heavy-Horse-Hind Shoe, Toe-piece and Calkins, 
shoes of a hor'se that twists his foot, necessitates the use of quarter clips more frequently than on other classes of shoe. In Scotland and in the North of England, the heary horse is shod with a shoe having calkins and toe pieces both fore and belind. This shoe is lighter than the level shoe used in London on the sane sized horses. It gives a level bearing and affords good foot-hold on paved streets. Especially is this the case when the paving stones are set with a space between each row. On level surfaces like asphalte, the toe-piece and calkin affords no extra foot-hold and may well be replaced by a level flat shoe.

It seems rather curious that the same class of horse in the North and South of Fngland should be differently shod though doing similar work. Managers coming from one district to the other have often tried a change of shoeing, but with the almost invariable result of returning very shortly to the prevailing system. Hor'ses, having become accustomed to toe-pieces, slip much more when shod with a level shoe. They have adapted themselves to the method of shoeing and cannot suddenly alter their ways to the new system. 'Then again, the farrier who has no experience of toe-pieces is not likely to make a shoe with them as well as the man accustomed to them. Above all there is the road-may which, in the North, is laid with a view to the foot-hold of the horse. Possibly, too, the load differs in weight. Were there not some advantages it is not likely that two distinct forms of shoes would be employed on horses in, say, Glasgow and London.

It will be noticed that a toe-piece is welded on the shoe a little behind the point of the toe-not at the very edge. Calkins on these large shoes are also fitted wide and made to stand rather behind the heel of the shoe than immediately under it. This, of comrse, increases the size of the base upon which the horse rests. 


\section{ChAPTER VII.}

\section{Fitting and Application of Shoes.}

Having selected shoes suitable for the feet and adapted to the special work of the horse, having also prepared the foot for shoeing, we arrive at another important part of the farrier's art-fitting the shoe. No matter what form of shoe be used, or how the foot be prepared for it, unless the two are properly fitted the horse does not obtain all the advantages of good shoeing, and may be positively injured. The owner of horses seldom knows anything about the fitting of shoes, and therefore fails to appreciate how some of his directions concerning feet and shoes are quite impracticable.

I have, in a previous chapter, attempted to show how a foot should be prepared for shoeing, and what bearing surface should be left for the shoe. I have also described what I consider the best forms of shoe. The object, at all times, should be to follow nature as closely as possible, but it often happens that we may, with benefit, depart from the exact indications given and still fulfil all essential requirements. If we examine the unshod foot which has

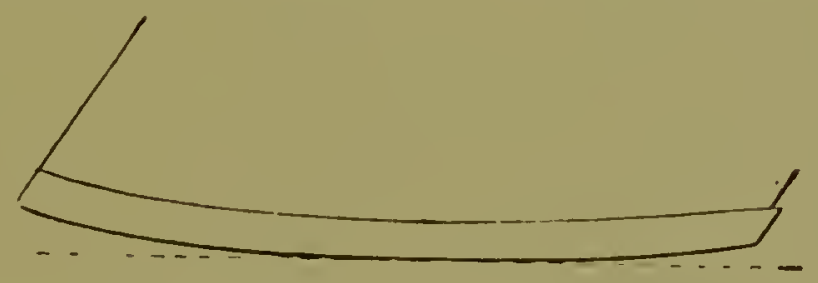

Fig. 69.-Shoe fitted to a curved loot-surface.

been worn down to proper proportions, we find the bearing surface is not level -it is worn more at the toe and heels than elsewhere. If we examine the ground surface of an old shoe the same thing is noticed-the surface is not level, the toe and heel show most wear. The question 
then arises, should we make the artificial bearing surface of the foot on the same plan and adjust the shoe to it, as in Fig 69 , or should we make the surface level and apply a level shoe as in Fig. 70? I believe that the ideal arrangement would be to follow the line suggested by a worn foot or a worn shoe, but it is difficult to carry out, and greater exactness of fit is more readily obtained by two level surfaces. The ground surface of a shoe may, if necessary, be altered to suit the outline of wear, whilst the level foot-surface is preserved. Whatever form the farrier adopts, a shoe should rest equally throughout, and the contact of foot and shoe should be exact over the whole bearing surface. Assuming then that a properly prepared foot presents a level surface, the fitting of shoes becomes simple so long as the smith possesses manual dexterity and follows the indications of common sense.

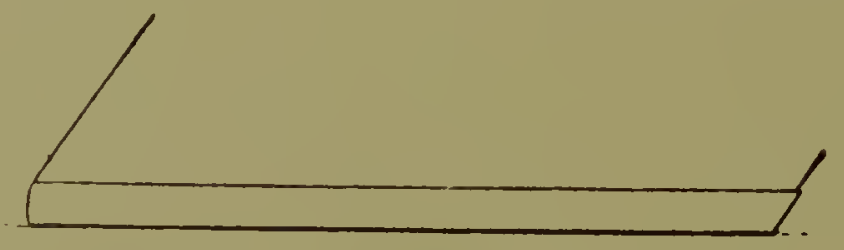

Fig. 70.-Level shoe fitted to level foot-surlaee,

There are two conditions to be fulfilled (1) to fit the shoe to the plain surface of the foot, (2) to fit the shoe to the circumference of the wall. Most amateurs judge shoeing by the way a shoe follows the ontline of the hoof, but the practical man knows that it is equally difficult and important to fit the surface.

Outline Fitting.-A shoe is first compared with the foot, it is then heated, and the heels cut off or turned down to the proper length. Each limb of the shoe is fitted to follow the outline of the wall, and it is necessary to warn the novice that the inside and outside borders of a foot are not alike. The outside is rounder and fuller, and the shoe should be shaped to follow exactly the direction of the wall. The outer branch of a shoe should always be as prominent as the outer border of the hoof; 
it should never be within it. The inner branch must not protrude beyond the wall lest the opposite leg be struck. A well fitted shoe must be fitted full to the foot. What is called "close" fitting, i.e., bringing the shoe rather within the circumference of the wall, is injurious, as it loses the best and strongest bearing of the wall, and permits the farrier to give an appearance of neatness by rasping away any horn which protrudes beyond the shoe. On a well-shaped foot, the shoe should follow the outer line of the hoof from toe to heel, but where the heels of a foot are turned inwards, there is an advantage in fitting the shoe wider at the heels, it is essential that the footsurface of the shoe should be level at the heels. If it be inclined, as it often is in seated shoes, a very grave defect in the fitting results, for the heels have no level bearingsurface.

A shoe fitted too wide is liable to be trodden off by the opposite foot, or it may cause the horse to hit the opposite fetlock joint. To guard against a shoe being trodden off, when it protrudes beyond the wall, the upper edge should be rounded either by the hammer or by the rasp. Where a portion of the wall is broken away a fullfitted shoe is not covered by the hoof and a sharp border or edge is visible. This looks ugly and affords a lodgment upon which the opposite foot, or even another horse's foot, may rest and tear off the shoe. Before a shoe is nailed on, this protruding edge should be rounded. The same attention should be given to the extremities of shoes fitted wide at the heels - as are heavy cart horse shoes. Heavy horses require a firm basis upon which to stand, and as they are not used at the faster paces there is not the same need of fitting shoes very close at the heels. The narrower the heels the less the firmness of base afforded by a shoe and, therefore, the heels of these heavy shoes are properly fitted wide and the protruding upper edge must be rounded off or " boxed up." This is done with the hammer and finished with a rasp. When calkins are used it is even more necessary to fit wide at the heels 
consequently to round off the upper edge from the quarters backward.

Provided the nail-holes are properly punched, they are brought to their right position when the outside border of the shoe is fitted nicely to the circumference of the hoof. When nail-holes are placed too near or too far from the outer border of the shoe-i.e., when they are too "fine" or too "coarse" - it may be necessary to correct their position by fitting the shoe "closer" or "fuller," as the case may be. When a farrier fits shoes made by another man he may overlook this, as we are all slaves to habit. The man who in his daily practice combines "close" fitting with "fine" nailing has to alter his routine when fitting a shoe with coarse nail-holes.

The length of a shoe at the heels is a matter of more importance than is generally recognised. As a rule, hunters are all shod too short, while most cart horses are shod too long. The objections to a long front shoe are that it is liable to be trodden off by the hind shoe, and that it may injure the elbow when the horse lies down. A long hind shoe is free from both these disadvantages, and as it usually has a calkin, is the best form to adopt.

In fitting the heels of front shoes, in all but galloping horses, the iron should generally extend slightly behind the extremity of the horn. (Fig. 70.) Horses used for galloping should have the end of the shoe just within the termination of the horn, and it should finish with an oblique extremity. (Fig. 71.) There is nothing gained by

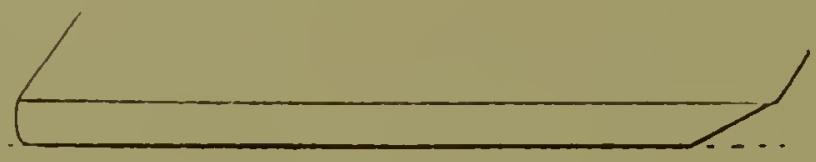

Fig. 7r.- Shoe fitted short at the heels.

greater shortening, if the iron be fitted exactly to the horn. Why shoes are often pulled off, when only just the length of the hoof, is because they are not fitted close 
enough, and very often because they are wilfully and mistakenly designed to leave a space between hoof and iron. This so-called "eased" heel is an unmitigated evil.

Surface-Fitting. - It is simple to direct that the bearing-surface of a shoe should be exactly adapted to the bearing-surfaee of a foot. It is not so simple to earry out. When the holn of the lower surfaee of a foot is thin, any uneven pressure-i.e., pressure applied directly to one spot-soon eauses injury, pain and lameness. When a good thick layer of horn exists, uneven pressmres are less injurious, because the horn distributes them over a wide surface. Good workmanship is displayed by leaving no uneven pressure, and by so fitting a shoe that it shall do no harm. With a narrow shoe-one only the width of the wall-no uneven pressure can be applied to the sensitive foot, but such a shoe is seldom used, as it is too light to afford sufficient wear. A wide shoe with a flat foot-surface is easily fitted on all concave feet-i.e., on all hind and most fore feet. To make use of the whole bearing-surface, a shoe must rest evenly from toe to heel-the flat surfaee of the shoe must take a lcvel bearing on the whole flat bearing-surface of the foot.

There are two plaees where injury from uneven pressure is most likely to happen-at the toe and at the heels.

In preparing a foot, the wall at the toe may, from want of care, be reduced a little below the level of the sole, or in making a shoe the inside border at the toe may be left higher than the outside, In each case, uneven pressure is placed on the sole just where the back border of the shoe rests. In fitting a hot shoe, wherever the hoof is unduly marked, warning is given that pressure at that point must be prevented by altering the surfaee either of the shoe or the foot. On a strong foot, the knife may be used to remove a little horn ; on a weak foot, the alteration must be on the shoe. 
At the heel, uneven pressure is most frequent on the angle of sole between the wall and bar, where it causes the so-called "corn" - a condition in the horse having no analogy to the affliction similarly named in the human subject. It is simply a bruise of the sensitive parts under the hoin.

A bruised heel-a corn-is most likely to arise from the use of a shoe too short, especially if fitted too close. It may arise from a properly-fitted shoe retained too long on the foot and shifted from its proper bearing on the wall to an improper bearing on the sole. A bruised heel may also result from the use of a well-made shoe if the preparation of the hoof has been faulty. Rule-of-thumb directions to "reduce the heels to a level by the use of the rasp, but on no account cut away any sole," may result in injury. In a strong foot with an overgrown sole it is easy to get a level surface and to fit on to it a level shoe, but the horn of the sole does not remain level. As it grows and flakes off, the portion between the bar and wall is raised. If the weather be wet it swells, and then, bound down by the shoe, it acts simply as a stone might, and bruises the sensitive parts within by its uneven pressure. It is always safe and it is never injurious to remove so much of the surface of this portion of sole with the drawing-knife as will ensure no uneven pressure on it by the shoe.

The more exactly the shoe fits the foot-surface the more easily it is retained in position by the nails, and the less likelihood there is of any part of it pressing unduly on a limited portion of horn. Exact fitting allows all bearing and pressures to be distributed equally over the surface of the hoof, and thus permits the shoe most nearly to resemble a mere continuation of the hoof in iron-an arrangement to prevent wear, but not to interfere with the natural functions. There is one departure from level fitting which requires special notice, since it is made, not by accident or negligence, but by design. It consists in taking the bearing of an inch, or an inch-and-a- 
half, of the extremity of the shoe off the foot. (Fig. 72.) It has been called "easing the heels," and the space permits a knife-blade, sometimes even a pencil, to be placed between the shoe and foot. It is one of the very worst practices that theory has forced into horse-shoeing. Men who do it say " the heels won't stand pressure." I

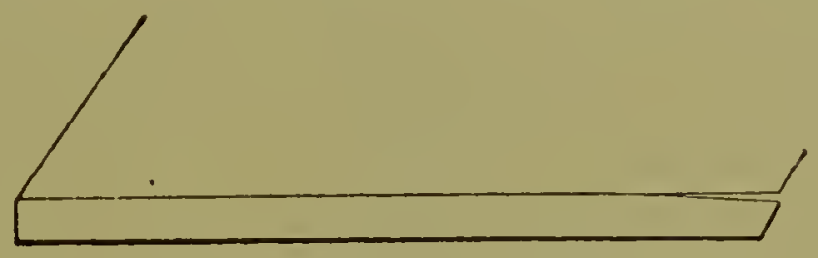

Fig. 72.-An " eased" heel.

reply they will stand all proper pressure, and a good deal more than the quarters. But the practice does not relieve the heels of pressure. If you examine a shoe fitted in this way, after it has done a month's service, you will find it sometimes polished bright, sometimes with a deep groove worn into it. You may also test its bearing by raising the foot from the ground and inserting between shoe and hoof a flat bit of wood, then on releasing the foot and raising the opposite one, you will find that the bearing is such that the bit of wood cannot be removed. The "eased heel" does not relieve the heels of pressure, but, instead of constant normal bearing, it permits a downward movement of the back of the foot at each stepwhich is unnatural, and which cannot occur in an unshod foot on a level surface. The "eased heel" does more than this. It wastes a large extent of good bearing-surface, and it concentrates pressure at one point-where the shoe and foot meet-at the quarters. It loses good bearing-surface where it is important to have it, and unevenly throws extra weight on the quarters, which are the weakest parts of the wall. An "eased heel" has not one single advantage, but it has every disadvantage which misplaced ingenuity could contrive.

For flat feet, a wide shoe with a flat foot-surface is unsafe, as there is liability to uneven pressure on the 
sole. For such feet, the safer form of foot-surface is one presenting a level narrow bearing-surface round its outer border, from which an inclined or bevelled surface continues the shoe inwards. (Fig. 73.) This for'n of shoe

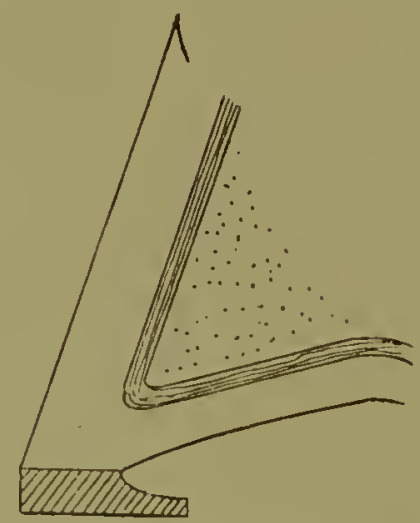

Fig. 73.-Section of a seated shoe.

can be fitted to nearly any kind of foot. To escape injury to a flat sole, "seating out" shoes is necessary, but the operation should always leave a level bearing-surface for the wall. When a shoe is seated from one sido to the other so as to produce a saucer-shaped surface, harm is done to the foot. Such a shoe presents no level bearingsurface, and the weight of the horse pressing the wall on an inclined plane causes the foot to be pinched or compressed in a inanner which soon causes lameness. (Fig. 74.) A few years ago, these shoes were too common, and to make them still inore injurious, the foot was pared out from the centre to the circumference like a saucer, and the two spoiled articles were fitted together. Their surfaces of contact were two narrow ridges, which even the most expert workman could not fit without injury to the horse.

In Fig. 74, a shoe with an inclined surface is applied to a foot with a bearing-surface as wide as the wall, but the only contact is at the edges. The horn at the edge will yield, and the hoof be pressed inwards, as the weight of the animal forces the foot into the saucer-shaped shoe. 
When the bearing-surface of the foot, instead of being as wide as the wall, is only a ridge, the horn yields most rapidly, the clinches rise and the shoe becomes loose.

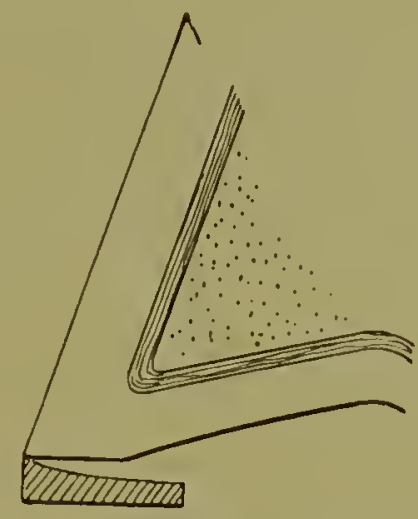

Fig. 74.--Section of a "saucer" shoe.

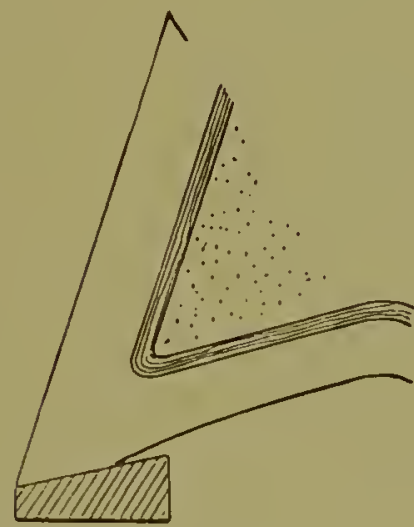

Fig. 75.-Bearing-surface inclined outwards.

In Fig. 75 is shown a section of another shoe with an inclined instead of a level surface, but the slope is fiom within outwards. The effect of this is exactly the opposite of the previous shoe. The wall is forced outwards, and if it does not as a whole yield to the pressure, the portion in contact is broken. When this form of bearingsurface is adopted at the heels of a shoe, the two side of the hoof are violently forced apart, and it has even been recommended as a means of expanding the 
foot; but forcible expansion is both unnecessary and dangerous.

Always regarding the shoe as an extension of the natural hoof in a harder and more durable material, it is evident that the most stability will be attained by the use of as wide a bearing-surface of foot and shoe as is compatible with ease and safety to the horse.

In Fig. 76 is shown a section of a narrow shoe which takes a bearing over the whole extent of its foot-surface.

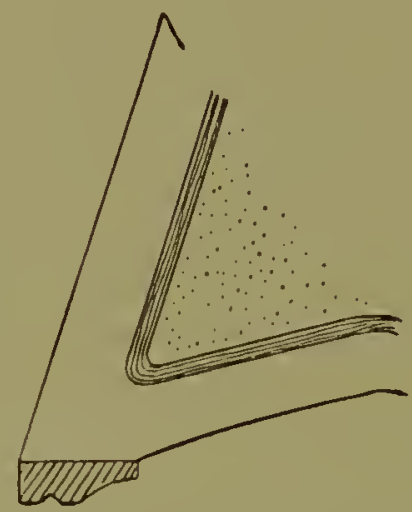

Fig. 76.-Narrow shoe with level bearing-surface.

In Fig. 77 is shown a shoe with as wide a bcaringsurface as in Fig. 76 , but which loses half its bearing because the foot-surface is too narrow to utilize it.

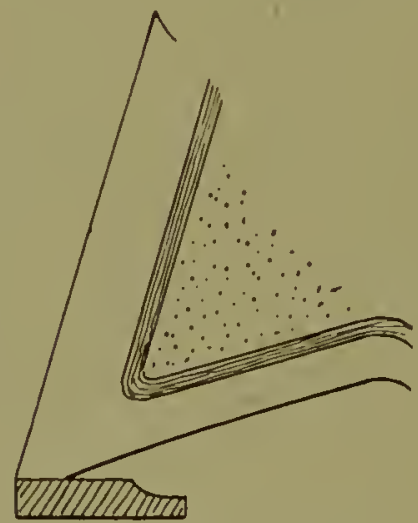

Fig. 77.-Bearing-surface of foot too narrow.

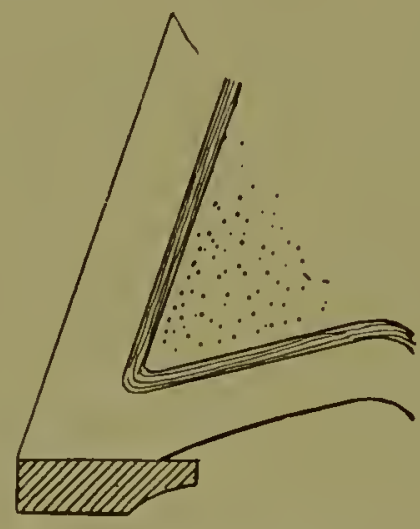

Fig. 78.-A good bearing surface.

In Fig. 78 we have a model bearing-surface on the foot, nearly twice the width of the wall, and we have a. 
sloe with a flat foot-surface capable of using the whole bearing. Such is the fitting of all hind shoes, and it might be adopted with advantage in all fore sloes on grood feet.

Wear of Shoes. Before fitting new shoes a good firrier notes all peculiarity of wear in the old ones. When a horse wears his shoes equally all over, there is evidence that his feet are in proper proportion and that the form of shoe is suitable. Irregularity of wear is noticeable on very many shoes and may be traced sometimes to faults in the action of the horse and sometimes to faults in the shoe or foot.

A horse that "goes on his heels" - a cormmon sequel to laminitis-wears the heels out of all proportion to the rest of the shoe. To meet this excessive wear a farrier often increases the thickness of a shoe at the heels. This is the very worst thing to do. The hoof at the heels should be lowered as much as safety will allow, and the shoe should be fitted a little longer than the bearingsurface of the foot. When the toe of a shoe shows

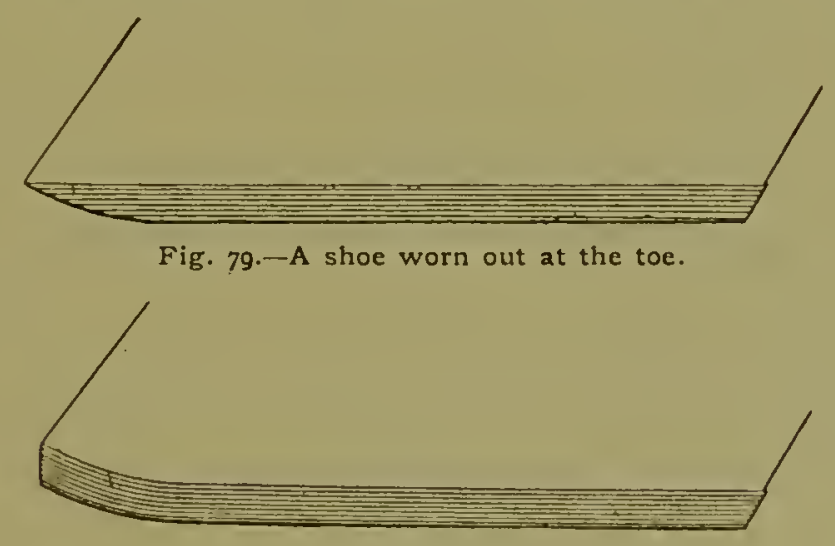

Fig. 80.-A shoe turned up at the toe.

excessive wear it may be due to the callins being too high, and if so their height must be decreased. It nay be due to the toe of the hoof being too long, and it may be the result of defective action of the horse. In any case it is not good practice to simply increase the anount of 
iron at the toe so as to make the shoe last longer. The toe of the shoe should be turned up out of the line of wear. In other words the toe of the shoe should be so fitted that its foot-surface resembles the worn surface of the old shoes. 'This requires that the hoof should be lowered, not in the usual way leaving a level bearing from toe to heel, but by an extra reduction of hor'l at the toe to an extent required by the bending upwards of the shoe. (Fig. 80.)

When one side of a shoe is more worn than the other the hoof must be reduced on the side showing excessive wear, and the shoe be fitted a little fuller.

To provide for a proper druation of shoes and to prevent too frequent re-shoeing, it is best to increase not the thickness of a shoe but its width, especially in those cases where wear is mainly confined to one part.

Clips are thin projections drawn up from the outer border of shoes for the purpose of giving greater security to their position on a foot. On heavy cart-horses, the clips are sometimes of great size, and encourage the idea that the smith looks upon them as designed to assist the nails to retain the shoe on the foot. They should have no such purpose, their use being merely to prevent the shoe shifting to one side. A clip should not be narrow and high, it should be low and wide, so that its bearing is taken against the lower edge of the wall. A high clip is a most serious danger when shoes get loose and are trodden on by the horse. The usual position for a clip is at the toe, but there are occasions when two clipsone at each side of the toe-are used. On some shoes, a clip is placed at the outer quarter to prevent the shoe being displaced inwards; this is more often required on hind shoes. A clip at the toe affords some assistance in fitting a shoe exactly, and it also affords steadiness to the shoe during the driving of the first nails. In America chips are not used, and when American machine-made shoes were first introduced into London 
they were fitted without clips. I am bound to confess that these shoes did not shift on the feet to any noticeable extent, but they are now all fitted with clips, so I suppose the workmen found they were an advantage. The greatest cvil resulting from clips is seen in slovenly fitting, when the farrier with his knife carves out a great hole in the wall in which to imbed the clip. As a clip is flat, it cannot be fitted to the rounded face of the wall, but all that is necessary is to reduce the round to a flat surface with the rasp, so that the clip may rest on it, care being taken that at the extreme edge the horn is not left so prominent as to be unduly pressed upon when the clip is driven close to the wall. It is easy to lame a horse by violently hammering up the clip, especially when the horn behind it has been so much cut away as to leave only a thin protecting layer. A clip should only be hammered up sufficiently to leare it firmly applied to the wall. A bad workman, in making his clip, may spoil the footsurface of a shoc by causing a ridge on the bearingsurface of the iron at the toe, and this, on thin or flat feet, may cause lameness.

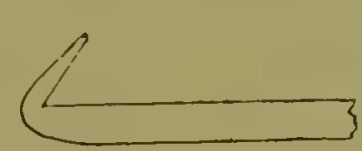

Well drawn clip.

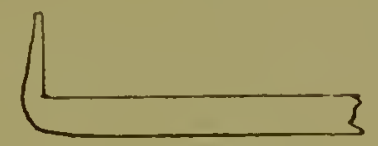

Fig. $8 I$.

Badly drawn clip.

A very unsightly appearance and very defective work results from the fireman leaving his clip at right angles to the line of the shoe. It should be inclined backwards at about the same slope as the portion of the wall against which it is to rest. The two diagrams (Fig. 81) illustrate what is meant.

Hot and Cold Fitting.-When an engineer or a carpenter has two surfaces to fit together with great cxactness he employs some coloring material to slow where they do come in contact and where they do not. When a farrier fits a shoe to a horse's foot, he tests its 
accuracy by applying the iron at a dull red heat to the horn. This proceeding shows with precision the bearing-surfaces, as the horn is charred in proportion to the contact. If the shoe be found not to fit exactly, it is taken back to the anvil and altered. It is then again for a few seconds applied to the horn and the surfice of contact examined. This proceeding is repeated until sufficient exactness is arrived at, and then the shoe is cooled ready for nailing on. As horn is a bad conductor of heat, this process of "hot-fitting" does no harm to the sensitive structures within the hoof, unless it be carried to an extreme. When the horn is very thin, the heat of a shoe retained too long in contact with it does serious mischief, and the injury known as a burnt sole has often resulted from careless work. If a shoe, whilst being altered to fit a foot, were cooled each time it was laid on the hoof, it would have to be re-heated before the necessary alterations could be made, and this would cause great waste of time. The abuse of hot-fitting may do harm without any direct burning of the sole. An ill-fitting hot shoe may be held on the hoof until it beds itself into the horn, and thus a complete correspondence between the surface of the foot and the surface of the shoe be affected. Such a proceeding is well described as "fitting the foot to the shoe," and is not only destructive to the horn but damaging to the foot, by permitting an uneven shoe to look as though it were properly fitted. When hot-fitting is used and not abused-when it is adopted merely to indicate how and where the shoe fits, and not to inake it appear to fit-I consider it has many advantages over cold-fitting. With some feet and some shoes it is quite possible to produce a good fit without heating the shoe. When a shoe requires much alteration to bring it into exact correspondence with the foot, even the most expert farrier cannot do justice to his work with cold iron; he gets as near to a fit as he can, and when the hoof is strong, little harm is done. The best work is that which includes the greatest exactness of fit, while uneven pres- 
sure or loose shoes result from inferior work. A badly fitted shoe requires more nails to retain it in place, and experience has shown that hot-fitted shoes give a smaller average of loose or lost shoes than those cold fitted. The slight charring of the end of the houn fibres, which results from proper hot-fitting, has never been found to do injury, and it apparently has some advantages. One is that the surface of the hoof less readily absorbs moisture than when not charred. Another is that the hom is softened for a time and expanded, allowing nails to be easily driven, and then contracting and retaining them more firmly. The objection to hot-fitting applies only to its abuse. The advantages are greater exactness of fit, greater security that the shoe will be firmly retained on the foot, and greater facility in the operation of shoeing. Perhaps I ought to add that when cold-fitting is inevitable, machine-made shoes are the best, because they are more regular in forn and more often level on the footsurface than hand-made shoes. Army studs on active service, and studs used in coal mines comprise, perhaps, the only animals upon which cold-fitting is unavoidable.

Tips re short shoes protecting only the foremost half of the font. Upon grass or soft roads, tips are quite

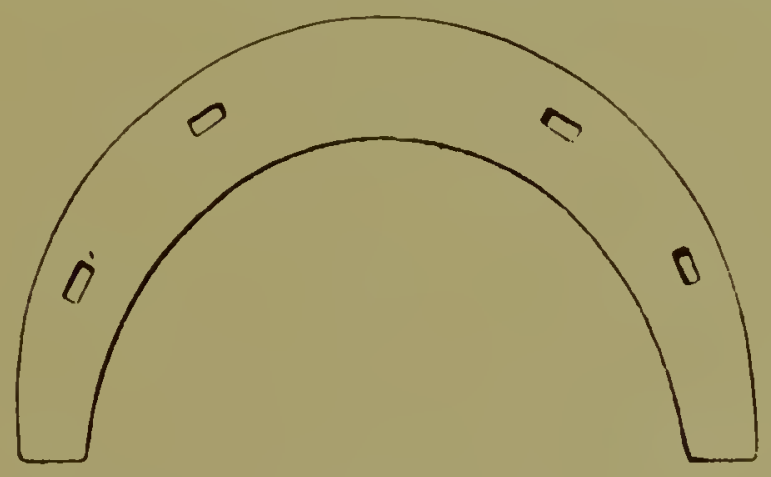

Fig. 82 .

sufficient to prevent undue wear of the hoof. Fven upon hard roads tips will protect the hoof in dry weather, but in wet seasons the horn becomes softened, and then that part coming in contact with hard road-surfaces wears 
rapidly, and lameness may follow. Tips require more care in use than shoes, because they protect from wear only the toe, and when retaincd on the foot ton long a time

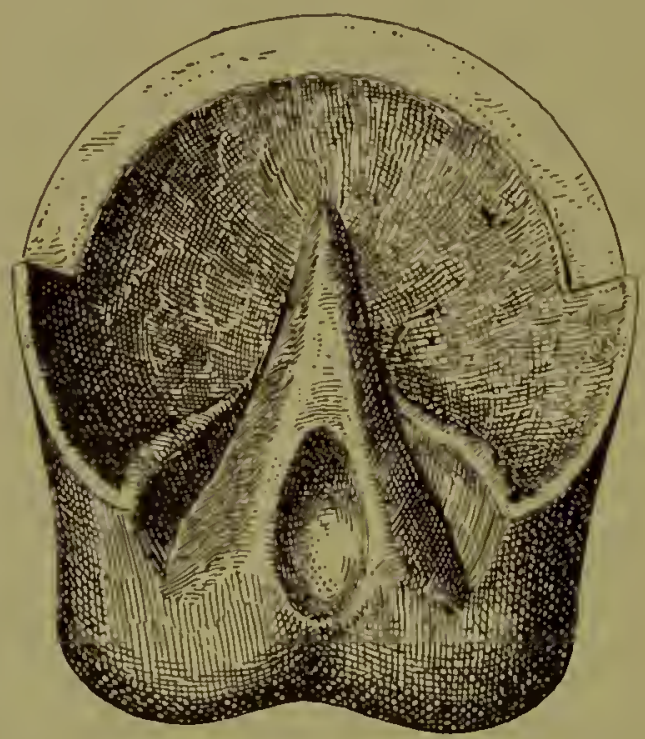

Fig. 83... Foot prepared for a tip.

cause the hoof to become very disproportionately long at the toe. In fitting a tip, care must be taken to afford the horse a level surface to bear on. The unprotected horn at the back of the lont must take a bearing on the ground

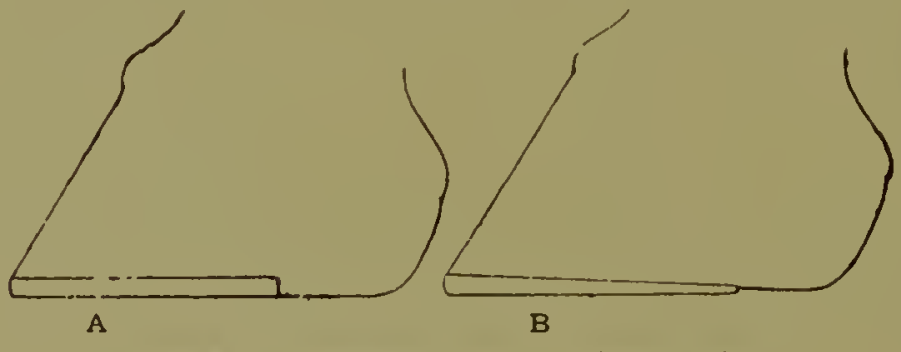

Fig. 84.-An ordinary and a "thinned" tip.

level with the ground-surface of the tip. (Fig. $84 \mathrm{~A}$ ). If there is sufficient horn on the foot, this can be easily effected by only removing the overgrown wall to just the length the tip extends and leaving the horn behind untouched. Where there is not sufficient superfluous horn, this method cannot be used, and we apply a tip gradually thinned off towards its extremities. (Fig. 84 B.) If a 
little hor'n can be removed obliquely from the front half of the foot by a lew strokes of the rasp, this "thimned" tip is mole easily fitted so as to get a level surface on the gromel. When a holse has worn this form for a month, it is generally possible to bring a tip, of even thickness thronghout, into the same line of bearing as the horn at the heels.

'Tips do not give a good foot-hold on grass, but they afford greater security of tread, on hard smooth roads and on ice, than long shoes. The great advantages of tips are two-fold-they me light, and they permit the greatest freedom of movement and action in the posterior part of the foot. In some cases of chronic foot lameness the use of tips and regnlar work will effect soundness when every other method of treatment has failed.

The Charlier System is a method of shoeing which a few years back took a very prominent hold on the fancy of hol'se-owners. Like most other systems it has advantages

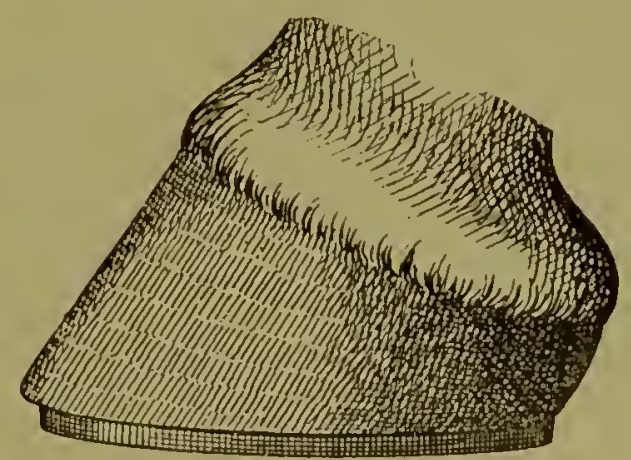

Fig. 85.-Groove for Charlier shoe formed by cutting away strip of wall.

and disadvantages - it has prejudiced enemies and indiscreet friends. 'The principle or theory upon which it is based may be thus stated. The lower border of the wall is it is said, the chief sustaining structure of the hoof, and as all that is required of a shoe is to prevent undue wear, therefore, remove a small strip of the lower border of the wall and substitnte for it a similar sized strip of iron, and we shall protect from wear at the same time that we leave entirely to natrre every other part of the hoof-sole, frog 
and bars. This seems eminently simple and logical, but it is easy to show that it is more plausible than true. First, I would point out that the wall only is not the natural sustaining structure of the hoof; the wall and the sole at its connection with the wall is. Next, I deny that the Charlier system does "leave entirely to nature every other part of the hoof." In cutting away the wall from the sole

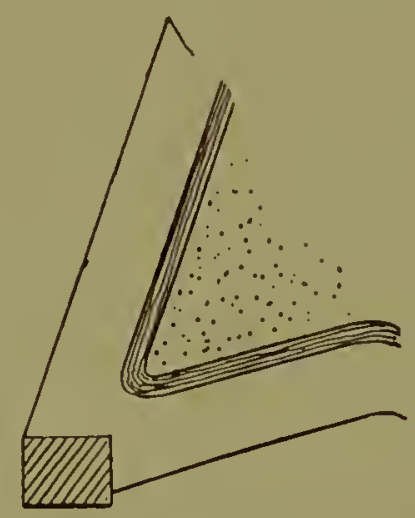

Fig. 86.-Section of Charlier shoe on foot.

to affix the shoe, the natural function of the sole is seriously interfered with, and the bearing on the wall, which ought to be partially distributed over the arch of the sole, is limited to the wall. It is claimcd that when the foot has had time to grow, the sole will be found on a level with the shoe, and thus directiy sharing in the weight sustaining function. I have examined many feet shod by Charlier specialists, and have never yet seen the sole of a hind foot level with the shoe three days after the shoeing. Only once have I seen the sole of the fore foot level with the shoe after a week's wear. I am often apologetically told, "Well, it is not quite in wear, but it is not an eighth of an inch below the surface of the shoe." Quite so, it is nearly in wear, but if not actually in wear, what becomes of the principle? The sole is not directly in wear, and bearing is confined to the wall. As to the frog, the Charlier affords no greater use to it than any other shoe of a sinilar thickness, unless, instead of being placed on sound, firm hom, it be danger- 
ously let down into the hoof so that its edge approaches very closely to the sensitive foot. It is sometimes difficult to arrive at the truth as to the significance of the phrase "embedding or letting down" the shoe of the Charlier system. At one time we are assured that "the shoe is not sunk, the sole is permitted to grow up." When this is so, very little positive objection to the system can be taken, because the shoe then rests at the same level on firm horn as does any other narrow shoe; but then the frog takes no better bearing than in other systems, and the superfluous growth of horn on the sole is of no value. When the shoe is really "let down" of course the frog does receive increased pressure-it is forced to share with the wall the primary function of sustaining weight instead of, as in nature, taling only a secondary share of such action. It does this at the expense of a shoe placed so close to the "quick" that if the upper and inner border of iron be not bevelled off, immediate lameness results.

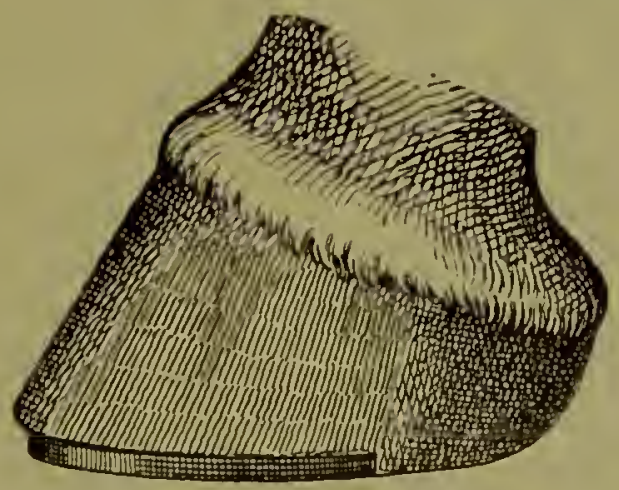

Fig 87.-Groove for modified or short Charlier

When the Charlier shoe was first introduced, it was applied the full length of the foot, but it was found that when thinned by wear, the heels spread and led to injury of the opposite leg or to its being trodden off. Now the Charlier is only applied like a tip round the front portion of the surface of the foot, and it therefore partakes of some of the advantages I have credited to tips. It is a very light shoe and only requires small nails to fix it securely, but as the shoe 
is only the width of the wall, the nails have to be driven solely in the wall, and their position is open to the objection applying to all too fine nailing. The disadvantages

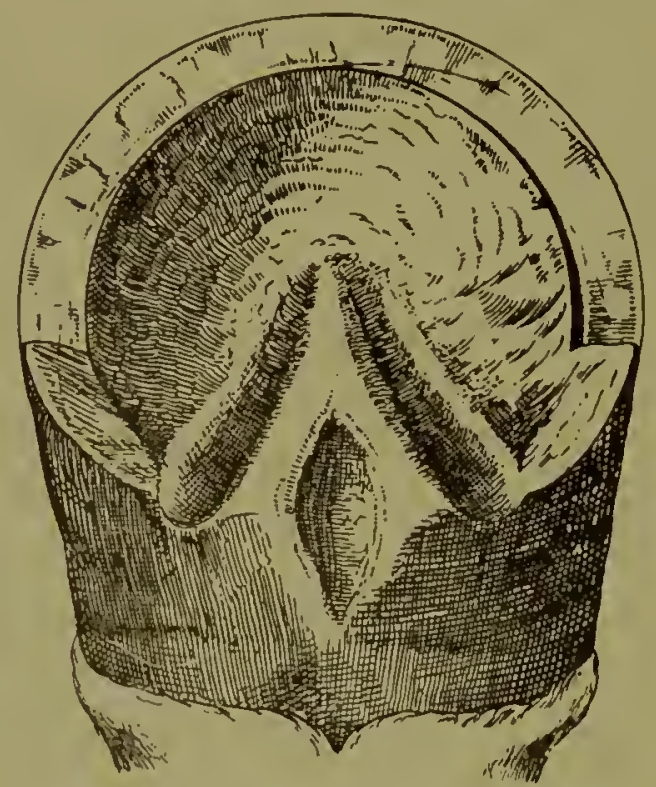

Fig. 88.-Foot prepared for short Charlier.

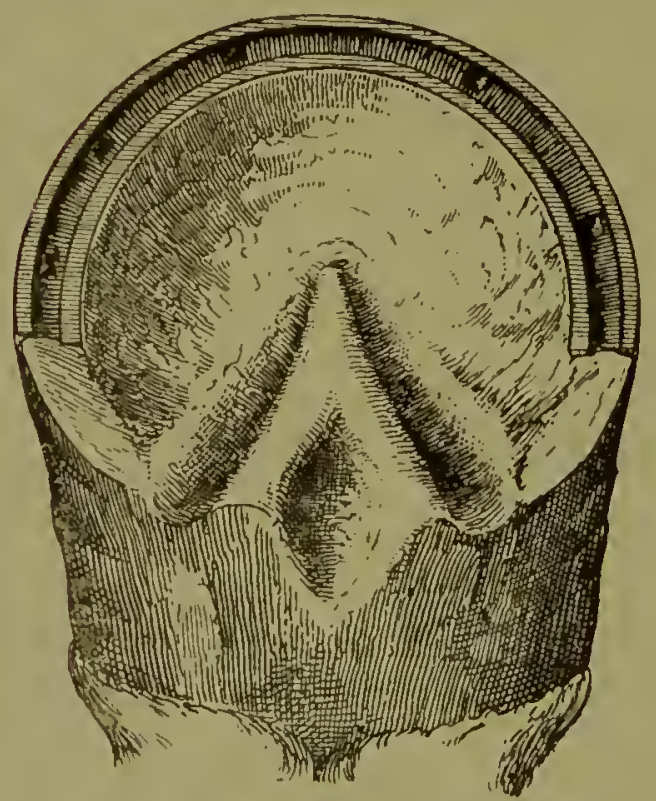

Fig. 89.--Short Charlier Shoe.

of the Charlier are its being "let down" too near the quick, its limited bearing, and its fine nail holes; the advantages are the lightness and the freedom given to the 
back of the foot, both of which are attainable with a narrow tip not let down. One very apparent effect resulting from the use of the Charlier system is the alteration in the action of the horse. All knee action is lost, and some lorises go decidedly tender, whilst others acquire a low shooting stride, which is certainly not in accordance with our notions of good free locomotion.

Nailing on Shoes. When a shoe has becn fitted exactly to the foot it is finished off with a file. Fiven the best hammer work can be improved by a few strokes of the file round the clip and heels and along the edges of a shoe. Very inferior work can be made to pass a casual inspection by liberal filing. A shoe is fixed in a vice for the purpose of being filed, and light shoes are sometimes twisted out of shape. It is most important that after such an accident the shoe should be refitted before being nailed on.

When a shoe is well fitted by the fireman, a doorman has no reason to alter the foot in any way before nailing on the shoe. In most cases a stroke of the rasp may be given to the front of the toe to remove a bit of charred horn, but on no account should more be done. It is obvious that any removal of firm horn from the toe, after fitting has been completed, permits the shoe to be placed further back on the foot, and thus the exactness of fit is destroyed, and the relative position of nail-holes to the wall modified-perhaps dangerously.

The fitted and filed up shoe when laid on the foot by the doorman, should rest evenly upon the whole bearingsurface. The borders of the shoe should follow the circunference of the wall, the heels be of proper length, and the nail holes in sucl a position as to admit of nails being safely driven into sound horn. No nail hole should be within the whitc line that marks the junction of solc and wall.

The doorman having satisfied himsclf that the shoe fits then sclects suitable nails. If the nail holes arc proportionatc to the foot there is no difficulty, but when they arc 
too large or two small the question arises-how the nail head is to fit the nail hole at the same time that the hoof is penetrated by a shank which will not split the hom or fail to give a secure clinch? If the head be ton small for the hole the nail cannot be firmly clenched, whilst if it be too large it protrudes, and when worn off has no hold of the shoe. Except in the case of a very thin wall it is better to select a nail that more than fills the nail-hole rather than the opposite. With a good fuller or stamped nail holes the head of a nail should always protrude a little when driven home.

Driving a nail is a delicate operation only to be mastered by practice. Its direction through the horn is governed by the point and by the fingers of the farrier. Its direction is indicated by the sound and feel transmitted by the taps of the hammer, and its exit should be felt by the fingers of the left hand before it appears. By these practical signs a farrier knows where his nail is going and is able to bring out the point at a proper height. Although an expert workman may safely drive a nail very high in the wall, there is danger in doing so, and no advantage. On the other hand there is a disadvantage in not taking sufficient hold-more chance of splitting the wall and less security for the shoe. The toe nails may be driven a little higher with safety than the heel nails. When all the clinches are of the same height from the shoe a neat appearance is given, but I prefer to see a slight diminution of height from before backwards-from the first toe-nail to the last heel-nail. Driving the first nail has a tendency to move the shoe from its bed across the foot, this must be guarded against, and a nail on the opposite side should next be driven to counteract this tendency. If necessary, a tap or two with the hammer on the side of the shoe may be given to keep it in its exact place. Each nail as it is driven through the wall should have its point turned down against the horn so as to avoid the possibility of accident to the workman or injury to the opposite leg of the horse. When all the nails are driven 
and the points cut off with the pincers, the whole are r'un over with the hammer and then each is "clinched." A clinch is formed by a blow or blows on the head of the nail whilst the edge of the pincers is pressed against the turned down point of the nail. Under the clinch a notch is made in the surface of the wall with the edge of the rasp. Into this notch the clinch is laid and a stroke of the rasp renders the clinch level with the horn. A clinch buried and filed in this manner is stronger and safer than when merely turned over on the hor'n.

Clinches rise and shoes get loose (a) when the shoe rests upon a bearing-surface so weak or narrow that the horn yields; $(b)$ when nail-heads do not fit the nail-holes; (c) when, instead of a notch being made in sound horn for the clinch, the end of the nail is turned over on the broken horn caused by the exit of the nail.

If the position of a nail-hole is so coarse as to render driving a nail through it dangerous, the nail should be left out. If a nail-hole corresponds to a crack in the hoof the nail should not be driven. Some feet are so broken that the shank of the nails can be seen above the shoe and yet sufficient hold of sound horn higher up be obtained to afford security for a shoe. 


\section{Chapter Vili. \\ "Roughing."}

In winter, ice, snow and frost render roads slippery, and it is necessary to provide some arrangement whereby horses may have the greatest security of foot-hold. In countries such as Canada and Russia, where a regular winter sets in at a tolerably uniform date and continues without intermission for some months, it is easier to adopt a good system of "roughing" than in Great Britain. There, on a thick layer of ice or snow, sharp projections on the shoes cut into the surface and afford foot-hold. The edge of the projections is not soon blunted, and when once properly placed, their duration is as long as the time desirable for retaining the shoe. Here, very different conlitions obtain. Sometimes a week or two of frost and snow may prevail, but more frequently the spells of wintry weather are counted by days. Two or three days of frost and then two or three days of mud and slush, to be followed by either dry, hard roads or a return of ice and snow, is our usual winter We require during this time to provide for occasional days, or more rarely for weeks, of frost-bound roads. Our horses' shoes wear about a month and then require replacing by new ones. When roads are hard and dry, we want no sharp ridges or points about our horse's shoes, and yet we must always be able at twenty-four hours' notice to supply some temporary arrangement which will ensure foot-hold.

The necessity for "roughing" and the evil effects of continuing to work unroughed horses on slippery, frostbound roads is demonstrated in London every winter by a very significant fact. If, after three days of ice and snow, anyone will vist a horse-slaughterer' yard, he will find the place full of dead horses which have fallen in the 
streets and suffered incurable or fintal injury. A sudden and severe attack of ice and snow hall paralyses the horse traftic of a large town for a day or two, and many owners will sooner keep their horses in the stable than go to the expense of having them roughed. The loss in civil life from unpreparedness for ice and snow is very serious, but the loss which has fallen upon military movements from similar neglect is appalling. Napoleon's rout from Hoscow in 1812, Bourbaki's flight into Switzerland in 1871, and the Danish retreat during the Schleswig-Holstein war in 1865 are terrible instances of the frightful loss sustained when horses are unable to keep on their feet at a walk, let alone drag guns and wagons over an icecovered surface.

A well-managed stud of horses which is required to face all weather and to work every day through an English winter should, from December 1st to March 1st, be shod in such a manner as to be easily and speedily provided with mechanism which will afford secure foot-hold. This may be effected by the use of movable steel "roughs" or "sharps." Of course the cost is the argument against them, but this should be considered in view of the probability or certainty of loss which will follow from neglect. If we allow common humanity to animals to enter into the consideration, economy will be served by adopting a well arranged system of roughing. Every good horseman appreciates the enormity of over-loading, but neglect of roughing causes just as much cruelty. A horse that on a good road can properly draw a ton would be considered over-loaded with two tons, and his struggles to progress would at once attract attention. The same animal with half a ton on an ice-covered surface would suffer more exhaustion, fatigue and fright, and run more risk of fatal injury than in the case of the over-loading, but his owner, who would indignantly repudiate the one condition, will designedly incur the other. Prohably this is only thoughtlessness, but it is a reflection on the prudence of a 
manager, and certainly not flattering to the feelings or intelligence of a man.

There are many ways of providing foot-hold for a horse on ice and snow. The most simple and temporary proceeding is to use frost-nails. Fig. 90 shows various sizes and shapes of these articles.

They are not driven through the hoof like ordinary nails, but through the shoe only, which is prepared for their reception at the time of fitting. A shoe to carry frostnails is fitted a little wider than usual at the heels and has at its extremities, or more often at its outer extremities, countersunk holes stamped and directed outwards, so that the frost-nail can be safely driven through by anyone, and its shank turned down over the shoe. There is a difficulty
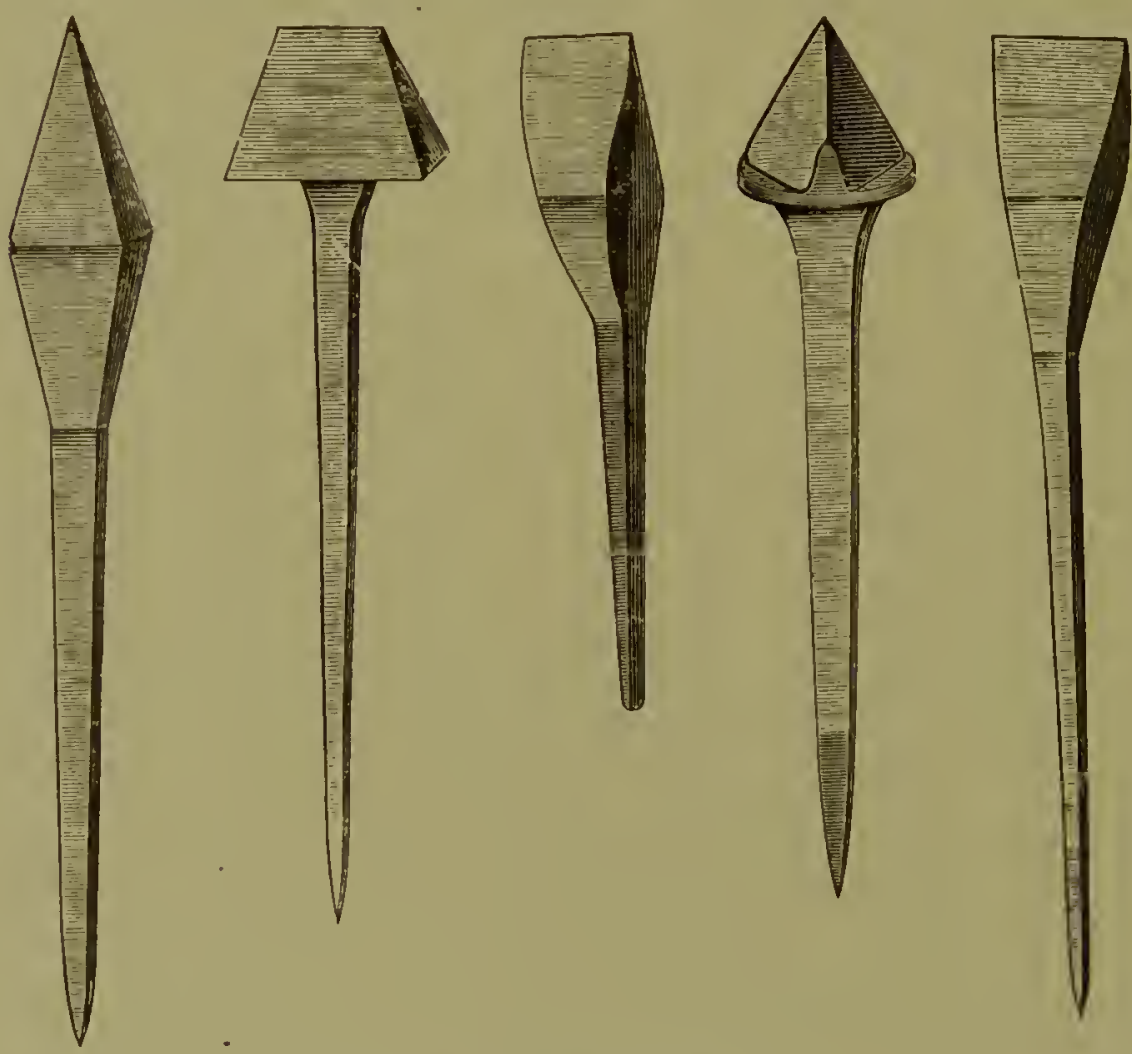

Fig. 90.-Various frost-nails.

in firmly securing them, they are apt to work loose and then become bent and useless. If used on the inside heel of a shoe, they constitute a danger to the opposite leg, 
should they bend and protrude from under the shoe. As a temporary provision against a sudden frost or fall of snow, they are useful, bnt they are only a malie-shift.

'The nore permanent and effective system of " loughing " consists in removing the shoes and turning down is char'p chisel projection at the heels. In very bad weather, a projeetion edge is also laid across the toe of the shoe.

The diagrams show the method of "sharping" a front and hind shoe at the heels only. The hind shoe, having callins, is not much altered. The smith simply eonverts the squarc calkin into a sharp-erlged one. 'The fore shoe, having no calkins, is turned down at the heels to afford enough iron to form the "sharp." But this shortens the shoe, and if it be repeated two or three times, as it often is, the bear'ing-surface is spoiled, and the slightest carelessness, in fitting the shoe eauses a bruised heel.
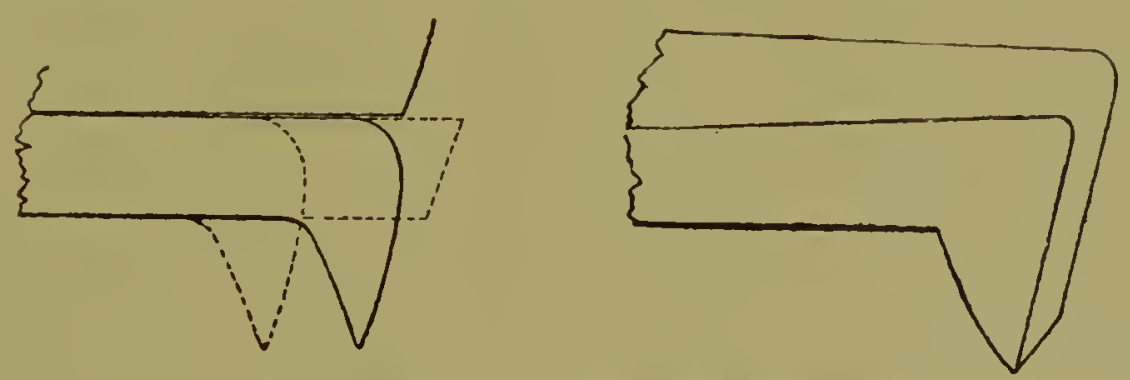

Fig. 9r.-Heels of fore and hind shoes, sharped.

"Roughing" is renerally done in a hul'y. A dozen hor'ses reaeh the farrier's shop at one time and all desire to return to work with as little delay as possible. The work is perforce hurried through, eareful fitting eamnot be done, and bad-footed horses suffer aceordingly. The dotted lines in Fig. 91 show the original length of shoe, and the shortening which results from a seeond roughing.

All horse-owners linow how many lame horses result from the repeated ronghings neecssitater by a week or two of wintry weather. Some of this is inevibable from the rush and hurry which cimuot be prevented. Valuable horses with weak feet should not be submitted to any 
such risk. They should be shod with renovable sharps. The mere fact of removing a horse's shoes perhaps five or six times in a month must injure the hoof. Add to this the shortening of the shoe, the raising of the licel by the roughing, and the irregular bearing due to hurried fitting, and we have conditions which only the very stongest feet can endure without serious injury.

For heavy dranght hor'ses, and for all where the roads are hilly, the toes as well as the heels must be "sharped" when ice and snow are fir'm on the surface. Fig. 92 shows this arangement at the toe. The remov-

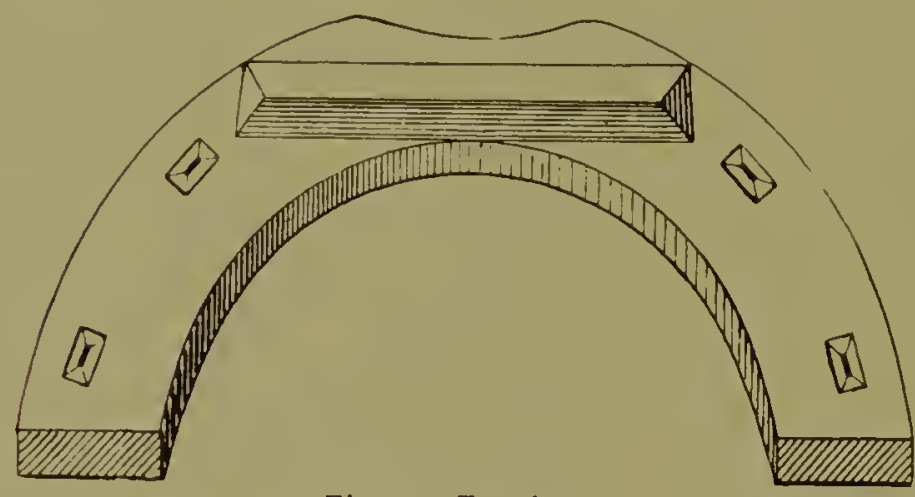

Fig. 92.-Toe sharp.

able steel "sharps," of which I have spoken, are certainly the least objectionable method of providing foothold in winter. They are made in various sizes to suit all kinds of shoes. They vary in shape somewhat, but their form is more a matter of fancy than utility. One

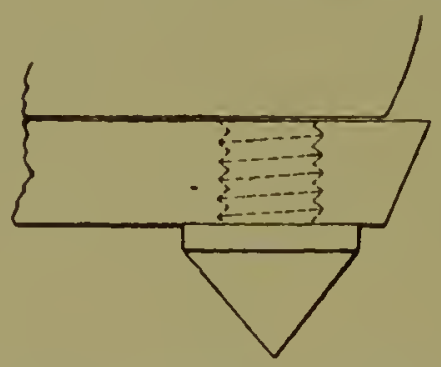

Fig. 93.- Removable steel sharp.

in each heel of a shoe is the usual number used, but if snow and ice are plentiful and the roads hilly, two additional "sharps" may be placed at the toe of the shoe. 
At the time of fitting the shoes, holes are made by first punching a round hole through the heels-and through the toe if desired ; then the hole is " tapped " and a thread formed to fit it to the shank of the sharp which is to fill it. If the sharps are not immediately wanted, the holes may be filled with corks to keep out the grit and dirt. When corks are used, the wear of the shoe causes a bur'r to form round the edge of the hole, and before the sharp can be screved in a "tilp" must be
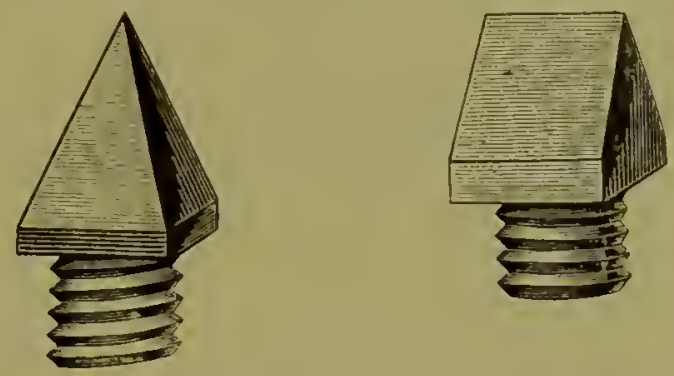

Fig. 94.- Steel sharps, screw.

worked into each hole to clear the thread. One great objection to this method is that as the shoe wears, it becomes thinner, and if much worn, the shank of the "sharp" may be too long, and when screwed home, cause pressure upon the hoof and consequent lameness. To guard against this, steel "blanks" are used to preserve the holes, and when a frost comes, they are removed and the "sharps" put in.
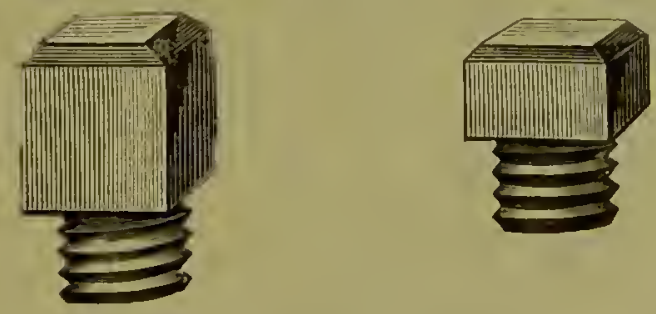

Fig. 95--Blanks, screwed.

'I'he blanks vary' in height, and, of course, those least in height are best for the horse's action, but they must not le allowed to get so wom that it is impossible to remove then. 
The "tapping" and "sclewing" of shoes is expensive, and in small shops nuust be done by hind. In lirge shops, a gas engine and a machine would reduce the cost very greatly, and if the systen canne into general use, this method of providing against frost-bound roads could

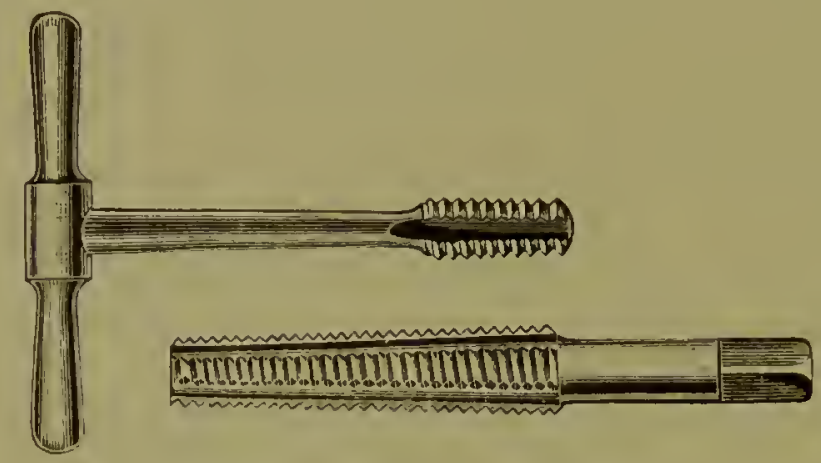

Fig. 96. - Steel Taps for screwing shoes.

be carried out at much less cost than now. With a view to economy and simplicity, a shalp has been invented which requires no screw. The shank may be either round or square. A hole is punched in the heel of the shoe and carefully gauged to the size of the shank of the "sharp." The sharp is then put in and a tap of the
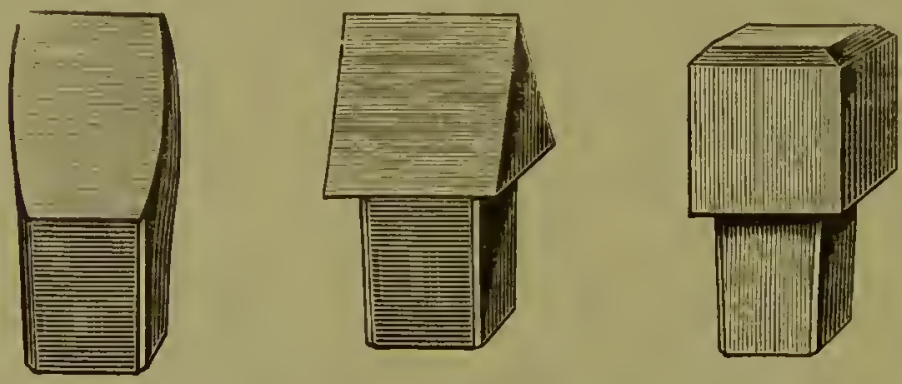

Fig-"97. Steel Sharps and Blank, Plug shanks.

hammer secures it. The difficulty is to get the hole in the shoe and the shank of the sharp of corresponding form and size. When this is done, the sharp lieeps its place and is not difficult to renove. Too often, however, they are not unilorn, and then the sharp falls out, or sometimes camnot be removed. When the holes are drillod instead of punched, the fit is nore exact, but this only applies to those with a round sliank. A slight taper 
is given both to the hole and the shank of the "sharp." As with the screw sharps, so with these, blanks are used to keep the holes open until the road-surface requires the sharp.

No shaps should be left in shoes when the horses are stabled at night, as serious injuries to the coronet may result from a tread by the opposite foot. The coachman or: horse-keeper must be supplied with a spanner to remove the screws, and with a tap to clear the holes if blanks are not used.

For roads not badly covered with snow and ice, sufficient security is afforded by some forms of india-rubber pads, which will be described in a future chropter. 


\section{CHATPRR IX.}

\section{INJURIES FROM SHOEING.}

Fren with the most careful firrier injury may occur during shoeing, or may arise as the result of the operation. Sometimes the foot, from its condition or form, renders an accident possible, and it may be so diseased, or defective, as to render shoeing with safety very improbable. Sornetimes the shoe is to blame, and sometimes the nail or clip. A few words about each of the common injuries may be uscful as helps to their avoidance or as guides to their remedying.

From Nails two kinds of injury may result. The most (onmon arises from the nail being driven ton near the sensitive parts, and is linown as a bind. The nail does not really penetrate the sensitive font, but is so near as to press nuduly upon it. T'lus condition causes lameness, which is generally not noticed till a day or two after the shoeing. It is readily detected by the farrier on removing the shos and trying all the tracks of the nails in the hoof ly pressure with pincer's. When the lameness is slight, removal of the nail and one or two day's rest are all that is required. When the lameness is great, it may be suspected that the injury has caused the formation of matter within the hoof. This must, of course, be allowed to escape, and the services of a veterinary surgeon are advisable.

Any neglect in these cases, such as working the horse after lameness has appeared, or delay in lenroving the offending nail, may lead to very serious changes in the foot, or even to death of the hor'se.

Another injury caused by mails is from a direct puncture of the sensitive foot. This may be slight, as in cases where the farrier in driving the nail misdirects it and so 
stabs the sensitive parts, but immediately withdraws the nail, knowing what has happened. The lameness resulting forn this is nswally slight. Very much more selious is the landencss resulting from a mail which pierees the scrisitive foot and is not recognised at once by the farrier. As a rule, lameness is immediate, and should the horse perform a joumey before the nail is removed, serious damage is certain to follow.

Want of skill in driving a nail is not always the chief cause of "binding " or " pricking " a horse. More often than not the form and position of the nail-holes is the primary cause, for if the nail-holes in the shoe are ton "coarse" or badly pitched, it is quite impossible to safely drive nails through them. Sometimes the mails are defective, and this was much more common when mails were all hand-made. Bar iron or bad workmanship led to mails splitting within the hoof, and whilst one half came out through the wall, the other portion turned in and penetrated the sensitive foot, causing a most dangerous injury. The best brands of machinemade nails, now generally used, are remarkably free from this defect.

No lameness resulting from injury by a mail shonld le neglected. If retected and attended to at once, few cases are serions. If neglected, the very simplest may end in permanent damage to the horse. By treating these accidents as unpardonable, horse-ownel's rather encourage larriers to disguise then or not to acknowledge them. If the workman would always be careful to search for injury, and when he found it acknowledge the accident, many simple cases wonld cease to rlevelop into selious ones. Frank acknowledgement is always best, but is less likely to take place when it is follower by unqualified blame than when treated as an accident which may have been accompanied by unavoidable rlificulties.

From Clips lameness may arise. A badly drawn clip is not easily laid level and flat on the wall. When 
hammered down excessively, it causes pressure on the sensitive foot, and lameness. When side clips are usedone each side of the foot-it is not difficult to cause lancness by driving them too tightly against the wall. They then hold the hoof as if in a vice. When shoes gret loose or are partially torn off, the horse many tread on the clip, and if it he high and sharp, very dangerous wounds result.

From the Shoe, injury results from any uneven pressure, especially when the horny covering of the foot is weak and thin. The horn becomes broken and split, and the bearing for a shoe is more or less spoiled. Flat feet are liable to be bruised by the pressure of the inner circumference of the shoe at the toe. Lameness from this cause is easily detected by removing the shoe and testing the hoof with the pincers. If attended to at once, and the bearing of the shoe removed from the part little injury results. If neglected, inflammatory changes in the sensitive parts are sure to arise.

Corns in horses are due to bruising of the angle of the sole by the heel of the shoe. A wide open foot with low heels is most likely to suffer, but any foot may be injured. The most common seat of injury is the inner heel of a fore-foot. Even a properly fitted shoe may cause a corn if retained too long upon a foot, as then, owing to the growth of the hoof, its extremity is carried forward from beneath the wall so as to press upon the sole. A short shoe, fitted too close on the inside, is the most common cause of corn. To guard against the shoe being trodden on by the opposite foot, the inside is generally fitted close, and to guard against being trodden on by the hind foot, it is often fitted short. Thus to prevent accidents of one kind methods are adopted which, being a little orerdone, lead to injury of another. A not nucommon error in the preparation of the foot for shoeing mity also lead to the production of the so-called corn. If the wall on the inside heel be lowered more than 
it should be, the horn of the sole is left ligher than the wall, and then a level shoe presses unevenly upon the higher part.

A com, be it remenbered, is not a tumour or a growth, it is merely a bruise of the sensitive font under the horm of the sole. It shows itself by staining the horn red, just as a bruise on the human body shows the staining of the skin above it. To "cut out a corn" with the idea a removing it is simply an ignorant proceeding. If a corn be slight, all that is necessary is to take off the pressure of the shoe, and this is assisted by removing a thin slice or two of horn at the part. When the injury is very great, matter may be formed under the horn, and, of course, must be let out by removal of the horn over it. Provided there is no reason to believe that matter has formed, a corn, i.e., the bruised and discolored horn, should not be dug out in the ruthless manner so commonly adopted. Cutting away all the horn of the sole at the heels leaves the wall without any support. When the shoe rests upon the wall it is unable to sustain the

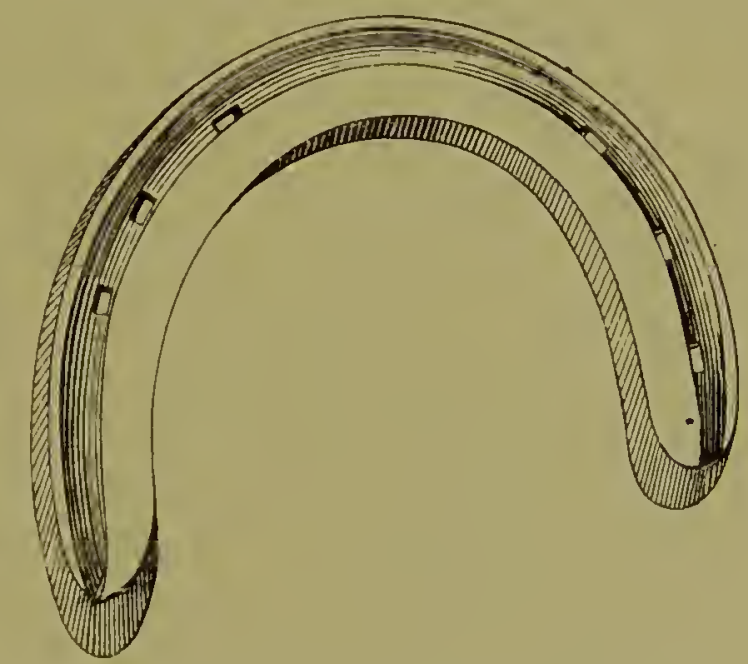

Fig. 98.-Three-quarter Shoe.

weight without yielding, and thus an additional cause of irritation and soreness is manufactured. The excessive paring of corns is the chice reason of the difficulty of gretting permanently rid of them. The simplest device fol: 
taking all pressure off a corn is to cut off an inch and a half of the inner heel of the shoe. With the three-quarter shoe (Fig. 98) a horse will soon go somend, and his foot will then resume its healthy state. 'l'he siying " once a corn, always a corn " is not true, but it is true that a bruised heel is tender and lialsle to bruise again, from very slight unevenness of pressure, for a least three months. All that is necessary is care in fitting and abstention from remoral of too much liorn at the part. Of comrse, when the degee of lameness is such as to suggest that matter is formed, the hor'n must be cut away, so as to afford an exit for it, but the majority of corns are detected long before the stage of suppuration has resulted from a bruise.

A Burnt Sole.-In fitting a hot sloce to a foot it sometines liappens that the sensitive parts under the sole at the toe are injured lyy heat. This is most likely to occur with a foot on which the hom is thin, especially if it also be that or convex. Buning the sole is an injury which must be put down to negligence. It does not occur from the shoe being too hot, but from its being too long retained, and may be expected when the fireman is seem holding a dull-red hot shoe on to a foot, with a doorman assisting to "bed it in "ly pressing it to the foot with a rasp. When the heat of a shoe penetrates through the horn with sufficient intensity to blister the sensitive parts of the foot, great pain and lameness results. In many cises, separation of the sole from the "quick" takes place, and some weelis pass before the horse can resume nork.

Treads are injuries to the coronet cansed by the shoe of the opposite foot, and are msually found on the front or inside of the lind feet. The injury may take the form of a bruise and the skin remain unbroken, it may appear as a superficial jagged wound, or it may take the form of a tolerably clean cut, in which case, although 
at first bleeding is very free, ultimate recovery is rapid. Bruises on the coronet--just where hair and hoof meetare always to be looked upon as serious. The slighter cases, alter a few day's pain and lameness, pass away, leaving only a little line showing where the honf has separated from the skin. This separation is not serions unless a gond deal of swelling has accompanied it, and cven then only time is required to effect a cure. In more serious cases, an extensive slough takes place, and the coronary band, which secretes the wall, may be damaged.

The worst cases are those in which deep seated abscesses occur, as they often terminate in a "quittor." The farrier should always recognize a tread as possibly dangrerous and obtain professional advice.

It is a common custom to rasp away the horn of the wall immediately beneath any injury of the coronet, but it is a useless proceeding, which weakens the hoof and does no good to the inflamed tissues above or beneath.

Treads are most common in horses shod with heavy shoes and high calkins - a fact which suggests that a low, square callin and a shoe fitted not ton wide at the heels is a possible preventive."

$$
\text { "Cutring:" ole "Brushing," }
$$

By these terms is meant the injury to the inside of the fetlock joint which results from bruising by the opposite foot. Possibly some sinall proportion of such injuries are traceable to the system of shoeing, to the form of shoe, or to the action of the horse. They are, with few exceptions, the direct result of want of condition in the horse and are alunost confined to young horses, old, weak horses, or animals that have been submitted to some excessively long and tiring journey. The first thing a horse-owner does when his horse "brushes" is to send him to the farrier to have his shoes altered. In half the cases there is nothing wrong with the shoes, and all that is required is a little patience till the horse gains hard condition. At the commencement of a coaching season, hall the horses 
"cut" their fetlocks, no matter how they are shod. At the end of the season, none of them touch the opposite joint, with perhaps a few exceptions aftlicted with defective formation of limb, or constitutions that bafter all attempts at getting hard condition. 'I'he same thing is secn in cab and omnibus stock. All the new horses "cut" their legs for a ferr weeks. The old ones, with a few exceptions, work in any form of shoe, but never touch their joints. They " cut "when they are ont of condition -when their limbs soon tire; but they never " cut" when they are in condition-when they have firm control of the action of their limbs. There are, however, a fer horses that are always a source of trouble, and there are conditions of shoeing which assist or prevent the injury. The hind legs are the most frequently affected, and this because of the calkins. Many horses will cease " cutting " at once if the calkins of the shoes be removed and a level shoe adopted. There are certain forms of shoe which are sup-

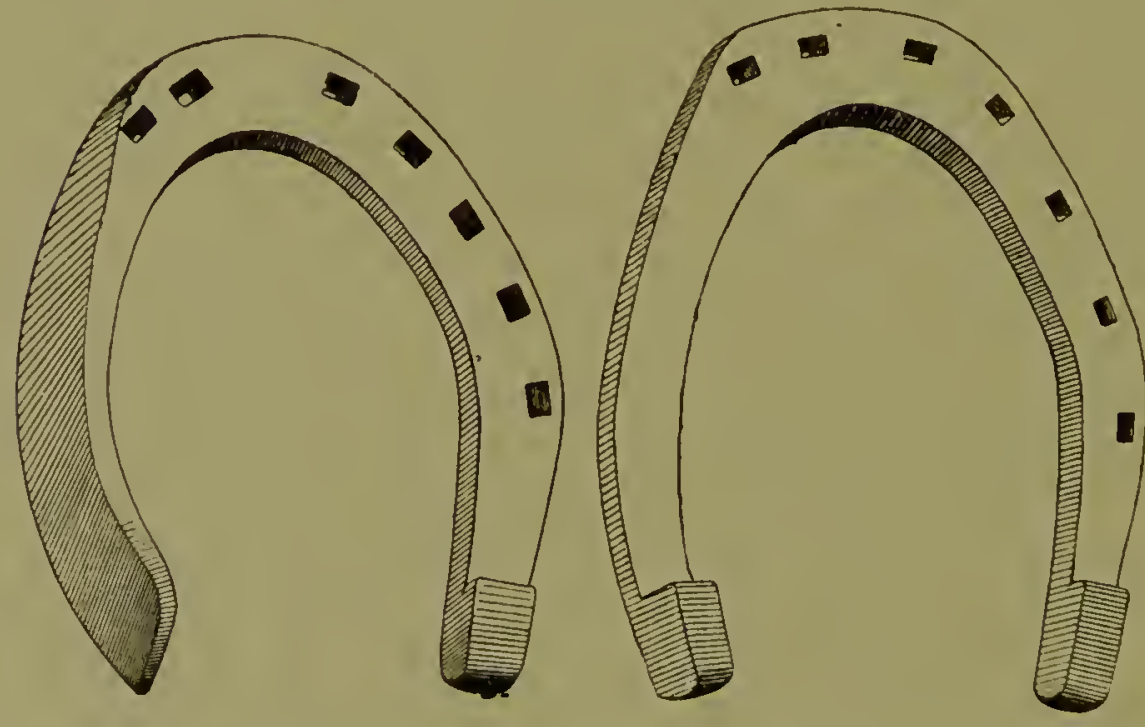

Fig. 99.-" Knocked-up" Shoes-with or without an inner Calkin.

posed to be specially suitable as prerentives. A great favourite is the "lnocked-r1p shoe," i.e., a shoe with no nails on the inside, except at the toe, and a skate-shaped inner branch. 
These shoes are fitted not only close to the inner border: of the wall, but within it, and the hom at the toe is then liusped off level with the shoe. Whether they are of any nse is a question, but there is no question of the harm they do to the loot. Some farriers are partial to a threequarter shoe-one from which a couple of inches of the inside heel has been removed. S'ome thicken the outside toe, some the inside toe. Some raise one heel, some the other, and some proless to have a principle of fitting the shoe based upon the formation of a horse's limb and the peculiarity of his action. If in practice success attended these methods, I shonld advise their adoption, but ny cxperience is that numerous farrier's obtain a special name for shoeing horses that "cut," when their methods, applied to quite similar cases, are as antagonistic as the poles. A light shoe without calkins has at any rate negative properties-it will not assist the horse to injure himself. For all the other forms and shapes I have a prolound contempt, but as people will have changes, and as the most marked departure from the ordinary seems to give the greatest satisfaction, it is perhaps "good business" to supply what is appreciated.

The two great cures for "cutting" are-legular work and good old beans. When a man drives a horse lorty miles in a day at a fast pace he, of course, blames the farrier for all damage to the fetlocks. He is merely illogical.

\section{OVER-REACHING.}

This is an injury to the heel-generally the inner-ol' a front foot. The heel is struck by the inner border of the toc of the hind shoe. Over-reach mostly occurs at a gallop in this country, but is seen in America as the result of a mis-step in the fiust trotter's. An over-reach can only oceur when the lore-loot is raised from the ground and the hind foot reaches right into the hollow of the foreloot. Whes the fore and hind feet in this position separate, the inner border of the toe of the hind shoc 
catches the heel of the fore-foot and cuts off a slice. This cut portion often hangs as a flap, and when it does, the

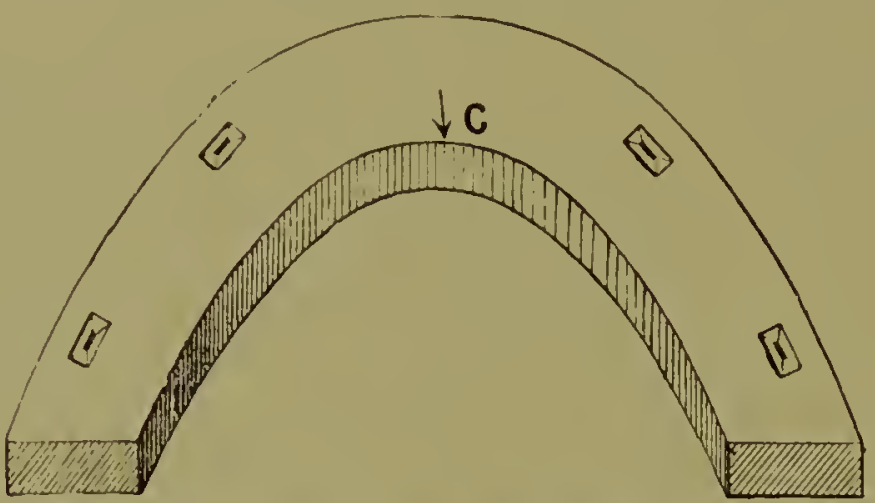

Fig. roo.- Toe of hind shoe showing the edge which cuts the heel of fore-foot.

attachment is always at the back, showing that the injury was not from behind forwards, as it would be if caused by a direct blow, but from before backwards; in other words, by a dragging action of the hind foot as it leaves the front one. An over-reach, then, may result either from the forelimb being insufticiently extended, or from the hind-limb being over extended.

The prevention of this injury is effected by rounding off the inside edge of the hind shoe as shown below.

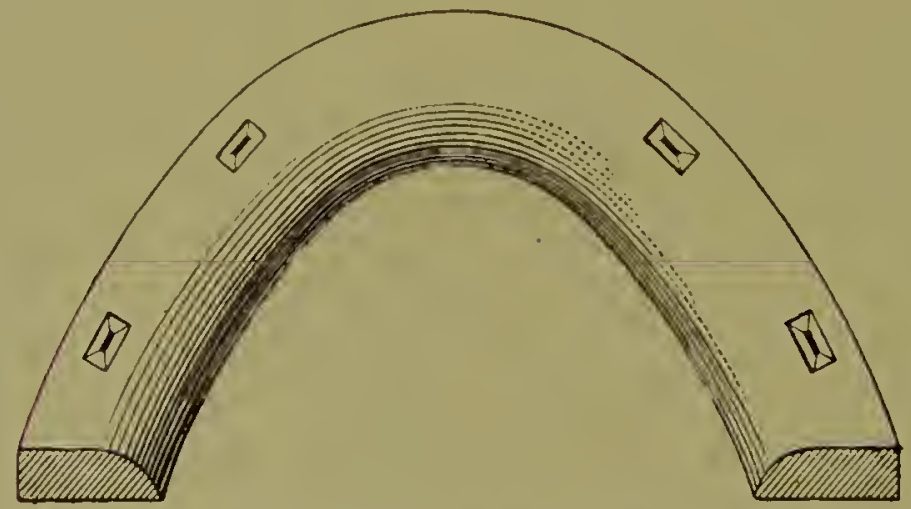

Fig. zor.-Toe of hind shoe showing rounded inside border.

\section{SPEEDY-CUT.}

This is an injury inflicted on the immer surface of the lower part of the knee joint by a blow from the toe of the shoe of the opposite foot. It occurs at a trot, and very 
seldom, except when a horse is tired or over-paced. A horse that has once "speedy-cut" is apt to do so again, and it may cause him to lall. Such horses should be shod "close" on the inside, and care should be taken that the heel of the loot which strikes should be kept low. In some cases, a three quarter shoc (see Fig. 101) on the offending foot prevents injury.

\section{"Foriniti" OR "CLACKing,"}

This is not an injury, but an annoyance. It is the noise nuale by the striking of the hind shoe against the front as the horse is trotting. Horses "forge" when young and green, when out of condition or tired. As a rule, a horse that makes this noise is a slovenly goel, and will cease to amnoy when he gets strength and goes up to his bit. Shoeing makes a difference, and in some cases at once stops it. 'The part of the front shoe struck is the inner border round the toe. (Fig. 102). The part of the

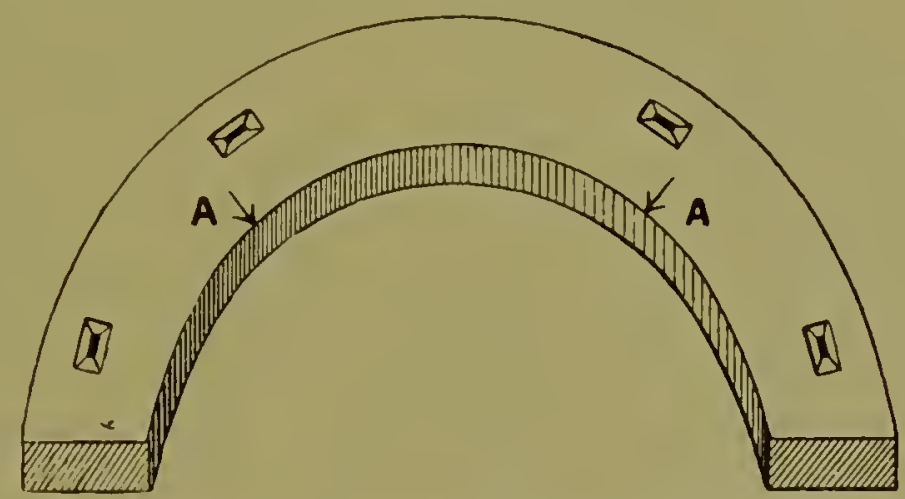

Fig. 102.-Toe of fore shoe. The arrows mark the place struck in "forging."

hind shoe that strikes is the outer border at the inside and outside toe. (Fig. 103).

To alter the fore shoe, round off the inner border; or use a shoe with no inner border, such as the concave hunting shoe. To alter the toe of the hind shoe is useless, but by using a level shoe without calkins some advantage is grined. A so-called "diamond-toed" shoe has been rocommended. It is not advisable, as it does no good, 
132

THE ART OF HORSESHOEING.

except by causing its point to strike the sole of the front foot. If by such a dodge the sound is got rid of, it is only by running the risk of injuring the foot.

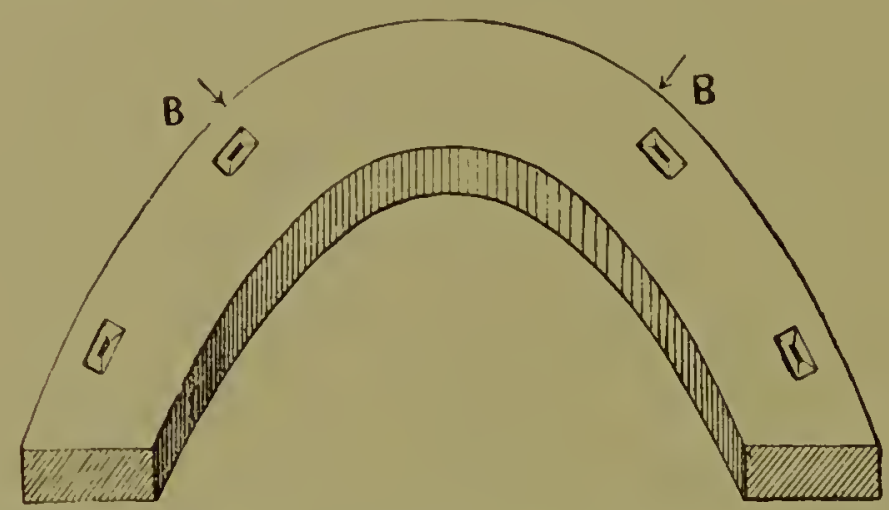

Fig. 103. --Toe of hind shoe showing the edge which strikes the fore shoe.

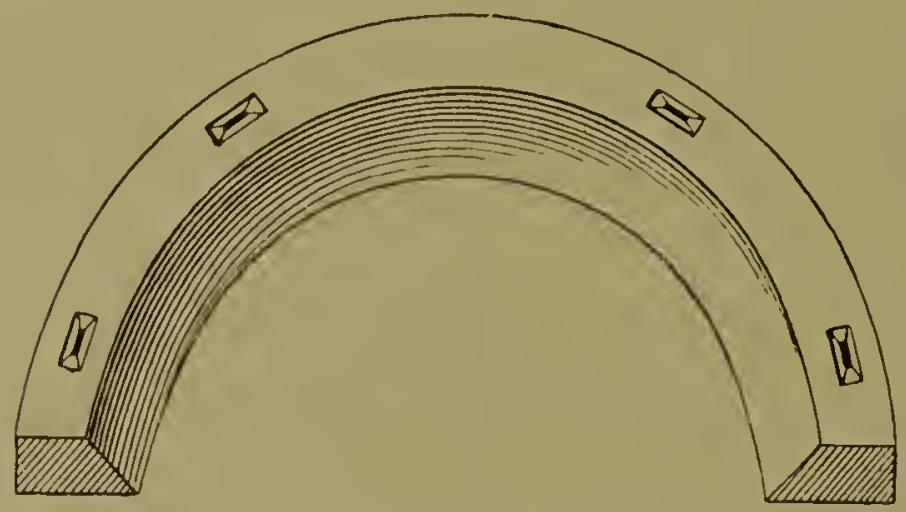

Fig. 104. -Toe of tore shoe with inner border bevelled off. 


\section{Chapter X \\ Shoeing Bad Feet.}

Any average farrier can shoe without immediate harm a good, well-formed foot that has a thick covering of horn, but when the horn is deficient in quantity or quality injury soon takes place if a badly fitted shoe be applied. There are feet which from disease or accident or bad shoeing have become, more or less, permanently damaged. Some are seriously altered in shape. Some are protected only by an unhealthy horn, and some show definite changes which cause weakness at a special part. These are the feet which really test the art of the farrier, for he must know just what to do and what not to do, and must possess the skill to practice what he knows.

Flat Feet.-Some horses are born with flat feet, others acquire them as the result of disease. Too often the flat sole has another defect accompanying it--low, weak heels. Such feet are best shod with a seated shoe so as to avoid any uneven pressure on the sole, and the shoes should always be fitted a little longer than the bearing-surface of the foot, so as to avoid any risk of producing a bruise at the heel-in other words, of causing a corn. The seated shoe is not advisable on a hunter. The concave shoe used for hunters has many distinct advantages and only one disadvantage for a flat foot, viz., that it has a wide, flat foot-surface. It may cause an uneven pressure at the toe on a flat sole, but this is easily avoided by not making it too wide; perhaps the very worst thing to do with it flat foot is to try and make it look less flat by paring it down. The thinner the horn the greater the chance of injury to 
the sensitive parts under it, and every injury tends to make the sole weaker. Leaving the sole strong and thick, whilst fitting the shoe to aroid uneven pressure, is the principle of shoeing to be adopted with flat feet.

Convex Soles.-The sole of the foot should be concave, but as the result of disease many feet become convex. This bulging or "dropping" of the sole varies in degree from a little more than flat to an inch or so below the level of the wall. When the under-surface of a horse's foot resembles in form the outside of a saucer, fitting a shoe becomes a work of art. Very often the wall is brittle and broken away, and it is most difficult to find sufficient bearing-surface on the foot for a shoe. Many of these feet may be safely shod with a narrow shoe that rests only on the wall and the intermediate hor'n between the wall and sole. Such a shoe may, according to the size of the foot, be five-eighths or even three-quarters of an inch wide. Its thickness is to be such as will prevent the sole taking any direct bearing on the ground, and sometimes a shoe of this form is much thicker than it is wide. The advantage of this shoe is that it is so narrow that any bearing on the sole is avoided. The disadvantage is that on rough roads the sole may be bruised by the flint or granite stones. When the hor'n of a " cropped " sole is very thin, or when the horse has to work on roads covered with sharp, loose stones, some cover for the sole is necessary, and the nar'ow shoe is not practicable. To provide cover'

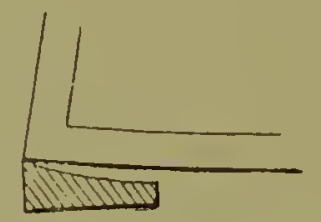

Improper bearing-surface.

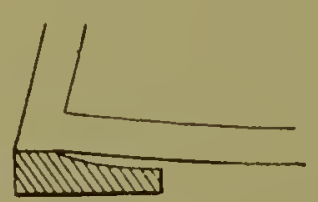

A level bearing-surface.

for the sole, the web of the shoe has to be wide, and therefore the foot-surface of the shoe inust be seated out, so as to avoid contact with the sole. 'Too often the seating is 
continued from the inner to the outer border of a shoe, so that no level bearing-surfice is provided for the wall to rest on. 'This lind of shoe is like the hollow of a saucer, and, when applied to a foot, is certain to cause lameness sooner or later. Each time the horse rests his weight on it the hoof is compressed by the inclined surface of the shoe, which, instead of providing a firm bearing-surface, affords only an ingenious instrument of torture.

In even the worst of these deformed fect some good, sound horn is to be found at the heels, where an inch, or sometimes two, can be utilized for level bearing. No matter how much seating is required at the toe and quarters, the heel of the shoe may always be made level.

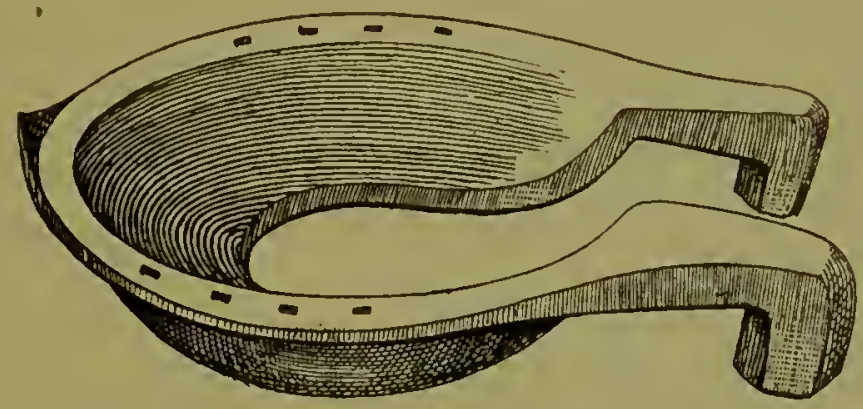

Fig. 106.-Box-seated Shoe.

What is called a "box-seated shoe" is now seldom used. It is the only shoe which renders a horse useful for work with the worst forms of convex soles. It is difficult to make and fit. The horse with such a deformed foot as to require it is never quite sound. Magistrates are very much inclined to look upon all lameness as constituting "cruelty" when cases are brought before them. Horse-owners, therefore, seldom attempt to lieep horses with the worst form of convex soles at work, and farricrs are not required to provide shoes for them.

It cannot be too strongly urged that in the prepariution of feet with bulging soles no horn is to be remover from the sole. The toe is to be shortened, the lieels 
lowered proportionately, and the bearing-surface of the wall made level with a rasp. At no place must the shoe rest on the sole. In nearly every case, the toe is left too long and the bearing taken upon it by the shoe only increases the deformity. In many feet, a large slice

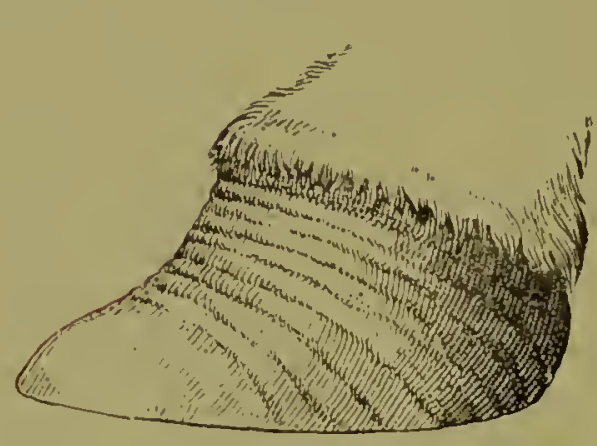

Fig. 107

Deformity resulting from laminitis.

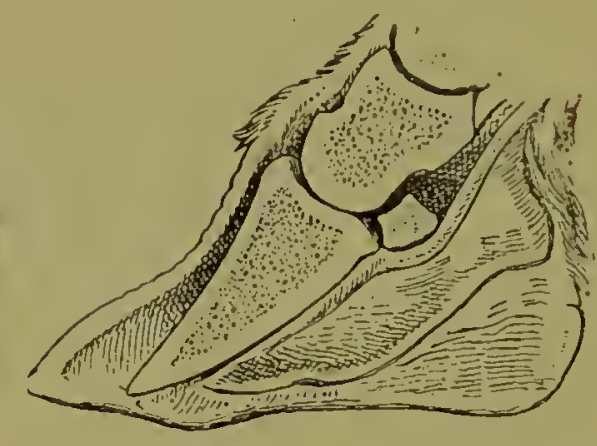

Fig. roy.-Section showing how front of wall is separated from sensitive laminæ.

might be sawn off the toe with advantage, as the sensitive foot is separated from the wall by a mass of diseased horn which presses the wall at the toe forward. (Fig. 107.)

Sandcrack.-This is the name given to cracks in the wall, which commence at the coronet and extend downwards. From their position at the toe, or at the side of the hoof, they are sometimes called respectively "toecracks " and "quarter-cracks." The crack may be very slight and may exist without causing lameness. It may appear suddenly, accompanied by great lameness and by the issue of blood from between the edges of the divided wall. These are grave cases which require surgical attendance. Sandcracks are most commonly seen in dry, brittle feet, and the horses most subject to them are those employed in heavy draught work. Railway shunt-horses and omnibus horses are very liable to be troubled with sandcracks in the toe of the hind feet.

In shoeing for this defect, there are two things to avoid: (a) not to place any direct pressure on the part; (b) not 
to fit a shoe which will tend to force the crack open. Following these lines, it is well not to put a clip exactly over a crack. If at the toe, place a clip each side of the crack, and never use calkins or high heels, which throw the neight formard. If at the quarter, avoid a springheeled shoe which permits the downward movement of the foot behind the crack and so forces it open. In all cases, after fitting the shoe level to the foot, remove alittle more horn just below the crack, so as to relieve the direct bearing on the part. (Fig. 109.)

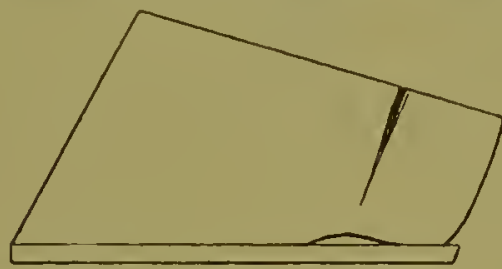

Fig. rog.- Horn removed to prevent pressure.

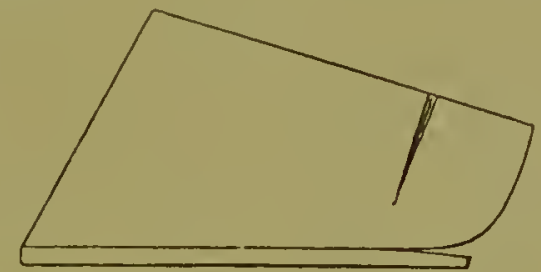

Fig. Iro.-Bearing relieved at wrong place by "springing" the heel.

In the case of a crack extending the whole space of the wall, some provision should always be made to keep it

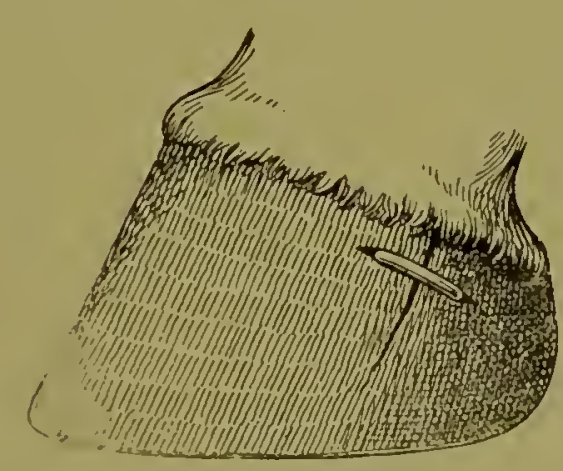

Fig. Iı..-French clip in quarter.

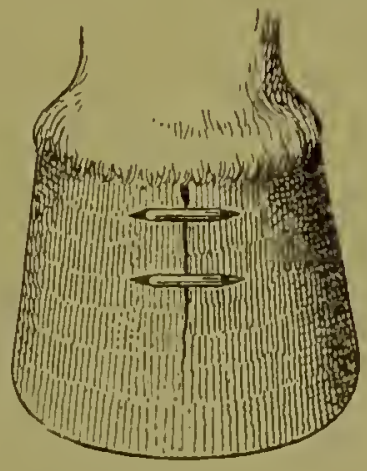

Fig. Ir2.-Clips in toe

from opening, hecanse every step of the holse, especially when draning a load, causes an outward pressure at the coronet. 'T'his pressure forces the hoof apart, and the injury caused does not cease with the pain and lameness which follow, and which may be temporary. Doubtless, the original cause of a sandcrack is some morbid condition of the coronary band--the band from which the 
wall grows. 'The sensitive laminæ are at first not affected further than by the inflamma-

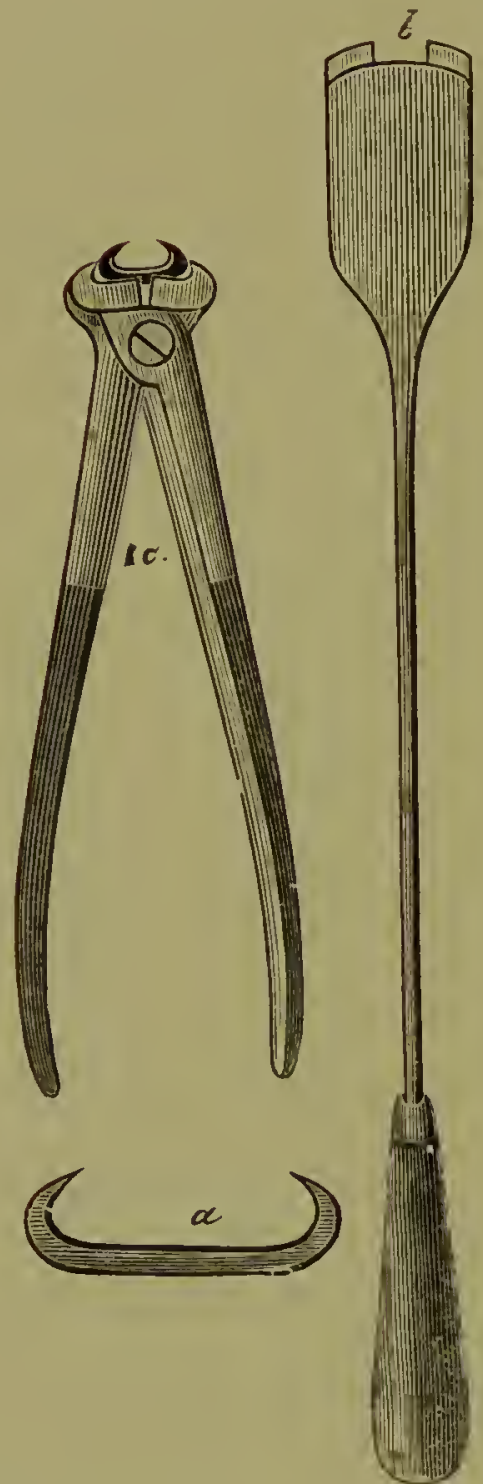

Fig. I13. tion consequent upon the direct tearing which occurs when the crack takes place. The continued inritation, kept up by a persistent fissure in the horn covering the lamine, soon causes other serious changes which tend to make the sandcrack a permanent disease. Thus, even the smallest crack should be attended to and measures adopted to prevent its enlargement, or, when extensive, to limit all opening and shutting movement of the hoof.

This is sometimes attempted by a simple leather strap tightly applied, or by binding the foot with string or tape. Tape is less liable to slip than string. When the hoof is sufficiently thick, two nails may be driven in opposite directions transversely through the crack and clinched; or French sanderackclips (Figs. 111 and 112) may be used, which are easily applied. The instruments necessary are shown in Fig 11:3. The iron (b) is made red-hot and pressed on the hoof across the crack, so as to burn a groove each side of it. Into these grooves the clip $(a)$ is put, and the pincers $(c)$ are then used to compress the clip firmly into its place. There is a strain upon the clips, and sometimes one breaks. It is therefore necessary always to use two, and for an extensive crack three inay be einployed. 
All these appliances tend to keep the lips of the erack from separating, but they do not prevent the edges of a deep, wide eraek from being forced together, and thus pinching the sensitive parts. To provide against this injury, a slip of hard wood may be fitted into the craek, and then the nails or clips may be more safely drawn tight without fear of injury, and with a better chanee of preventing any movement in the edges of the craek. To insert the rood, the erack is ennverted into a groove nearly as deep as the wall, about three-eighths of an ineh wide, with straight sides, or, better still, with a little greater width at the bottom than at the surface. Into such a groove, a piece of wood formed to fit it is gently driven from below and rasped off to fit exaetly. Or softened gutta-pereha may be pressed firmly into the spaee and levelled off when eold.

To "eut out" a sandcrack, except for the purpose of refilling it, is bad praetiee, as it favors movement and helps to make the defeet permanent. To rasp away the horn so that only a thin layer is left is also injurious. No horn

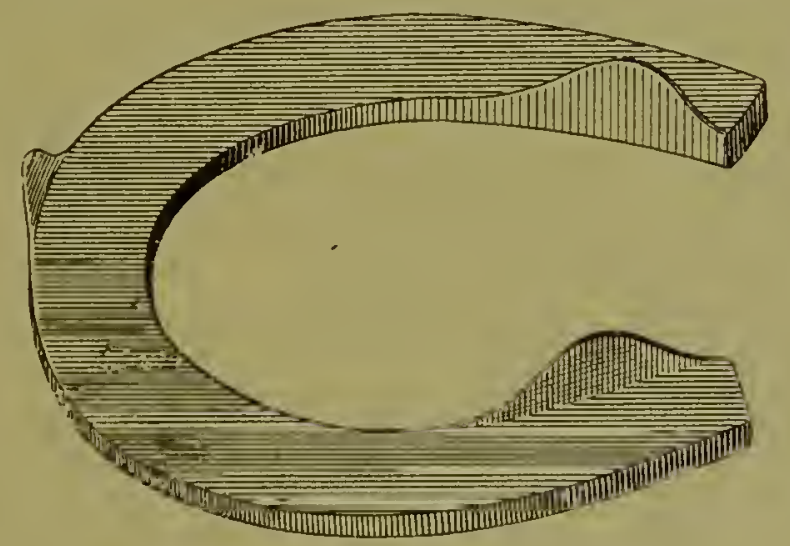

Fig. I14.-Shoe with heel clips for sandcrack

should be removed, except for the fitting of a plug, as above deseribed, or, under veterinary direetion, for the purpose of giving vent to matter whieh has formed within the hoof.

In many Gurnean countries, a shoe is used for toecracks which has two clips drawn on the inside border of 
the shoe at the heels. These clips catch the bars of the hoof and prevent the heels of the foot closing in. The idea is that when the wall at the heels contracts, there is a tendency for the wall at the toe, if separated by a crack, to open. Fig. 114 shows the position of the clips, which must be carefully fitted, so as to rest on the inside of the bars. Mr. Willis, V.S., has tried the shoes and speaks mell of their utility.

When the crack is in the quarters of the foot, it is not the tendency to expansion of the hoof that has to be guarded against. It is the downward motion of the heels that forces open a crack in this position. The farrier provides against this by taking care to have a firm bearing of the shoe on the hoof behind the crack, as shown in Fig. 109.

Contracted Feet. - Some diseases of the foot lead to contraction of the hoof, which is most noticeable round the coronet and at the heels. Any long continued lameness, which prevents the horse placing the usual weight on the foot, may be accompanied by contraction. Constant cutting away of the bars and paring the frog, so that it takes no contact with the ground, also leads to shrinking in of the heels. By lowering the heels and letting the frog alone, many feet will in time widen out to their proper size, but no system of shoeing is so good for contracted feet as the use of tips, which leave the whole back part of the hoof to take direct bearing on the ground.

Many shoes have been invented for forcing open the heels of contracted feet. Some have had a hinge at the toe and a moveable screw at the heel. Some have had the bearing-surface at the heels made with a slope outwards (see Fig. 39, page 66), so that the weight of the horse should constantly tend to force the heels apart. There is no necessity for any of these contrivances. A properly fitted tip (see Fig 89 page 110) rvill permit the hoof gradually to expand to its healthy size and form. 
Seedy-Toe.-This is a condition of the wall usually found at the toe, but not uncommon at the quarters. It is not common in hind-feet, but occurs sometimes. When the sloee is removed, a separation is noticed between the sole and the wall, and this separation may extend up the wall nearly to the coronet. As a rule, the space so formed is a narrow one, but it may be wide enough to adnit three fingers of a man's hand. Probably all seedy toes result from some injury or disease of the coronary band, from which the wall grows, and the first appearance is not a cavity, but a changed and softened horn, which may be dry and crumbly, or moist and cheesy. The diseased horn may be scraped out and the cavity filled with tar and tow. The wall bounding the cavity should be relieved of all pressure on the shoe, and if a radical cure be desired, all the unattached wall should be cut away. This, however, should be done under veterinary guidance.

Turning in of the Wall.-By this expression, I mean those cases of weak, low heels in which the border of the wall turns inwards. Such a form of horn offers no suitable bearing, and if submitted to pressure by a shoe, gets worse. Too often this condition is treated by paring away the sole within, which increases the deformity. The sole should not be cut, but be left as strong as possible. The curled-in border of the wall should be cut down and all bearing taken off the shoe. In one or two shoeings, the wall will resume its proper form. When both heels are so affected, and the horse has to remain at work, only one heel must be treated at a time. The extreme point of the heel is never affected and affords a point for bearing when the border of wall in front of it is cut away, so as not to touch the shoe.

Twisted Feet.-There are many feet of irregular shinpe, some natural to the horse- born with it-some caused by neglect or by bad shoeing. Very little can be done by the 
farrier to improve a natural badly formed foot. The "twisted" foot that results from negligence may be remedied or at least much inproved by care in shoeing. The wall of the foot is constantly growing, and under normal conditions grows at the same rate all over. As it grows it follows a certain direction in accordance with the form of the bone within the hoof. If one side of the hoof be allowed to long remain higher than the other side, the weight of the horse is unevenly distributed and the growing horn is deflected from its proper line. The higher side receives the most pressure and the foot is canted over. If the inner side of a hoof be left too high, the tendency is for it to come in at its lower border whilst the outer side is pushed outwards, If the outer side be left too high there is not such a tendency to turn in, because the outer side is always more inclined outwards than the inner, and the result of excessive pressure is simply to unnaturally increase the outward bulge of the border. The direction of the twist depends upon the height of the sides of the hoof, but it is modified by the original direction of the horn and also by the form of the limb, especially by that part froin the fetlock downwards. When a hoof is permitted to remain twisted for many months a permanent deformity results, as the bone within becomes altered in form by absorption due to pressure. Such cases cannot be cured, but they may be prevented from getting worse. It is obvious that when once the wall of a foot has become deflected from its proper course the evil rapidly increases, because the weight of the animal is constantly acting to aggravate the condition. 'T'oo often no notice is taken of a twisted foot until it is too late to bring it back to the natural form.

The first thing to do with this deformity is to lower the higher side of the hoof with the rasp. If the whole foot be overgrown both sides must be lowered, but if there is very little excess of horn the lower side should not have any renoved. It must not be attempted to make a twisted foot level at one shoeing. The alteration requires 
growth of horn, and the over-lowering must be repeated at two or three consecutive shoeings to bring about a gradual return to healthy form. In Figs. 115,116, I have attempted to show a normal foot and a twisted one. In

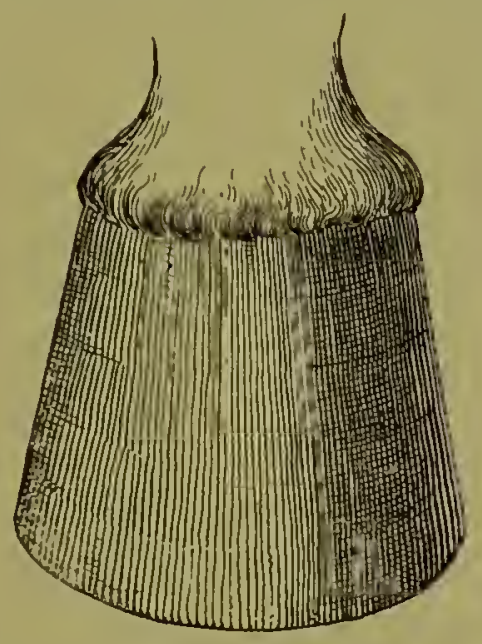

Fig. II5.-Normal Foot.

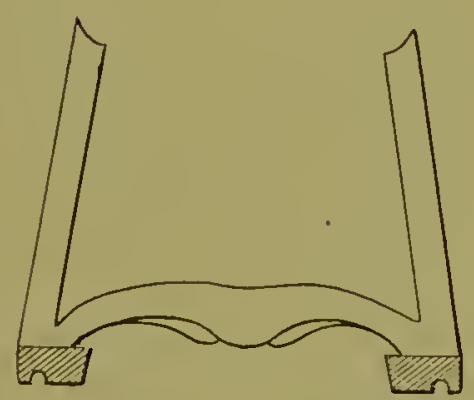

Normal Foot and Shoe.

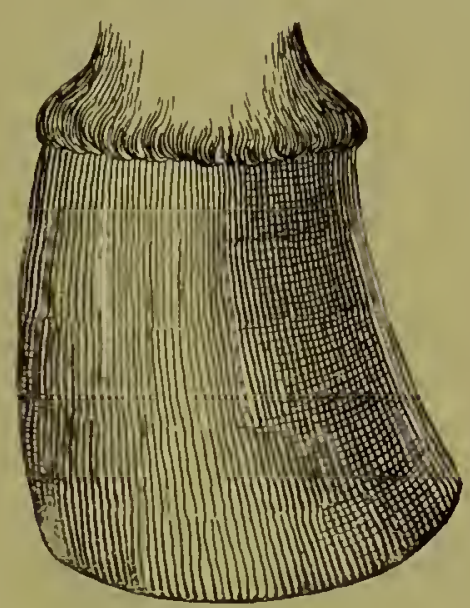

F1g. I16.-Twisted Foot.

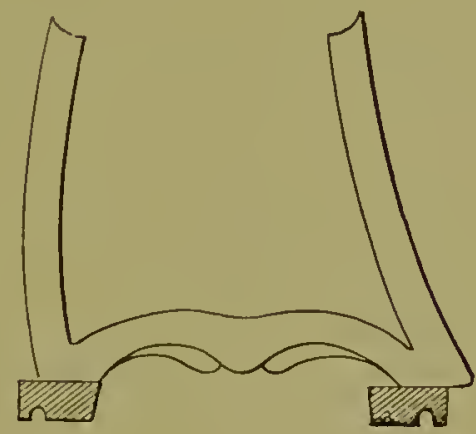

Twisted Foot and Shoe.

Fig. 117 the same feet are indicated in section to show how shoes should be applied. Instead of making the border of the shoe follow the border of the wall with exactness we alter the fitting considerably. Where the wall is turned inwards towards the centre of the foot we fit the shoe proninently full, so as to bring the base upon which the limb rests as near as possible to the position it would occupy were the foot normal. On the side where 
the wall deviates away from the centre of the foot we fit the shoe as close as safety in driving nails will allow, and rasp off the too prominent border of wall. Thus the bearing for the horse is brought more into the proper position, and pressure on the growing wall is so distributed that a return to the natural form of hoof is permitted and assisted. 


\section{CHAPTER XI.}

\section{Leather and Rubber Pads.}

In the days when farriers were driven by theoretical teachers to pare out the soles and otherwise rob the foot of its natural covering of horn, artificial protection had frequently to be given to the foot. A horse with a thin sole could not travel over rough roads, on which sharp, loose stones were plentiful, without great risk of injury; consequently, in those times, plates of leather were often used to protect the foot. When a horse went " a little short," his owner not unnaturally concluded that he had bruised his foot and that the protection of a leather sole would be beneficial. In many cases, the defective action was due to other cause than bruising, but still the leather was adopted, and it soon became an accepted theory that leather soles modified concussion and protected the foot from jar. This is more than doubtful, and I hold a very firm opinion that a plate of leather between the shoe and the foot has no such effect, whilst it interferes with the exactness of fit of the shoe. "Leathers" are useful on weak feet to protect a thin or defective sole from injury. When the under surface of a foot has been bruised, cut through, or when it is diseased, leather offers a useful protection, but when the sole is firm and sound, it is quite unnecessary.

To apply leather properly, a square piece fully the size of the shoe is taken. A portion is then cut out where the clip has to fit, and all protruding parts cut away level with the border of the shoe. If applied without more precautions, an open space would be left between leather and sole, into which mud and grit would find their way, and the leather would soon be cut through by resting on the 
irregular surface of the frog. To prevent this mischief, the under surface of the foot is made level before the shoe is applied. The leveling is managed by spreading a paste of tar and oatmeal over the sole, and filling up the space at the sides of the frog' with tow. 'Then the shoe, with the leather, is nailed on in the usual manner.

The belief in leather as an anti-concussive appliance has led to the use of what are called "ring-leathers." These are not plates covering the whole under surface of the foot, but narrow bands fixed between shoe and hoof. They are absolutely useless; in fact, their only possible effect is to spoil the fit of the shoe. Plates of india-rubber have bezn tried between the shoe and the foot as preventives of concussion. They invariably fail by reason of their effect upon the shoe. At each step when the weight of the horse comes on the foot, the elastic rubber yields, the shoe is pressed closer to the foot, the nails are loosened, and when the foot is raised the rubber rebounds. The shoe soon becomes so loose that it is cast or torn off. Nothing elastic should be placed between shoe and foot. Whell an elastic or spring is applied it must be between the shoe and the ground.

Various arrangements have been adopted to supply the horse's foot with some provision against concussion. Injured and diseased feet may no doubt be benefitted by some elastic appliance, which secures them from the jar of contact on a hard road. They may be protected against direct bruise. The healthy foot requires no such protection. Nature has covered it with a thick layer of horn and has provided against concussion by quite other means -by the co-ordinate action of muscles, by the oblique position of the pastern, and by the construction of the back part of the foot.

Quite apart from any attempt to prevent concussion, a valuable use has been found for india-rubbor pads in connection with horse-shoeing. The improvement in modern road-surfaces has been accompanied by an increased facility for slipping, and it has been found that no material 
gives such security of foot-hold on smooth surfaces as india-rubber.

The earliest of these contrivances with which I am acquainted was formed so as to leave the frog uncovered whilst a bearing of rubber was given all round the inner circunference of the shoe. This pad had a wide, flat border, which fitted under the shoe, with which it was nailed on the foot. Its great objection was that it could not be nicely fitted on many feet without first cutting away the bars.

Then we had rubber pads which were not nailed on with the shoe, but which fitted into the shoe and wore removed at will. 'The objection to these was that they could only be used with a seated shoe and could not be applied with a narrow shoe or one possessing a flat footsurface.

The next form to appear was a leather sole on which

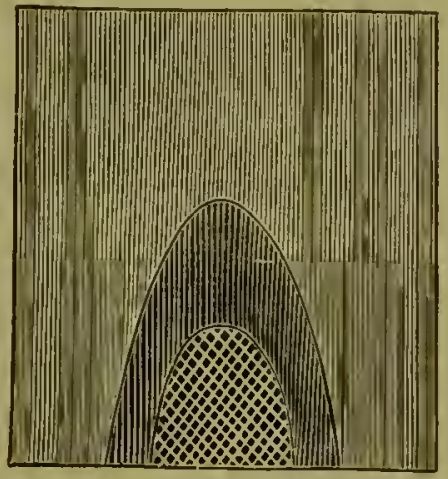

Fig. Ir8.-Frog-pad.

an artificial frog was fixed. Great difficulty was at first experienced in fixing this frog so that it remained firm. The difficulty has not yet been surmounted by all makers, but Mr. G. Urquhart, of London, makes a most reliable article. These "frog-pads" certainly give a very good foot-hold on all kinds of paved streets.

A pad of very elegant appearance is "Sheather's Pnenmatic." It is not solid like the ordinary frog-pad, but hollow, and is compressed at each step, but immediately resumes its prominent form on being relieved of pressure. 


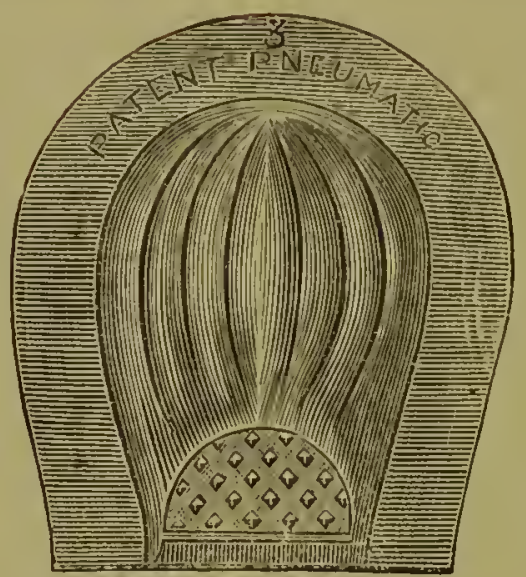

Fig. IIg.-Sheather's-pad.

One of the simplest anti-slipping pads is "Balls and Keep's wedge-pad." It possesses one advantage in not covering up the whole under-surface of the foot. When properly fitted, it is firmly retained and does its work, but a careless farrier may so apply it that it shifts on the foot. To fit it exactly, the wall of the back part of the foot must be lowered more than that in front, so that shoe, foot and pad may all be closely adjusted.

What is called the "bar-pad" is a leathcr plate on which an india-rubber pad occupies the whole of the back

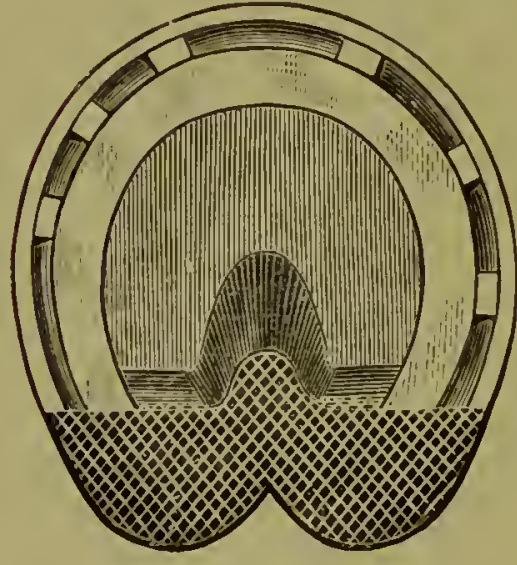

Fig. 120.-Bar-pad with shoes.

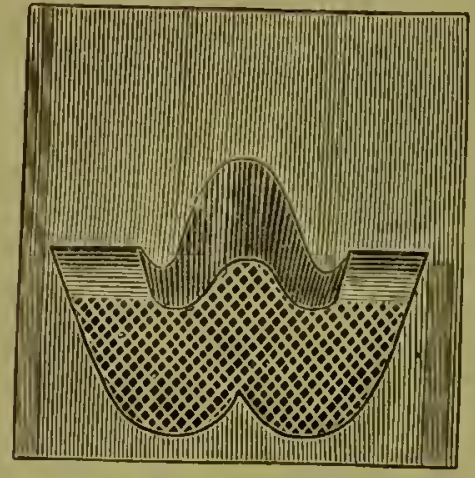

Fig. I2r.-Without shoe.

portion, and it is fixed to the foot with a short shoe. This pad is not only an anti-slipping agent, it is anti-concussive, and for some diseases and some injuries of the heels is a 
most valuable appliance. For long-standing "corns," for cases of chronic laminitis, and for horses that markedly "go on their heels" the bar-pad is without doubt the most efficient arrangement yet invented. The best are made by Mr. Urquhart.

All these pads increase the cost of shoeing, but what they save, by preventing falls and injuries to the horse and fear and anxiety to the driver, far more than balances the account in their favour. The cost, however, is an item, and inventors have turned their attention to the production of some other miethods of applying rubber in connection with the shoe for the prevention of slipping.

Shoes have been manufactured into which cavities of different forms and sizes have been made. These are filled by correspondingly shaped pieces of rubber. The cavity must be so formed as to retain the rubber, and this renders the manufacture very difficult, except by the employment of malleable cast-iron shoes. This is a great disadvantage.

Another plan is to make from rolled bar iron a hollow shoe, section of which would be $\mathbf{U}$-shaped, but level to the foot. Into the groove so formed, a thick cord of rubber is placed after the shoe is nailed on the foot. This wears well and affords good foot-hold, but it entails the serious objection that the nails are difficult to drive and far from being so safe as in the ordinary shoe. If rubber is ever to be available in a grooved shoe, it should be designed so that the nails and nail-holes are not interfered with. This would require two separate grooves in the shoe-something of the form now adopted in the Rodway bar. The outer groove would, as usual, take the nails, whilst the inner would hold the rubber. Writing to Land and Water in $1870 \mathrm{I}$ suggested this combination of iron and rubber as likely to afford the best shoe for the prevention of slipping-if some inventor would show us how to fix the rubber securely after the shoe has been fitted. Fig. 122, which I am allowed to produce by the courtesy of the owners, represents a 
patented shoe-the "Martin"-for which success is claimed. I have no experience of its use, but I see no reason why it should not be developed into a good practical shoe. Tike the Rodway, the Martin is made from a bar in which parrallel grooves are rolled. The requisite length for a shoe is cut off, turned round and fitted to the foot. Then the rubber is placed in the inner groove and fixed by hammering up the heels and the inner ridge of iron. A good workman, with a little practice, is able to fix the rubber securely, but there is a difficulty in turning the shoe

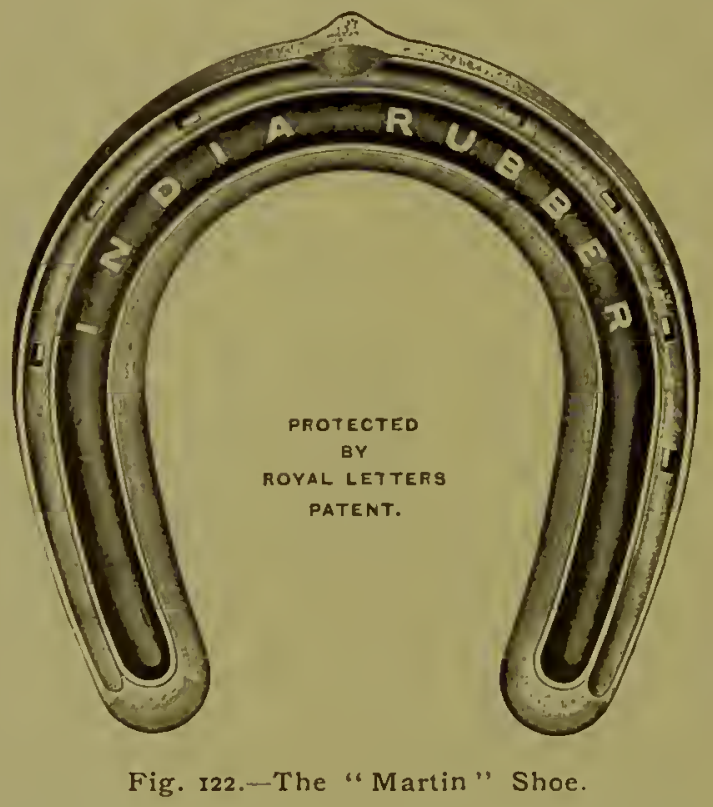

from the bar without buckling the grooves and ridges. To bring the shoe into regular use it should be saleable to the trade in shoe form, so that only fitting would be required before inserting the rubber. Fixing the rubber by hammering is a method apt to spoil the fit of a shoe, and I should much prefer some mechanism by which the shoe was firmly held whilst gradual pressure closed the walls of the groove upon the rubber. Whilst I should like to see some combination of iron and rubber for the ground surface of a shoe I must insist that the exactness of fit of the foot-surface is the great essential. 


\section{Chapter XII.}

\section{Occasional Shoes.}

The Bar Shoe differs from the ordinary in being joined at the heels by a bar which takes a bearing on the frog. In making it care is required to prevent spreading at the heels when the bar is welded, as after that very little alteration can be made in its width.

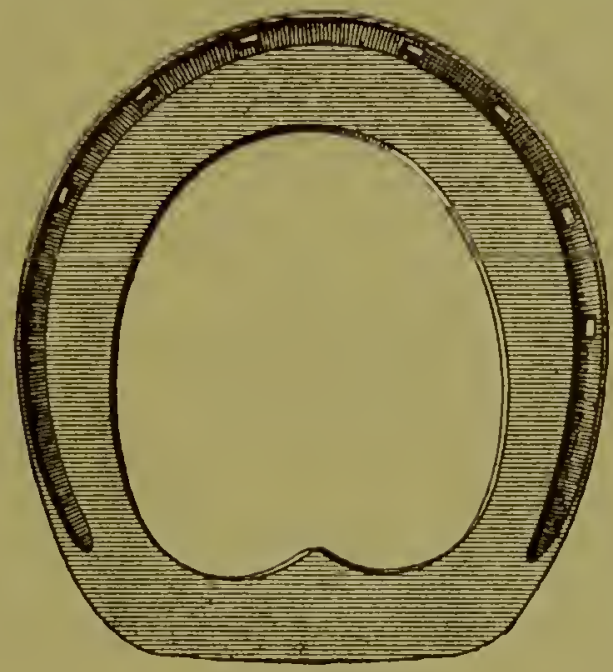

Fig. 123.-Bar Shoe.

Far too much value has been placed upon this shoe, which has nothing to recommend it except its bearing on the frog. It has been widely used on horses with convex soles resulting from laminitis. Such horses go on their heels, and the shoe is thinned at heel and toe so as to give a "rocker" motion to the foot. Unless these cases have weak hoels or colns an ordinary shoe fitted in the same way is equally beneficial.

Where the bar-shoe is useful is on horses that have heels incapable of taking their proper amount of bearing. In 
cases of corn which have suppurated, and in cases of falsequarter, relief is afforded to the heels by taking a bearing on the frog. In some cases, when a "seedy" foot shows separation from the quarter's back to the heel, the part may be relieved of pressure by a bar-shoe which takes a bearing on the frog.

The bar-shoe is also useful when it is desired to retain some medicated dressing in the heels. It is not a satisfactory shoe for hunters, and it adds considerably to the insecurity of foothold on stone-paved streets.

The "Patten" Shoe.-This is a high-heeled shoe with a bar connecting the heels. Its name is apparently derived from some resemblance to "pattens" worn by old women in wet weather. Its promiscuous use on lame horses suggests that the name is not inappropriate-that it is a favourite article with old women.

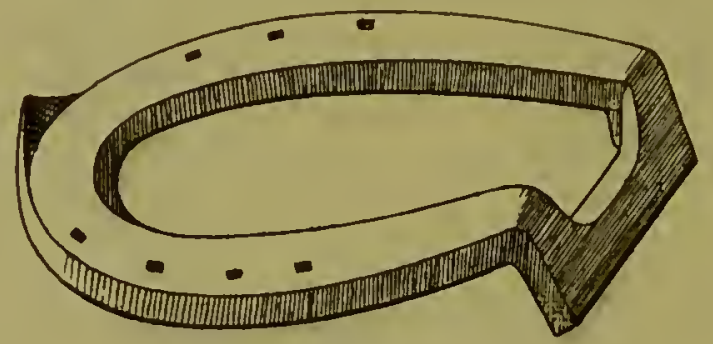

Fig. 124.-A Patten Shoe.

The only rational use of this shoe is to fix the foot in such a position that the back tendons are relaxed. There are doubtless cases of lameness in horses when the shoe may be used with some good result ; but not every case of sprain of the ligaments or tendons at the back of the leg should be treated with a high-heeled shoe. One of the worst results-and one of the most common-to be expected from sprain is contraction of the injured parts. The prolonged use of a high-heeled shoe facilitates this contraction, and affords very little more rest to a sprained tendon than a horse can give himself by flexing the knee. 
The FitzlVygram Shoe. In "Holses and Stables" by (renl. Sir F. Fitzwygram, Bt., a shne with a turned-up

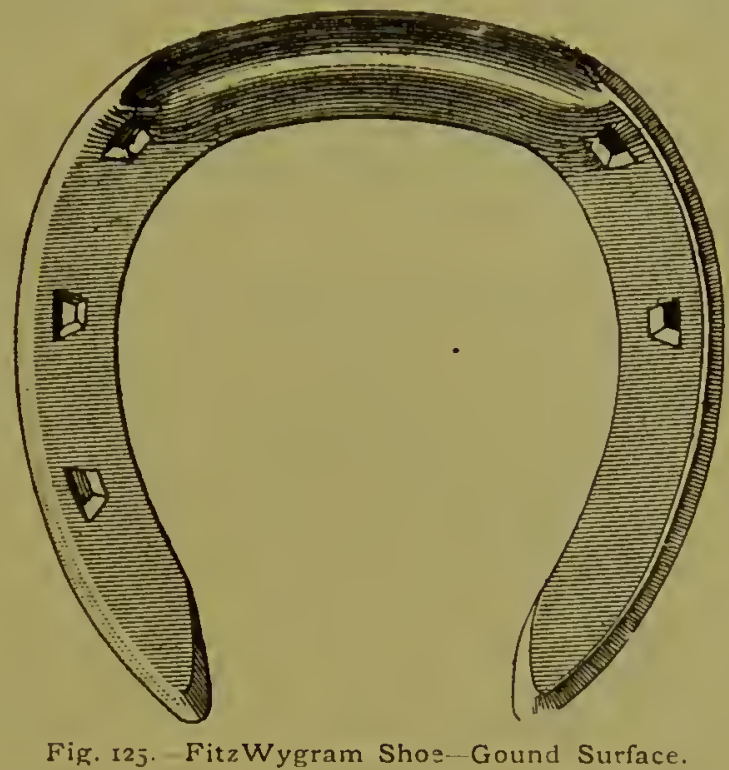

toe is strongly recommended. The accompanying figures are copied from plates in that book and show a narrow

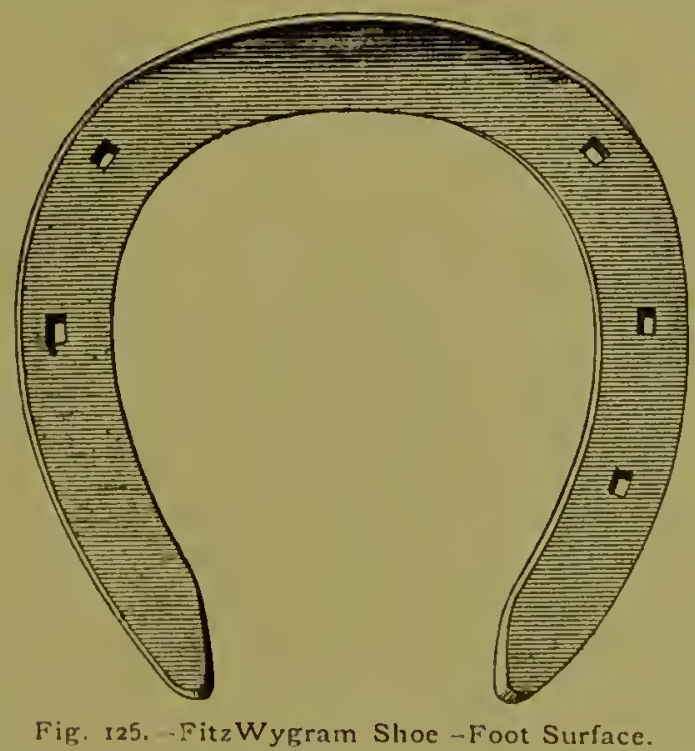

shoe, concave on the romul surface, with the toe tumed11p. For horses that stmuble ol strike the ground whilst advancing the foot this shoe is useful, but for any other. 
horse its value is not evident. 'The way in which the toe is turned is not easily mastered by a smith, and I do not see any advantage in it ovel the simpler. method noted on page 102.2 . Fig. 80 .

The Hinged Shoe. - A shoe with a linge at the toe ras first made with the idea of providing for the rythnic expansion of the foot. Now it is used only as a handy temporary article to be carried by a horseman in case of a lost shoe. The hinge allows it to be closed or opened

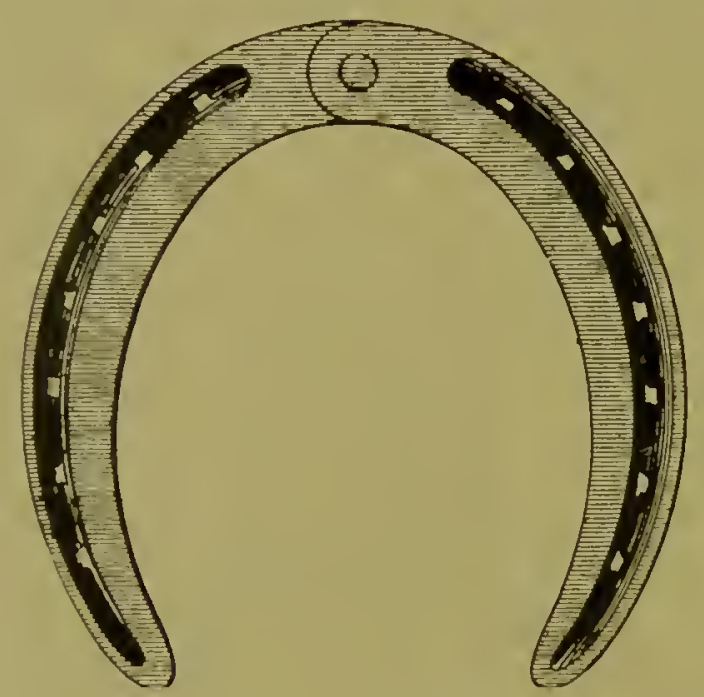

Fig. 127.-A Hinged Shce.

and so to fit more or less accurately different sized feet, and even a fore or hind foot. To enable a man to nail on this shoe more easily and safely each branch should have five or six nail holes placed closely together, so that the farrier may choose which to use when a hoof is much broken.

An Expansion Shoe.-This is a curious result of misplaced ingenuity. The inventor desired to provide for an expansion, which may be disregarded, and to do so has placed two ordinary nail-holes at the toe whilst he replaced the back nail-holes by slots in which the nail-head was permitted a free lateral inotion. If sufficient lateral move- 
ment existed it is certain the nail-head could not have a secure hold on the shor, so mnless the nail had a defective hold its expansion action would be wanting.

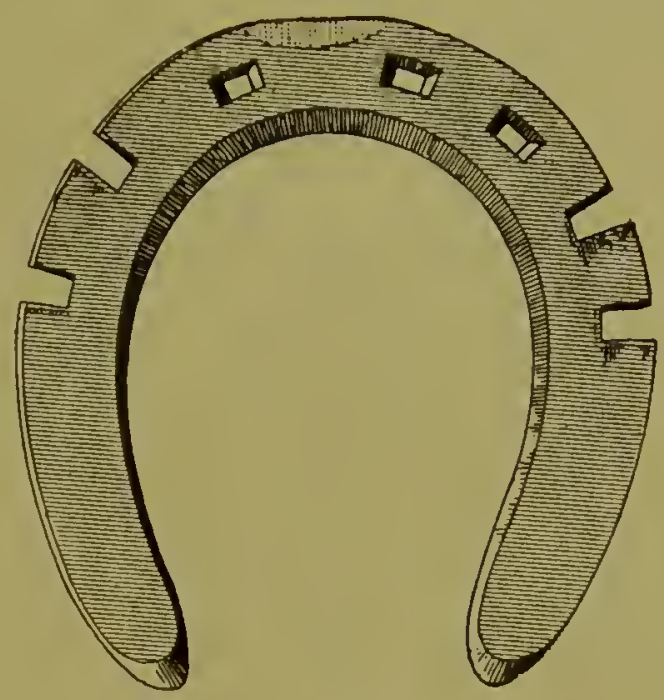

Fig. 128. An Expansion Shoe.

Expansion shoes are a fallacy. They seem based upon the idea that contraction is an active process, whereas it is simply a passive action and ought to be called shrinkage. A healthy foot, if not interfered with, does not shrink.

Nailless Shres. - Very various are the devices which have been invented to crade the supposed evils of nails. Not one has attained its object but by introducing evils worse than those due to fixing a shoe by nails. A properly driven nail, through a properly fitter shoe, is absolutely harmless, and any substitute for mails should be at least as effective and as free from ham. When horses' leet were robbed of all the horn a farrier thought necessary to remove for the purpose of making the hoof a pretty geometrical figme, nails often did ham. So little somnd horn was left that very great skill was necessary to drive a nail in the attenuated horn. In those days fine nail-holes were used and shoes were fitter too close. Now that nail-holes are properly placed, shoes fitted full to the foot, and all useful horn carefully preserved, injuries from mails are uncommon. 
The inventors of nailless shoes are men with no practical knowledge of shoeing. They are able to recognise the palpable injury inflicted by a wrongly driven nail, but they seem entirely ignorant of the much more common injuries due to badly fitted shoes. In all their circulars they exhibit this ignorance by stating that their invention can be fixed by anyone. They know nothing of the netessity of the growing hoof being liept proportionate, or of the exactness of fit required by a shoe on the bearing-surface of the hoof. Their invention needs only a novice to attach it to the foot-so they say !

The two most common methods by which inventors have tried to supersede nailing are- (a) by clips on the toe and quarters, (b) by metal bands running accross the front of the hoof and attached to the shoe on either side tomards the heels. The three following figures show a nailless shoe in which a short sharp spike or stud is fixed on the foot surface of the shoe in addition to the clips.

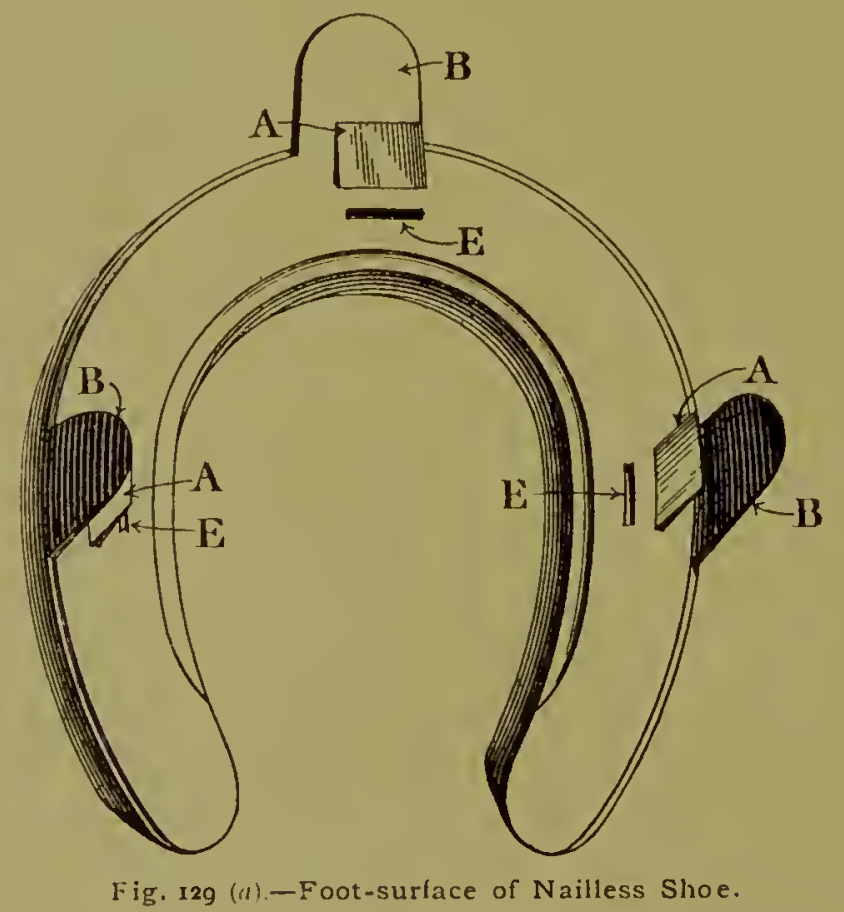

The spike assists to give firmness to the attachment. T'he following directions are copied, with the figures. 
"The Shoe is fixed in the following simple manner:-

I. Obtain a shoe of the correct size and should it not he the exact shape of the hoof open or close the forks. This can he done cold, there being so many si\%es that only a very slight alteration would ever be necessary.
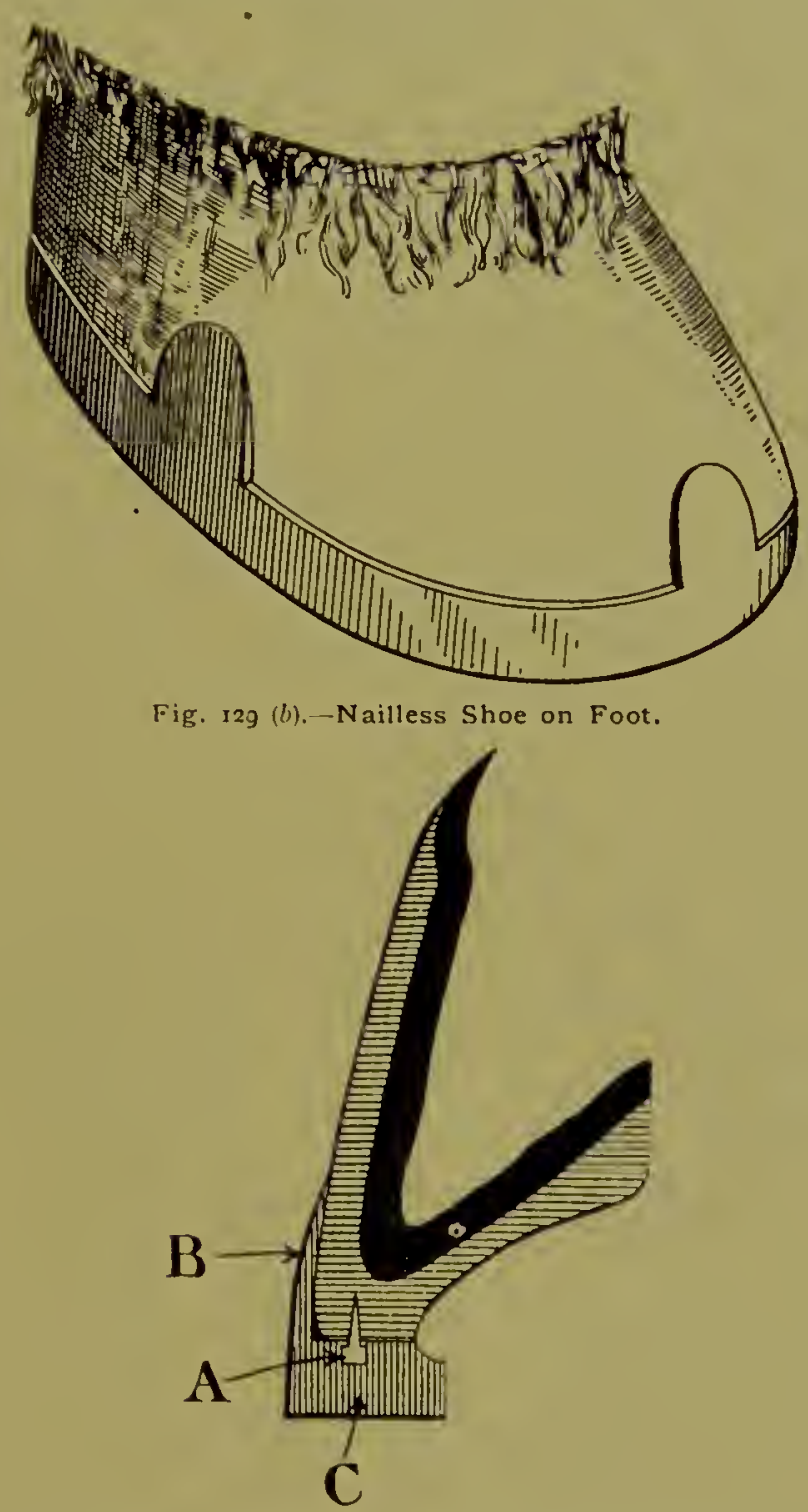

Fig. 129 (C).- Section showing Spike (A) and Clip (B).

2. Put the Studs A-- which are supplied loose in order to olvain the exact contour of the hoof more easily, -in their holes and fasten them. This is done by clenching the metal of the Shoe $\mathrm{C}$ over the shoulder of the Stucls $A$ with a blunt chisel applied at $\mathrm{l}$. 
3. The Shoe is then placed in position and a blow from below causes the Studs $A$ to become embedded in bottom of the wall of the hoof.

4. The foot is then placed on the ground and the clips 13 hammered up against the hoof without penetrating it. These clips can be made to any desired pattern. A portion of the outer wall of the hoof is thus wedged in hetween the clips $B$ and the Studs A, and the shoe is fixed."

It is a safe prophecy to say that this contrivance will fail-as have all its predecessors. No security of hold can be obtained by clips unless they are very strong and hammered dorn so firmly as to cause lameness.

The Steel-band method of attachment is shown in Fig. 1:30. Some ingenuity has been displayed in the way in which the band is attached to the shoe. Sometimes a single long clip runs from the toe of the shoe upwards and is bent over the band. In others two or three thin stecl

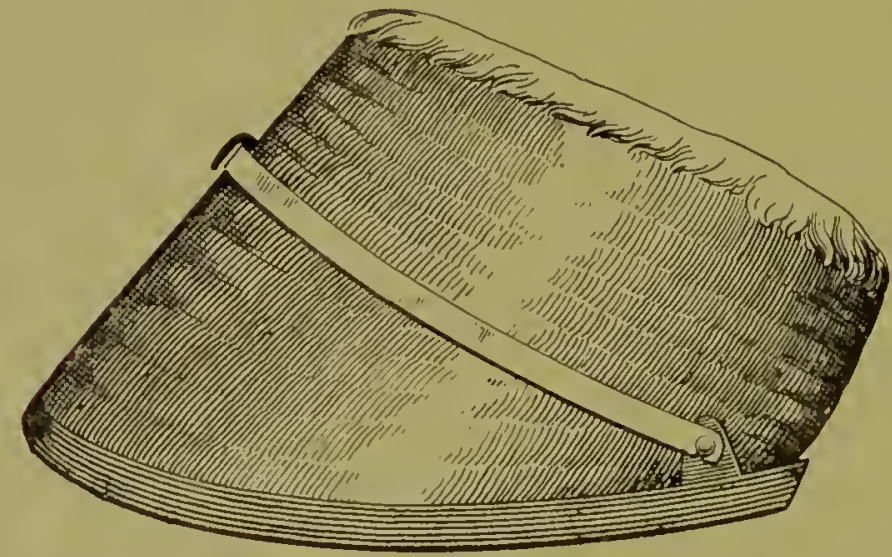

Fig. 130.-A Nailless Shoe.

connections pass from the shoe to the band so as to give steadiness. Very seldom does this plan give security enough to prevent frequent loss of shoes. In the only case in which $I$ have seen shoes retained a rery unch worse injury to the hoof resulted than mere loss of shoe. The band gradually wore a groove in the horn and as this groove grew down with the hoof the time soon arrived when the band could not be fixed, 
Side-weights and Toe-weights. - The two shoes shown in Figs. 131 and 132 are not much used in this country. They are believed in by the trotting fraternity of the United States, who imagine that some curious alterations in the action of

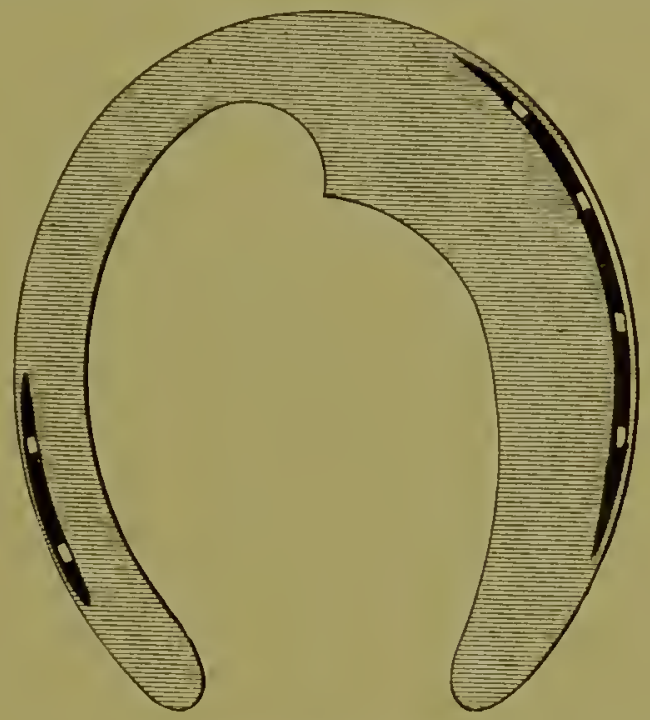

Fig. 131.-. Side-Weighted Shoe.

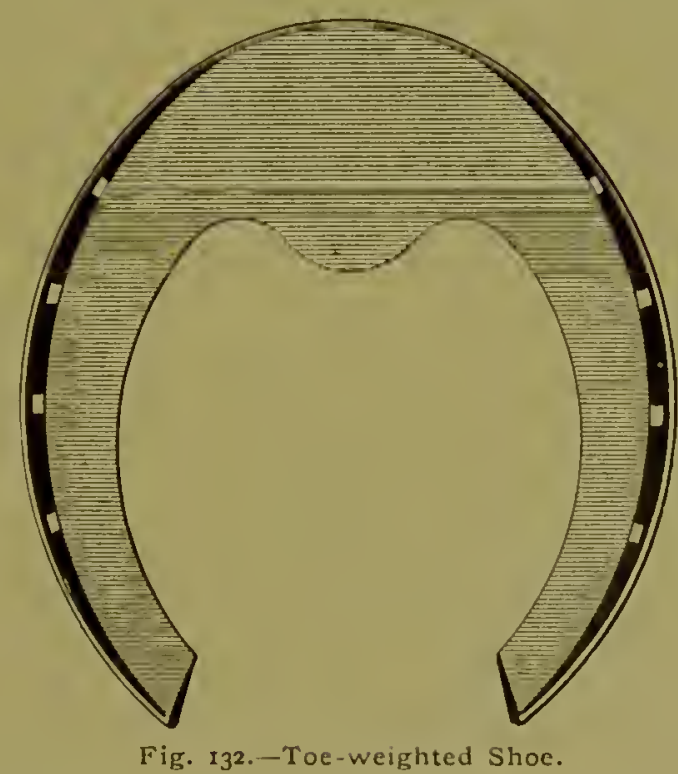

horses can be effected by increasing or decreasing the weight of iron at different parts of the shoe. No careful experiments have been made to prove the theories; but 
when a horse has from any cause increased his pace on the track and coincidently been shod with some curious pattern of shoe the credit has been given to the shoe. When dealing with living animals great difficulty is experienced in tracing effects to causes. Horses, like men, are affected by their surroundings, and by their internal arrangements. Work, food, excitement, and constitutional changes all affect the performances of animals, and lead to the invention of theories to account for the rariations. Without going so far as to assert that no shoe can be relied upon to increase or decrease the length of stride made by a horse during progression, I may say that until careful experiments demonstrate the possibility I decline to believe it. I also confess to a strong disbelief in the ability of weighted shoes to widen the action. That heary shoes or weights on the hoof canse a horse to lift his feet higher I know is a fact, and therefore young horses may be trained by their aid to bend the knee and lift the foot. The position of the weight of the shoe for this purpose is immaterial and is best applied evenly over the whole shoe.

I willingly grant that effects are produced by means which we adopt, but which we do not understand. If I am conrinced by empirical experience that a certain thing causes a definite effect $I$ accept the fact even if 1 am unable to explain it. If toe or side weights were found by experiments, carefully conducted, to do what they are supposed to do I should acknowledge the fact, and might try to find an explanation. But they do not. The facts are contradictory and the explanations ridiculous. The general acceptance of the queer-shaped shoes by the trotting men is no argument in their farour. Horsemen are among the most credulous of human beings, and never more prone to accept error than when it is accompanied by mystery.

Fig. 13:3 shows what is fancied by some persons to be the acme of invention in toe weiglats. The weight can be moved down to the shoe, up to the coronet or fixed any- 
where between those two points. The idea that such precision is attainable in modifying a horse's action by shift-

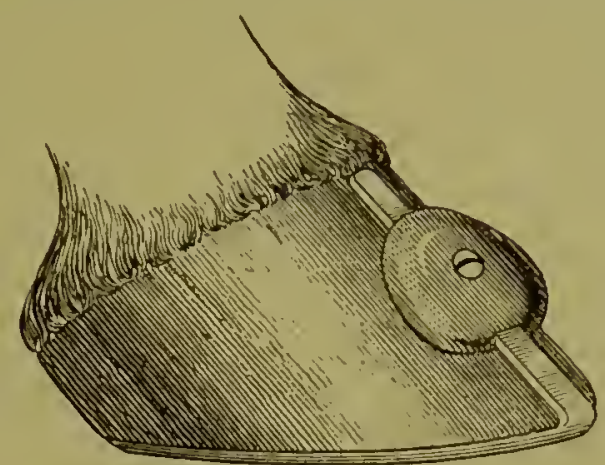

Fig. 133.-A Moveable Toe Weight.

in the weight half an inch is preposterous. The whole thing is a piece of empiricism.

Mr. Jos. Cairn Simpson published a book at San Francisco in 1883 on "Tips and Toe Weights." No writer hasapproached the subject with more knowledge, but his work is far from convincing. In his last chapter"Unsolved Problems"- - he says, "When I wrote the preceding chapters of the appendix, about two years ago, I then thought I had a fair knowledge of weight on the feet of horses. Now, after that length of time of study, observation and tests of many experiments, I am in doubt, and in place of offering rules for the guidance of others, am forced to admit a want of confidence to make statements with any degree of authority." A few pages further is the heading-"Side-weights Useless." His whole position is summed up in the quotation from page 38- "Weight is advantageous in the education of many trotters, but I am greatly in doubt of any benefit accruing after the schooling has progressed to a certain stage. Further than that, I have faith that the trotter of the future will be relieved from the incumbrance of heavy masses of metal on the feet, whether in the shape of shoes or weights."

In another work on shoeing, published in 1895, the author-Mr. W. Russell, of Cincinnati-attempts an explanation of what he calls "balancing" a horse by 
alterations of his shoes. He says-" Upon examination it will be found that the fourteenth dorsal vertebra is the pivot or axis around which the weight is poised-being the centre of gravity. It is plain, therefore, that if the symmetry of the horse be affected either by disproportionate construction, by acquired faults or by wrong shoeing, that his centre of gravity is disturbed, that is, he is unbalanced. . . . When, therefore, a horse is found with some fault the all important thing is to determine how he is unbalanced, and proceed to distribute equally around the centre of his gravitation the natural and acquired weights he must carry. No general rule can be given for this."

All I need add to this remarkable mixture of ideas is that the writer exhibits a want of even an elementary knowledge of his subject.

I can find neither in practice nor in theory a single reason to believe that toe-weights and side-neights on shoes are more than the product of perverted ingenuity, maintained in practice by ignorance and credulity. 


\section{Chapter XIII.}

\section{Shoeing Competitions.}

The Agricultural Societies that have made horseshoeing competitions a feature of their annual shows have distinctly done good to the art. In those districts which have had the benefit of those competitions for many years past, horse-shoeing is best done. In those districts where no competitions have been held, shoeing is generally badly done. When the farrier takes a pride in his work he is more careful with details. Provided proper principles are adopted, no calling is more dependent upon care in details for the best results than that of the farrier. Competitions stimulate emulation amongst men. Public appreciation, as displayed by the prominence given to the art by the show authorities and by the admiring crowd that generally assembles to see the men at work, encourages a feeling of responsibility and gratifies the natural and honest pride of the workman. Very few trades have suffered more from public neglect and indifference than that of the farrier.

T'he success of a shoeing competition depends almost entirely upon the secretary of a show, unless that officer has amongst his stewards an energetic horseman who has grasped the importance of good shoeing and who possesses some organizing powers.

All the arrangements for the competition must be completed before the work is commenced, and upon their perfection depends the success of the whole thing. There should, if possible, be two classes-one for heavy horses and one for light horses. At large competitions, there should also be a champion class. There are farriers who 
travel from show to show and generally appear in the prize list. This handicaps the local men, and is not encouraging to those who have not quite risen to front rank. The object of the competition is to improve the work of the district, and it is quite a question whether the rules should not exclude men who have taken, say, two first prizes at any large competition. The only argument in favour of letting the well known smith who has taken many prizes enter a competition is that his work may be seen, examined and imitated. By confining prize winners to the champion class, this good would be attained; at the same time, more encouragement would be given to local men.

At all times it is the young man who most readily yields to teaching, and the competitions make no attempt to cultivate the emulation of the younger men. In these days when apprenticeship has almost fallen into disuse some provision might well be made for bringing out the lads working in farriers' shops. A class for young fellows under twenty years of age would certainly do good. It would inspire emulation and offord opportunity for seeing the best work in the district.

The necessities for a competition include anvils, fires tools, iron and horses.

For every five men there should be one anvil, with its accompanying vice and forge. The anvil should be so placed that the sun is not full on the face of the workman. The exact relative position of anvil, vice and forge should be entrusted to a practical farrier, and the whole placed the night before they are wanted. Coal, nails and iron should also be provided. If competitors are allowed to bring their own iron or nails, some poor men may be placed at a disadvantage, and the habitual competitor, versed in every detail, is given an advantage. Each man should bring all smaller tools he may want. In broken weather a canvas roof should be supplied both for horses and workmen. At all times, a temporary wooden floor should be put down for the horses to stand upon. This should be a 
little longer than the line of anvils, so that each man has his horse opposite his anvil. It should be at least twelve feet deep, so that there is room enough behind and in front of the horses for men to pass. On the side farthest from the anvils a firm rail nust be fixed, to which the horse's halters may be tied, and outside of this-at least six feet distant-should be another line of post and rails to keep back spectators.

Horses have to be borrowed or hired, and one horse is sufficient for two competitors. Care should be taken not to have any horse with unusually bad feet. The most suitable horses are those with over-grown hoofs. Under no circumstances should a vicious or fidgety horse be selected.

When time is not an object, the best test of a workman is to require him to make a fore and hind shoe and put them on the horse. At a one-day show, or at a competition when the entries are large, it is sufficient to require the making of a fore and hind shoe and the fitting and nailing on of the front one. A reasonable time should be fixed, and undue haste should be deprecated.

There should always be two judges, who should be supplied with books in which each division of the operation of shoeing should be separately marked. There are only three important divisions of the subject: (1) Preparation of the foot; (2) making the shoes; and (3) fitting and nailing on.

Sometimes these operations are marked separately for fore and hind feet. I consider this quite unnecessary. There is not sufficient difference either in principle or detail to require each foot to be specially marked. The judge, of course, notes everything in his mind, and it is sufficient for him to estimate and mark the value of the work under the three different operations. The great fault I find with most competitions is that "the proparation" of the foot for tha shoe is not more strictly defined. 'T'he competitors are pernitted to mix up the "preparation" and the "fitting." Some of them do nothing to the foot 
until they commence to fit the shoe. 'T'his is wrong, and every foot should be properly prepared-the bearing-surface formed and the proportions of the hoof attended to-before the fitting is attempted. A rule to this effect should be added to the conditions in the schedule of the competition. Each judge may perhaps be permitted to fix his own standard of marking, but a uniform system would be useful for comparison. If the maximum be indicated by too small a figure, difficulty often arises in exactly determining the merits of men who have come out equal in the totals, and there is too often, in a large class, a number whose marks are about equal. The three operations-preparing the foot, making the shoe, fitting and nailing on-are about equal in value. A maximum of five points in each is too small a number to make distinctive marking easy, but there is nothing gained by adopting a higher maximum than ten. A marking sheet for the judges of a shoeing competition may be something in this form:

\begin{tabular}{c|c|c|c|c|c}
\multicolumn{5}{c}{ CLASS - } \\
\hline $\begin{array}{c}\text { No. of } \\
\text { Competitor. }\end{array}$ & $\begin{array}{c}\text { Preparation } \\
\text { of feet. }\end{array}$ & $\begin{array}{c}\text { Making } \\
\text { slloes. }\end{array}$ & $\begin{array}{c}\text { Fitting and } \\
\text {-nailing onl. }\end{array}$ & Total. & Remarks. \\
\hline & & & & & \\
\hline
\end{tabular}

The stewards should see that each competitor has a number, and that the same number is attached to the side of the horse on which he works. The steward also should take the time at which each batch of competitors commences work and see that none exceed it.

Excessive rasping of shoes should be prohibited, and the men should see the sizes and kinds of nails provided, so that they may make their "fuller" and nail-holes accordingly.

Shoeing competitions are almost entirely confined to country districts. It is a great pity that they are not 
attempted in large towns. The only difficulty is the expense. It would well repay large horse-owners to subscribe and support this method of improving the art.

In conclusion, I must say that the best of all ways to improve the art is by giving practical instruction at the anvil. A few lessons from a competent, practical teacher are worth more than all books or lectures, as the work has then to be done, errors are pointed out and corrected, and reasons given for each step as it is attempted.

'The Berkshire County Council has adopted a travelling forge-the suggestion of Mr. Albert Wheatley, V.S., of Reading-which is accompanied by an instructor and passes from town to town and village to village. In this way is supplied the tuition which used to be obtained by apprenticeship to a good workman. Other County Councils should adopt this method.

[Since writing the paragraph recommending classes for Apprentices at Competitions, I hear the Yorkshire Agricultural Society have practically tried the idea and that it has been attended with marked success. - W.H.] 


\section{INI)EX.}

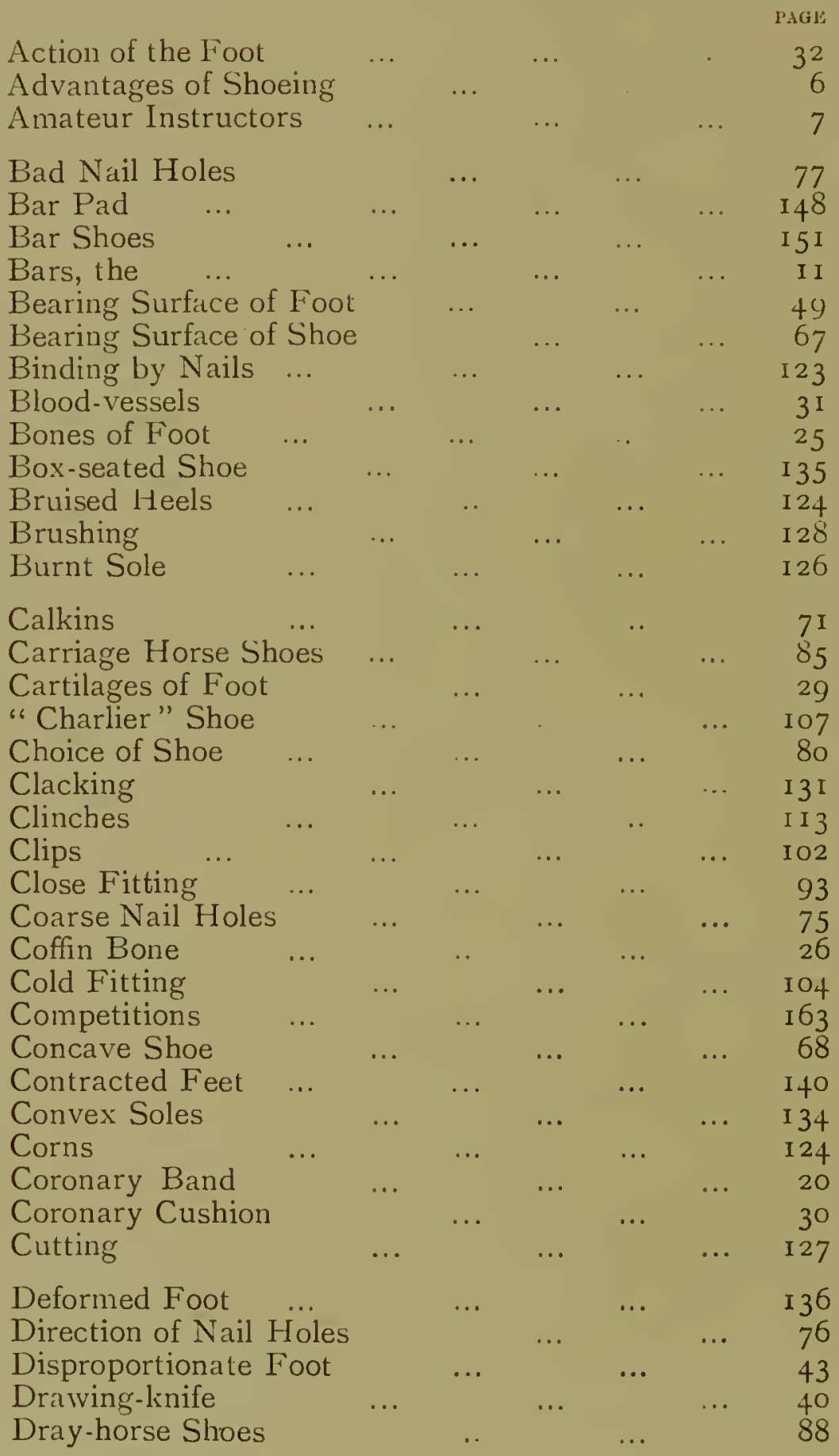


INDEX.

Driving Nails

"Dropped" Sole

$\begin{array}{lll}\ldots & \ldots & \text { II } 2\end{array}$

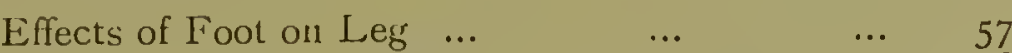

Elastic Structures

Easing the heels

Excessive Rasping

Expansion of Foot

Expansion of Shoes

Farriery, definition of

Feet, form of

Fine Nail Holes

Fitting the Shoe

Fitting Tips

FitzWygram Shoes

Flat Feet

Foals' Feet

Foot-surface of Shoe

Forging

Form and Action of Foot

Form of Shoes

French Clips

Frog, The

"Point of

" Cleft

" Band, The

Frog-pad

Frog Pads

Frost Nails

Fullered Bar-iron

Fullered Shoe

Ground Surface of Shoe

Growth of Hoof

Hack Shoes

Hoof, Form of

"Quality of

"Growth of

High Heels

Hinged Shoes

Horn-its Properties

Horny Laminæ

Hot Fitting

Hunting Shoes

Injuries from Shoeing

Injury from Clips

"Interfering"

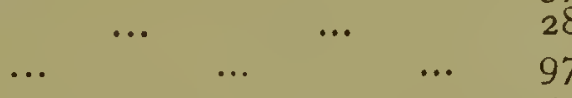


INDEX.

$\begin{array}{lllll}\text { Irregular Wear } & \ldots & \ldots & \ldots & \text { IOI }\end{array}$

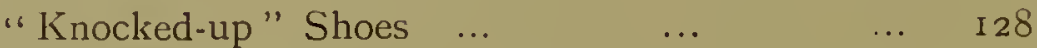

Laminæ, Horny $\quad \ldots \quad \ldots \ldots$ I2

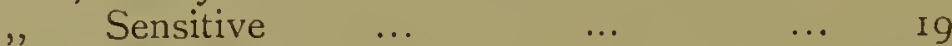

$\begin{array}{lllll}\text { Lateral Cartilages } & \ldots & \ldots & 28\end{array}$

Leather Soles

Length of Shoes

Long Toe

Machine-made Shoes

"Martin" Shoes

Model Bearing Surface

Moveable Toe-weight

Movement of Hoof

Nail Holes

Nailing on Shoes

Nailless Shoes

Nails, Form of

Narrow Feet

Navicular Bone

North of England Shoes

Notched Shoes

$\begin{array}{llllll}\text { Omnibus Horse Shoes } & \ldots & \ldots & \ldots & 87\end{array}$

$\begin{array}{lllllll}\text { One-sided Hoof } & \ldots & & \ldots & & \ldots & 47\end{array}$

Opening the Heels

Outline Fitting

Overgrown Foot

Over-reaching

Over-reduction of $\ddot{\mathrm{H} o o f}$

Pads for Horse Shoes

Paring the Sole

"Patten" Shoes

Pedal Bone

Plantar Cushion

Pneumatic Pad

Position of Nail Holes

Preparation of Foot

Prepared Bar-iron

Prepared Feet

Pricking by Nails

Properties of Horn

Proportionate Foot, A

"Quick," The

Racing Plates

Rasp, The

81 
INDIEX.

Ridged Shoes

Ring Leathers

"Rodway" Shoe

Roughing

Rubber Pads

Rubber and Iron Shoes

Sandcrack

Saucer-shaped Shoes

Scotch Cart Horses

Screw "Sharps"

Seated Shoes

Section of Foot

Seedy Toe

Selection of Shoes

Sensitive Foot, The

Sharping Shoes

Shoeing Bad Feet

" Competitions

" Hacks

" Hunters

", Racehorses

Shoeless Horses

Shoes for Vanners

Side-weights

Sole, The

" Structure of

Speedy-cut

Steeplechase Plates

Stumped-up Toe

Surface Fitting

Surface of Shoes

Tapping Shoes

Temporary Shoe

Theory of the Charlier System

Thickness of IVall

Thickness of Shoe

Three-quarter Shoe

Tips

Toe.pieces

Toe-weights

Toeing-knife

Treads

Treatment for Sandcrack 
INDEX.

Turned-in Wall

Twisted Feet

Uneven Bearing Surfaces

Uneven Feet

Uneven Pressure of Shoe

Unshod Feet

Value of Horse Shoeing

Van-horse Shoes

Wall, The

Wear of Shoes

Wedge Pad

Weight of Shoes

IVeighted Shoes

White Line, The

Wide Fitting

IVidth of Shoe

Winter Shoeing

Printed by H. \& IV. Brown, 20 Fulihas Road, Lonnon, S.W. 

||

,
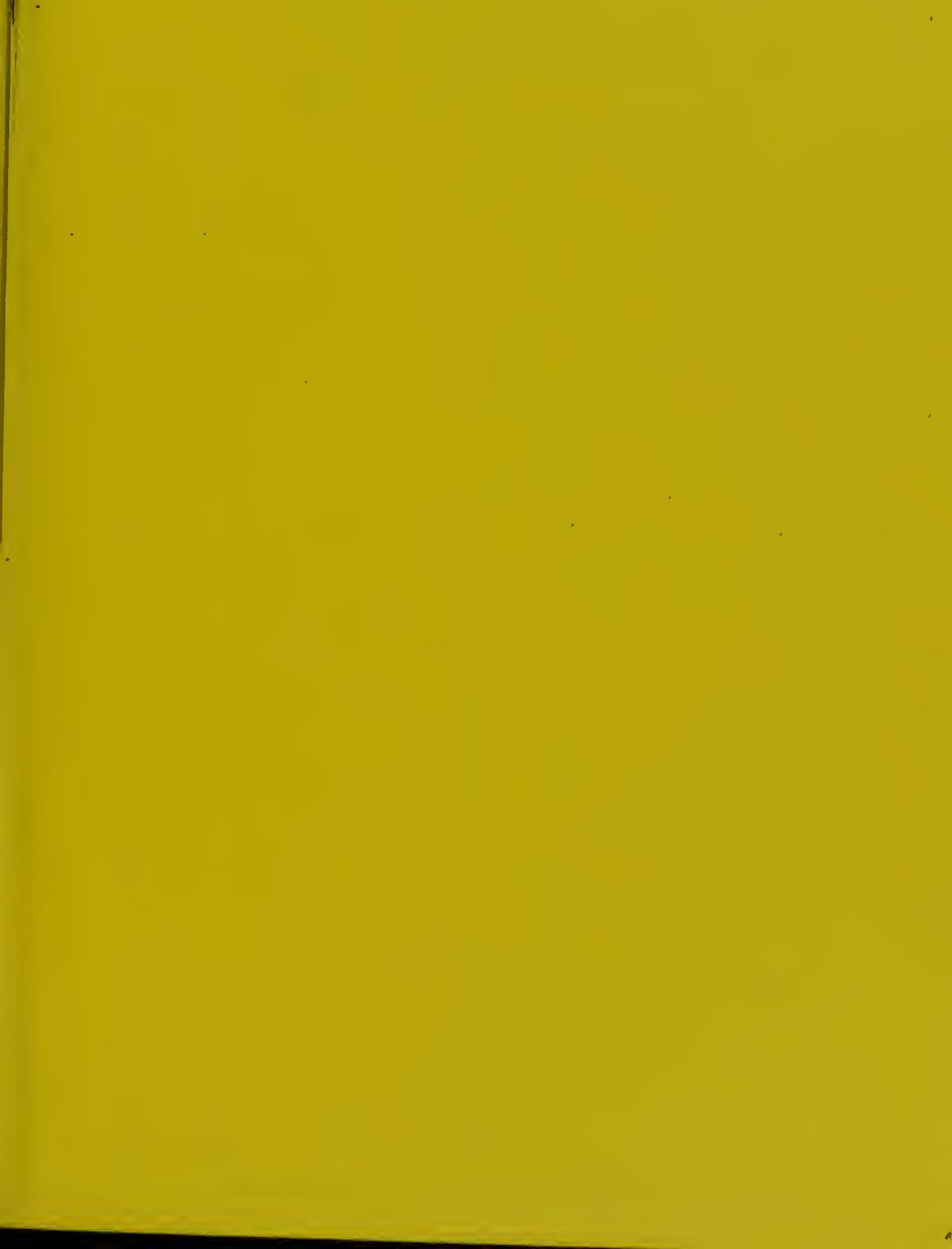
19.

(1)

(1)

(1)

.

(1)

-1)

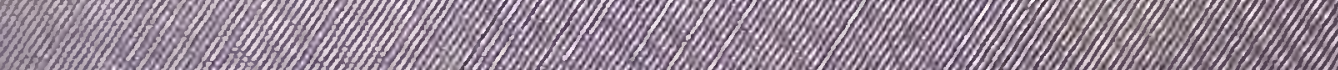

D.

D. (1) m. D. (1)

1.
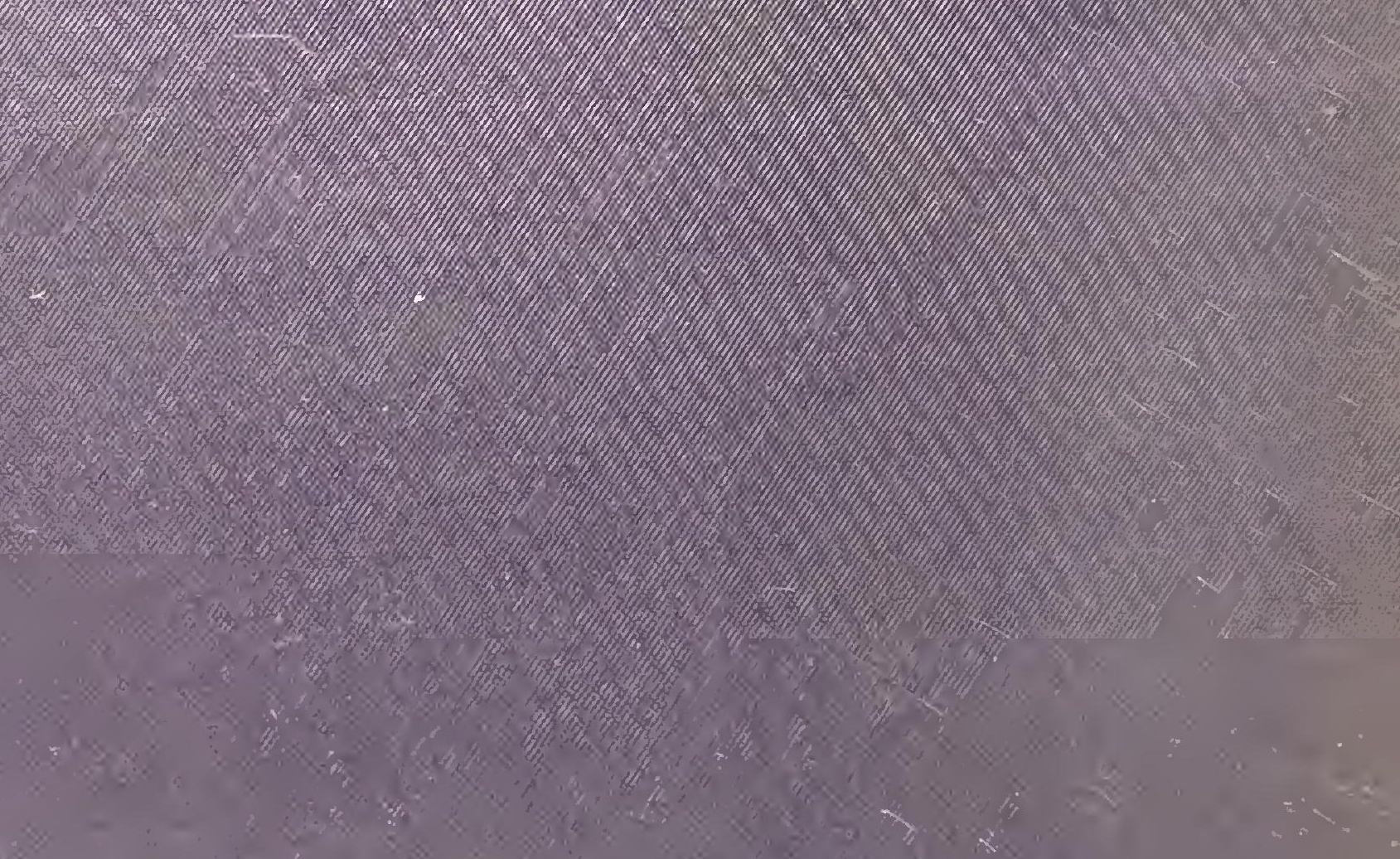

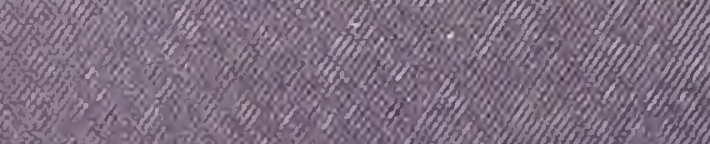
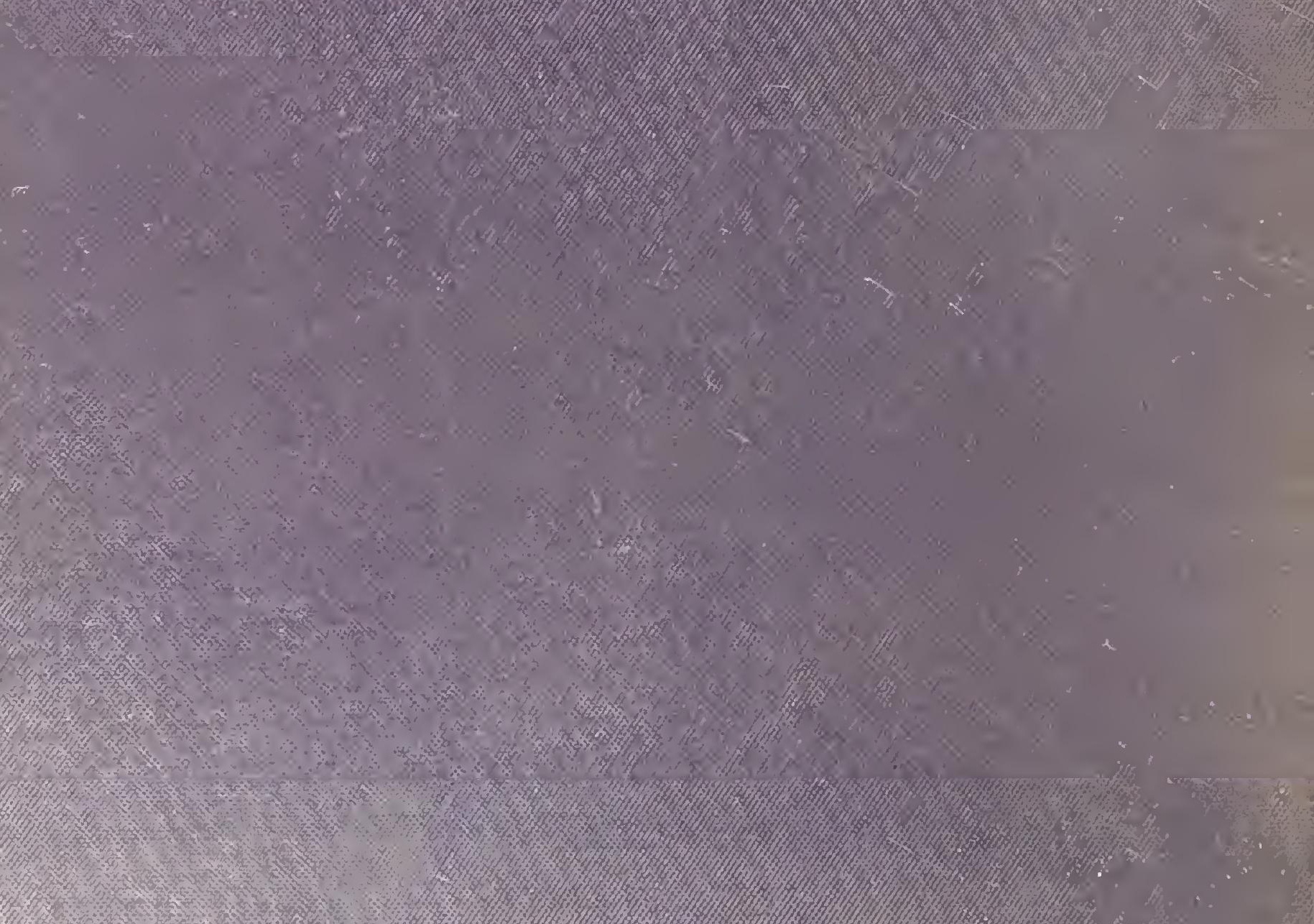

N-1.2:

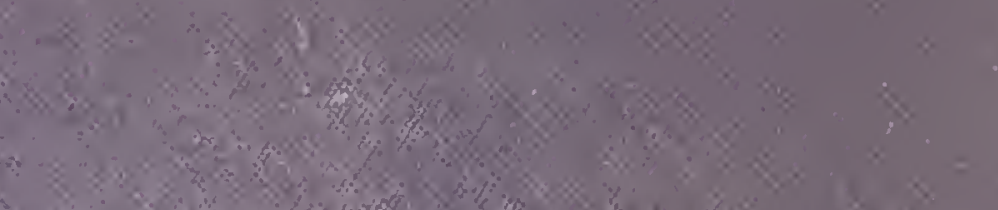

2. 